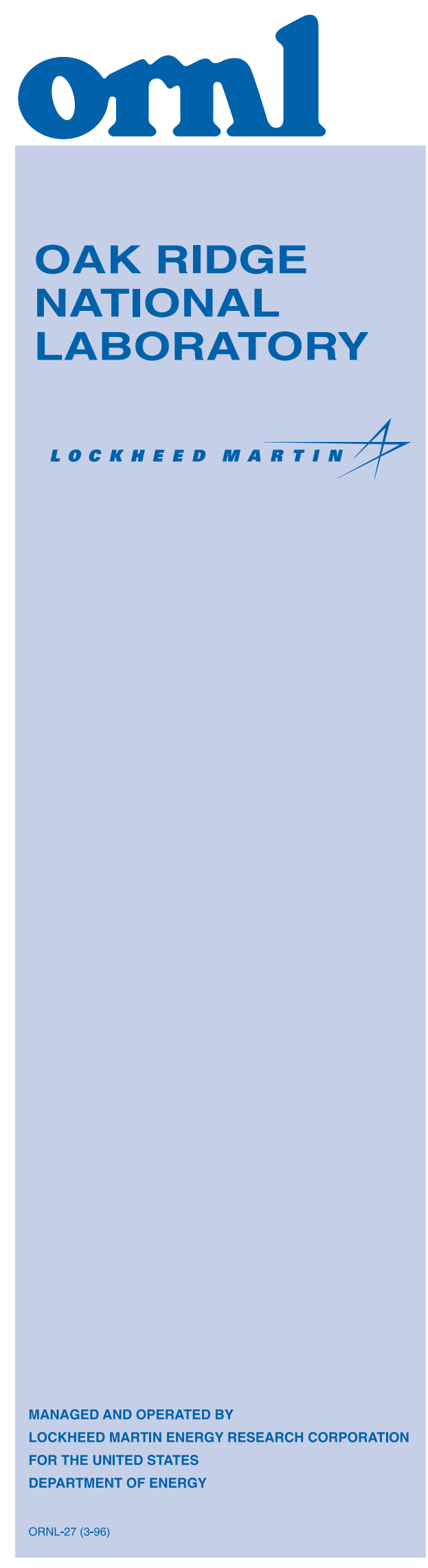

\title{
Revised Conceptual Designs for the FMDP MOX Fresh Fuel Transport Package
}

\author{
S. B. Ludwig \\ R. D. Michelhaugh \\ L. B. Shappert \\ S. M. Chae \\ J. S. Tang
}

Transportation \& Packaging Technologies Team Fissile Materials Disposition Program 
This report has been reproduced directly from the best available copy.

Available to DOE and DOE contractors from the Office of Scientific and Technical Information, P.O. Box 62, Oak Ridge, TN 37831; prices available from (423) 576-8401.

Available to the public from the National Technical Information Service, U.S. Department of Commerce, 5285 Port Royal Rd., Springfield, VA 22161.

This report was prepared as an account of work sponsored by an agency of the United States Government. Neither the United States Government nor any agency thereof, nor any of their employees, makes any warranty, express or implied, or assumes any legal liability or responsibility for the accuracy, completeness, or usefulness of any information, apparatus, product, or process disclosed, or represents that its use would not infringe privately owned rights. Reference herein to any specific commercial product, process, or service by trade name, trademark, manufacturer, or otherwise, does not necessarily constitute or imply its endorsement, recommendation, or favoring by the United States Government or any agency thereof. The views and opinions of authors expressed herein do not necessarily state or reflect those of the United States Government or any agency thereof. 
ORNL/TM-13574

Dist. Category UC-523

Chemical Technology Division

\title{
REVISED CONCEPTUAL DESIGNS FOR THE FMDP FRESH MOX FUEL TRANSPORT PACKAGE
}

\author{
S. B. Ludwig \\ R. D. Michelhaugh \\ L. B. Shappert \\ S. M. Chae \\ J. S. Tang
}

Date Published: March 1998

\author{
Prepared by \\ OAK RIDGE NATIONAL LABORATORY \\ Oak Ridge, Tennessee 37831 \\ managed by \\ LOCKHEED MARTIN ENERGY RESEARCH CORP. \\ for the \\ U.S. DEPARTMENT OF ENERGY \\ under contract DE-AC05-96OR22464
}


Page Intentionally Blank 


\section{CONTENTS}

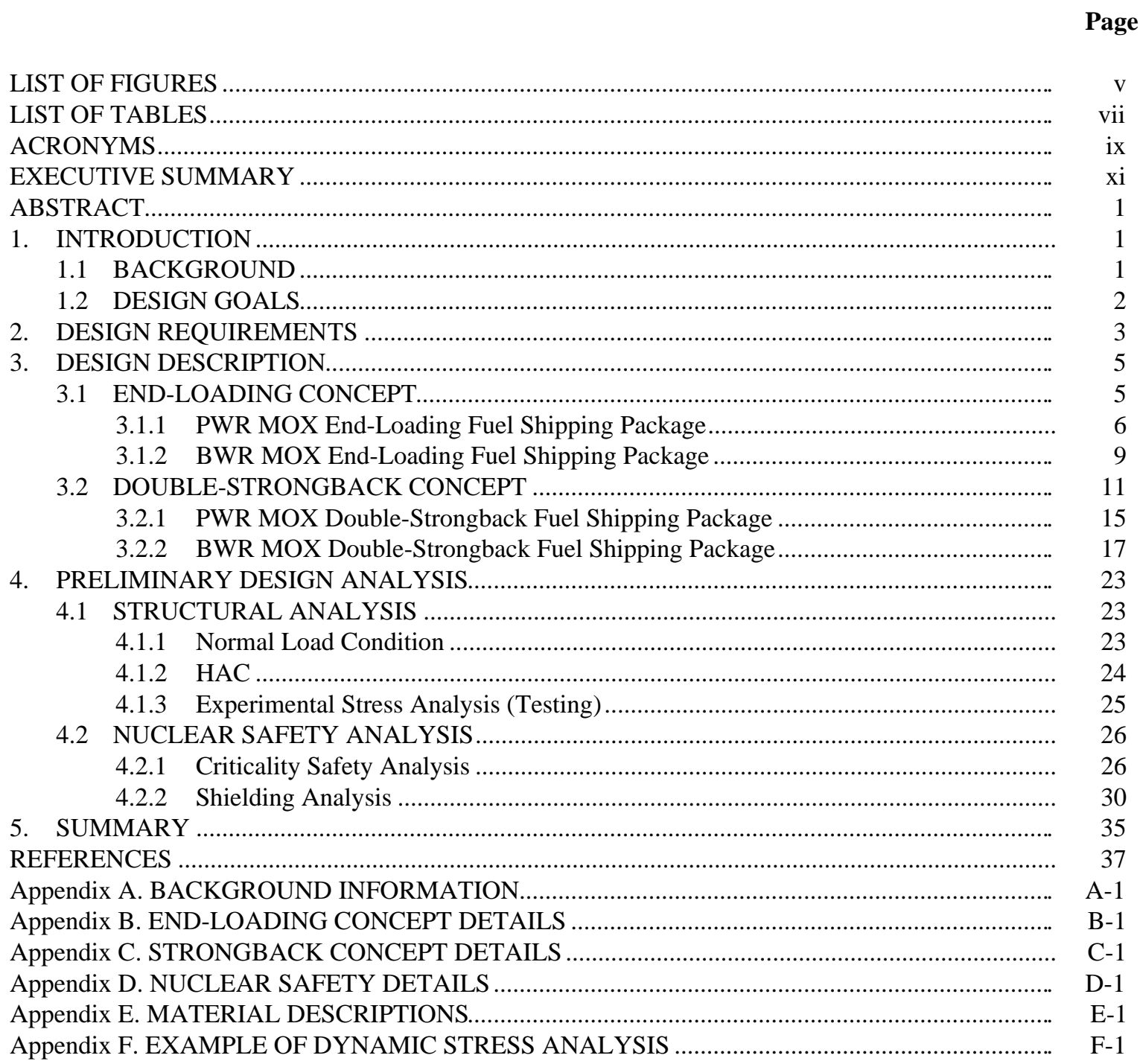


Page Intentionally Blank 


\section{LIST OF FIGURES}

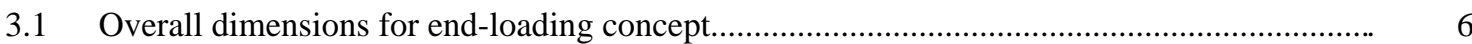

3.2 Cutaway view of end-loading concept for PWR fuel ...............................................................

3.3 Cross-sectional view of end-loading concept for PWR fuel ....................................................

3.4 Exploded view of end-loading shipping package for PWR fuel ..............................................

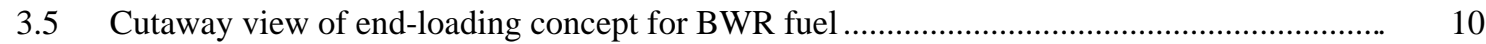

3.6 Cross-sectional view of end-loading concept for BWR fuel..................................................

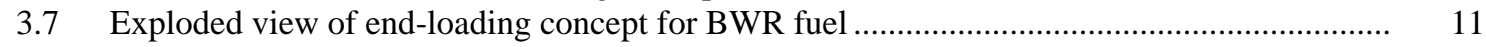

3.8 Double-strongback concept for PWR fuel ……..................................................................... 12

3.9 Exploded view of double-strongback concept for PWR fuel .................................................... 13

3.10 Cutaway view of double-strongback concept for PWR fuel.................................................... 13

3.11 Double-strongback concept for PWR fuel …….................................................................. 14

3.12 Cross-sectional view of double-strongback concept for PWR fuel ............................................ 14

3.13 Containment volume for double-strongback concept …....................................................... 16

3.14 Strongback frame for double-strongback concept.............................................................. 17

3.15 Secured PWR fuel assemblies in strongback concept ........................................................... 18

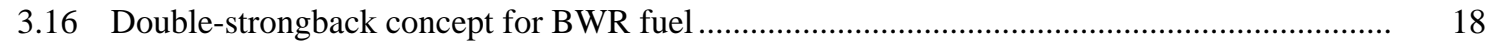

3.17 Exploded view of double-strongback concept for BWR fuel …….......................................... 19

3.18 Cross-sectional view of strongback concept for BWR fuel ...................................................... 19

3.19 Cutaway view of double-strongback concept for BWR fuel................................................... 20

3.20 Strongback frame concept for BWR fuel ……................................................................... 21

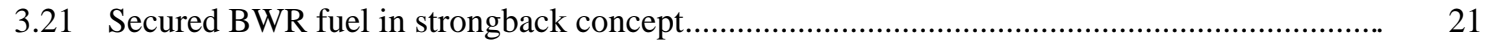

4.1 ABAQUS nonlinear 3-ft drop analysis results ..................................................................... 25

4.2 Cosmos/M nonlinear 3-ft drop analysis results—close-up of contact region ............................. 26

B.1 PWR fuel shipping package —end-loading option ........................................................... B-1

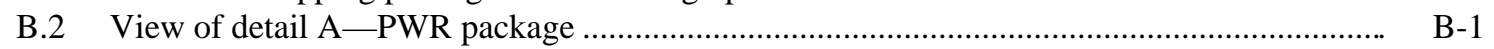

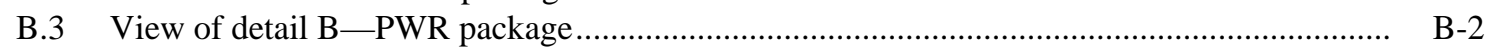

B.4 BWR fuel shipping package —end-loading option ............................................................ B-2

B.5 View of detail A-BWR shipping container............................................................. B-3

B.6 View of detail B-BWR shipping container....................................................................... B-3

C.1 Cross-sectional view A-A of PWR shipping container......................................................... C-1

C.2 Cross-sectional view B-B of PWR shipping container ......................................................... C-1

C.3 Cross-sectional view C-C of PWR shipping container ........................................................ C-2

C.4 Detail view D1 of PWR shipping container …….......................................................... C-2

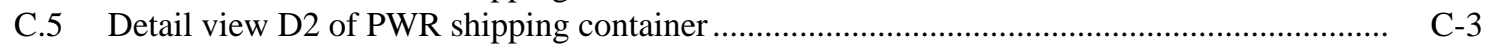

C.6 Cross-sectional view A-A of BWR shipping container ……............................................ C-3

C.7 Cross-sectional view B-B of BWR shipping container...................................................... C-4

C.8 Cross-sectional view C-C of BWR shipping container...................................................... C-4

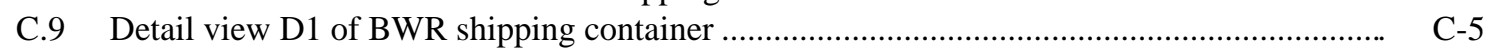

D.1 KENO model of BWR end-loading package ……….................................................. D-2

D.2 KENO model of PWR end-loading package _....................................................................... D-3

D.3 KENO model of $2 \times 2$ array of end-loading PWR packages............................................... D-4

D.4 KENO model of $2 \times 2$ array of damaged end-loading PWR packages under hypohetical accident conditions ........................................................................................ D

D.5 KENO model of BWR double-strongback package ……................................................ D-6

D.6 KENO model of PWR double-strongback package ………….............................................. D-7

D.7 SAS4 model of BWR end-loading package ………......................................................... D-8

D.8 SAS1 model of PWR end-loading package..................................................................... D-9

D.9 SAS1 model of BWR double-strongback package …….................................................... D-10 
D.10 SAS4 model of PWR double-strongback package ………................................................ D-11

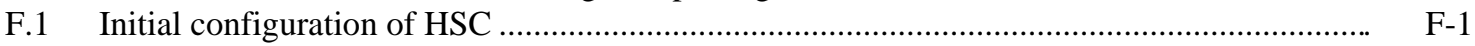

F.2 Final configuration of HSC ……............................................................................. F-2

F.3 Surface effective plastic strain in the HSC stainless steel lid ................................................. F-3 


\section{LIST OF TABLES}

Table

Page

3.1 MOX fuel shipping package design envelope for PWR and BWR MOX fuel assembly and fuel assembly cavity ..................................................................... 5

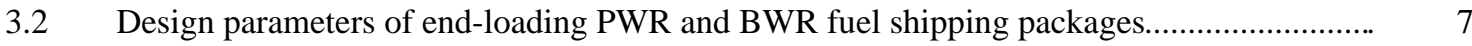

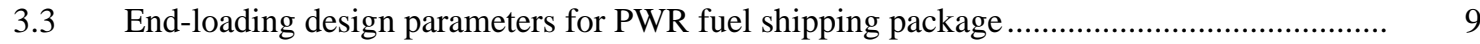

3.4 End-loading design parameters for BWR fuel shipping package .................................. 11

3.5 Design parameters of double-strongback shipping packages for PWR

3.6 Double-strongback design parameters for PWR fuel shipping package.............................. 15

3.7 Double-strongback design parameters for BWR fuel shipping package.............................. 20

4.1 The $\mathrm{k}_{\mathrm{eff}}$ values for MOX fuel end-loading concept with HD foam basket............................ 27

4.2 The $\mathrm{k}_{\mathrm{eff}}$ values for MOX fuel end-loading concept with steel-clad $\mathrm{B}_{4} \mathrm{C}$ poison plates ......... 28

4.3 The $\mathrm{k}_{\mathrm{eff}}$ values for MOX fuel double-strongback concept with steel-clad

$\mathrm{B}_{4} \mathrm{C}$ poison plates .................................................................................................... 29

4.4 The $\mathrm{k}_{\text {eff }}$ values for MOX fuel $2 \times 2$ arrays of packages with steel-clad

$\mathrm{B}_{4} \mathrm{C}$ poison plates ................................................................................................ 29

4.5 Dose rates at side of container for MOX fuel end-loading concept, dry, with

$0.26-\mathrm{cm}$ steel-clad $\mathrm{B}_{4} \mathrm{C}$ poison plates ....................................................................... 32

4.6 Dose rates at side of container for MOX fuel end-loading concept, wet, with

0.26-cm steel-clad $\mathrm{B}_{4} \mathrm{C}$ poison plates ....................................................................... 32

4.7 Dose rates for MOX fuel double-strongback concept, dry, with 0.26 -cm steel-clad

$\mathrm{B}_{4} \mathrm{C}$ poison plates .................................................................................................... 33

4.8 Dose rates for MOX fuel double-strongback concept, wet, with 0.26-cm steel-clad

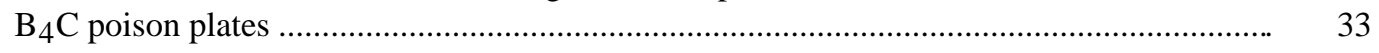

D.1 Dimensions of generic PWR and BWR assemblies ................................................ D-1

D.2 Material number identification ................................................................................ D-12

D.3 The $\mathrm{k}_{\text {eff }}$ values for MOX fuel end-loading concept with water and

borated inner steel can .................................................................................... D-12

D.4 Dose rates for MOX fuel end-loading concept with HD foam ...................................... D-12

D.5 Dose rates for MOX fuel end-loading concept, dry, with $1.2 \mathrm{wt} \%$

borated inner steel can ........................................................................................... D-13

D.6 Dose rates for MOX fuel double-strongback concept, dry, without poison plates ............... D-13

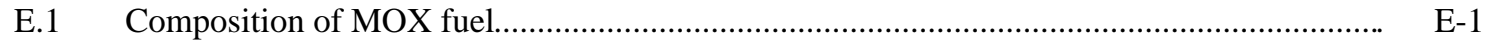

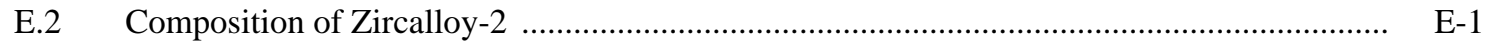

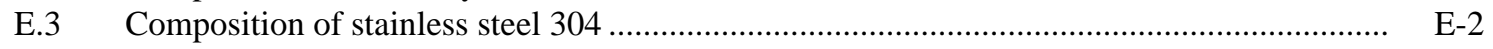

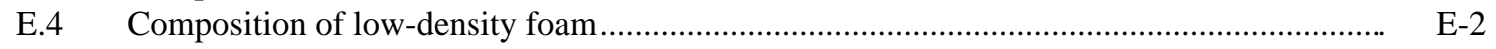

E.5 Composition of borated high-density foam............................................................... E-2 
Page Intentionally Blank 


\section{ACRONYMS}

\begin{tabular}{|c|c|}
\hline ALARA & as low as reasonably achievable \\
\hline ANSI & American National Standards Institute \\
\hline ASME & American Society of Mechanical Engineers \\
\hline ASTM & American Society of Testing and Materials \\
\hline $\mathrm{B}(\mathrm{U}) \mathrm{F}$ & Type B fissile-designation for a Type B package that may carry fissile material \\
\hline BWR & boiling-water reactor \\
\hline CFR & Code of Federal Regulations \\
\hline c.g. & center of gravity \\
\hline CRNL & Chalk River Nuclear Laboratory \\
\hline DNFSB & Defense Nuclear Facilities Safety Board \\
\hline DOE & U.S. Department of Energy \\
\hline DOE/AL & U.S. Department of Energy, Albuquerque Operations Office \\
\hline DOE/MD & U.S. Department of Energy, Office of Fissile Materials Disposition \\
\hline DOE/OR & U.S. Department of Energy, Oak Ridge Operations Office \\
\hline DOT & U.S. Department of Transportation \\
\hline FEA & finite element analysis \\
\hline fsd & fractional standard deviation \\
\hline FMDP & Fissile Materials Disposition Program \\
\hline GVW & gross vehicle weight \\
\hline HAC & hypothetical accident conditions (10 CFR 71.73) \\
\hline HD & high density \\
\hline HLW & high-level waste \\
\hline HSC & horizontal shipping container \\
\hline IAEA & International Atomic Energy Agency \\
\hline IMO & International Maritime Organization \\
\hline INF & irradiated nuclear fuel \\
\hline $\mathrm{k}_{\mathrm{eff}}$ & effective neutron multiplication factor, a measure of nuclear criticality \\
\hline LD & low density \\
\hline LEU & low-enriched uranium \\
\hline LWR & light-water reactor \\
\hline MFFP & MOX fresh fuel package \\
\hline MOX & mixed-oxide (generally, for reactor fuels that combine $\mathrm{UO}_{2}$ and $\mathrm{PuO}_{2}$ ) \\
\hline MT & metric ton (or tonne) \\
\hline NCT & normal conditions of transportation (10 CFR 71.71) \\
\hline NIST & National Institute of Standards and Technology \\
\hline NRC & U.S. Nuclear Regulatory Commission \\
\hline ORNL & Oak Ridge National Laboratory \\
\hline PAS & Program Acquisition Strategy (for MOX Fuel Fabrication and Irradiation Services) \\
\hline $\mathrm{PCV}$ & primary containment vessel \\
\hline PWR & pressurized-water reactor \\
\hline QA & quality assurance \\
\hline RFP & Request for Proposals \\
\hline ROD & Record of Decision \\
\hline SARP & safety analysis report for packaging \\
\hline SGT & safeguards transport (secure trailer) \\
\hline SNL & Sandia National Laboratories \\
\hline SNM & special nuclear material \\
\hline SSNM & strategic special nuclear materials \\
\hline
\end{tabular}


SST

TI

TSD

USL

WG safe secure trailer

Transport Index

Transportation Safeguards Division, DOE Albuquerque Operations Office upper subcritical limit

weapons grade 


\section{EXECUTIVE SUMMARY}

To accomplish the disposition of surplus weapons plutonium using mixed-oxide (MOX) fuel, the unirradiated MOX fuel must be transported from the MOX fabrication facility to one or more commercial reactors. Because the unirradiated fuel contains large quantities of plutonium and is not sufficiently radioactive to create a "self-protecting" barrier to deter the material from theft, the Department of Energy (DOE) intends to use its fleet of safe secure trailers (SSTs) to provide the necessary safeguards and security for the material in transit. The DOE requirements for the transport of radioactive materials refer to regulations of the Department of Transportation and the Nuclear Regulatory Commission (NRC). In particular, NRC requires that the packages meet strict performance requirements. The requirements for shipment of MOX fuel specify that the package design must be sufficient to ensure that the materials contained in the packages are not released and remain subcritical after undergoing a series of hypothetical accident condition (HAC) tests. Packages that pass these tests are certified by DOE as Type B fissile [i.e., Type $\mathrm{B}(\mathrm{U}) \mathrm{F}]$ packages.

This document provides a summary of the design aspects of two different preliminary MOX fresh fuel packaging concepts that have been developed by Oak Ridge National Laboratory (ORNL). These designs have been undertaken with the following programmatic requirements in mind:

- the designs shall be compatible with and shall efficiently use available payload capacity of the SST, and

- the designs shall be operationally compatible with the MOX fuel fabrication and reactor facilities in which they will be used.

In addition, the new fresh MOX fuel package designs were developed to meet the following technical design requirements:

- the package shall be certified by DOE as a Type B(U)F material package in accordance with requirements prescribed in DOE Order 460.1A [and 10 Code of Federal Regulations (CFR) 71];

- the package design shall have one verifiable level of containment for the package contents, testable to a level of $10^{-6} \mathrm{~A}_{2} / \mathrm{h}$ [10 CFR 71.51(a)(1)] and $1.0 \mathrm{~A}_{2}$ /week [10 CFR 71.51(a)(2)]; and

- the package shall be so designed to maintain subcriticality of the fissile contents under the HACs in 10 CFR 71.

This document summarizes the latest information about the status of the preliminary conceptual designs for two different fresh MOX fuel package design alternatives that have undergone analysis and revision since the initial concepts were developed in 1997. The two different concepts are called the endloading concept and the double-strongback concept.

Refinements to both designs have included changes to structural designs (to improve package strength and provide a more sound engineering design). This has resulted in a minor increase in the package gross weight. Based on recent activities undertaken by ORNL and DOE/Office of Fissile Materials Dispositon, the payload capacity limitation for SST and safeguards transport may be relaxed to the SST-2 limit of 16,500 lb. This will permit either of the new package designs to be acceptable for transport within an SST-2.

Major revisions have occurred to the criticality safety design. Initially, the conceptual designs utilized a high-density, boron-impregnated foam material to provide criticality control for the multiple fuel assembly package designs. Upon review, however, it was determined that the foam should not be relied on to provide more than a single function (i.e., structural integrity plus criticality control). Therefore, stainless steel plates over a $\mathrm{B}_{4} \mathrm{C}$ sandwich were added to the package design. This resulted in a slight increase in the package gross weight, but will ultimately lead to a more defensible design.

Because of the need to provide a summary of the package designs (this report) in support of the issuance of the final Request for Proposals (a planned March 1998 release date), additional analyses (structural and thermal performance under accident conditions, etc.) have not been performed. Ultimately, continued analyses will result in additional revisions to the package designs and will lead to development of information needed to be included in the safety analysis report for packaging that will be submitted to DOE to obtain certification of the new MOX fresh fuel transport package as a Type $\mathrm{B}(\mathrm{U}) \mathrm{F}$ package design. 
Page Intentionally Blank 


\title{
REVISED CONCEPTUAL DESIGNS FOR THE FMDP MOX FRESH FUEL TRANSPORT PACKAGE
}

\author{
S. B. Ludwig \\ S. M. Chae \\ R. D. Michelhaugh \\ L. B. Shappert \\ J. S. Tang
}

\begin{abstract}
The revised conceptual designs described in this document provide a foundation for the development and certification of final transport package designs that will be needed to support the disposition of surplus weapons-grade plutonium as mixed-oxide (MOX) fuel in commercial light-water reactors in the United States. This document is intended to describe the revised package design concepts and summarize the results of preliminary analyses and assessments of two new concepts for fresh MOX fuel transport packages that have been developed by Oak Ridge National Laboratory during the past year in support of the Department of Energy/Office of Fissile Materials Disposition.
\end{abstract}

\section{INTRODUCTION}

The purpose of this document is to provide a preliminary description of conceptual designs for a new, fresh mixed-oxide (MOX) fuel transport package that is under development by Oak Ridge National Laboratory (ORNL) in support of the Department of Energy/Office of Fissile Materials Disposition (DOE/MD). The new MOX fuel transport package would be used by DOE and contractors to ship MOX fresh fuel, fabricated using surplus weapons-grade plutonium, between the MOX fuel fabrication facility and one or more commercial light-water reactors (LWRs) in the United States. New shipping packages are being developed for transporting unirradiated MOX fuel assemblies to both pressurized-water reactors (PWRs) and boiling-water reactors (BWRs) in support of the use of reactor-based technologies for the disposition of surplus weapons-capable plutonium. The new package designs could reduce the number of PWR MOX fuel assembly shipments by at least a factor of 2, as well as facilitate shipment of multiple BWR fuel assemblies. This report also provides results of preliminary analyses and assessments of the package design that provide a foundation for further development and certification of the package.

Chapter 2 of this report provides a summary description of the key design requirements for the new, MOX fresh fuel transport package. Chapter 3 of this report provides a description of two leading preliminary conceptual package designs. Chapter 4 provides a summary of some initial design analyses that have been completed, particularly criticality safety and shielding analyses. Chapter 5 summarizes the results of design activities and provides recommendations for future work. Appendixes A-F provide additional details.

\subsection{BACKGROUND}

Under the mission of the Fissile Materials Disposition Program (FMDP), a large portion of the surplus plutonium may be dispositioned as MOX fuel in existing domestic commercial reactors (BWRs or PWRs) with subsequent disposal of the spent fuel in a geologic repository. To accomplish the MOX disposition, the fuel must be transported in certified Type B fissile [Type B(U)F] packages between the MOX fuel fabrication facility and one or more existing commercial LWRs in the United States. The specific reactors and fabrication sites have not been chosen at this time. In FY 1997, ORNL was tasked by DOE to begin development of preliminary conceptual designs for a new MOX fresh fuel package.

In July 1997, DOE initiated efforts to procure the expertise and services of the private sector to aid in the disposition program by issuing its Program Acquisition Strategy (PAS) for MOX Fabrication and 
Irradiation Services. ${ }^{1}$ PAS assumed that DOE (ORNL) would develop the new MOX package design and that the private sector would be responsible for acquiring sufficient packagings from DOE to carry out the MOX fuel disposition mission. Supporting this effort, ORNL prepared a report describing the transportation and packaging issues involved in transporting MOX fresh fuel in new Type B(U)F packages by safe secure trailer (SST) between the MOX fuel fabrication facility and the commercial reactors. ${ }^{2}$ SSTs would be required to provide physical protection for the weapons-grade MOX fuel in transit. PAS was followed by release of a draft Request for Proposals (RFP) ${ }^{3}$ in November 1997. In addition to providing DOE's vision for how to proceed with disposition of surplus plutonium via reactor-based alternatives, the draft RFP placed the burden of developing and certifying the new MOX fuel package design with a privatesector consortium that would be selected through a procurement process. In support of the draft RFP, ORNL issued a report describing the technical and programmatic requirements for the new, fresh MOX fuel transport package. ${ }^{4}$ The package design requirements, coupled with the concepts and analyses provided herein, are intended to provide the consortium with a foundation for continued development and certification of a new package design for the shipment of fresh MOX fuel assemblies.

ORNL has undertaken an extensive review of available MOX fuel packages. There are only a few shipping packages in the world that are currently certified to carry fresh MOX PWR fuel assemblies. In the United States, only a single package design is currently certified, and that package is limited to carry only two PWR fuel assemblies. No U.S. package exists for transporting multiple BWR MOX fuel assemblies. Modifications of existing shipping package designs to carry more fuel assemblies, or to carry BWR fuel assemblies, would necessitate a significant redesign effort and recertification. In addition, modification of the existing shipping packages to carry more fuel assemblies could cause them to exceed the SST/safeguards transport (SGT) payload weight limitation. Therefore, ORNL has begun the development of the preliminary conceptual designs for new MOX fuel shipping packages. The new design for the PWR MOX fuel shipping package is envisioned to increase the number of PWR MOX fuel assemblies per package from two to at least four. The new design for BWR MOX fuel shipping packages will be similar to that of PWR MOX fuel shipping packages but will accommodate more fuel assemblies.

\subsection{DESIGN GOALS}

The new shipping packages shall be designed to maximize the number of fuel assemblies that can be carried. Specifically, the goal shall be to carry at least four PWR or eight BWR fuel assemblies per package in an SST. For a detailed description of the MOX fuel assemblies, see Appendix A of ORNL/TM-13526. ${ }^{4}$ The capacity of the package will be affected by the weight limitations and size constraints imposed by SST restrictions identified in Appendix B of ORNL/TM-13526. ${ }^{4}$ Capacity may also be influenced by any size, weight, and other physical limitations imposed by the fuel fabrication facility and the receiving reactor sites. Details on the transport of MOX fuel assemblies between the fuel fabrication facility and commercial LWRs and on the package handling at the involved sites are discussed in ORNL/TM-13526. ${ }^{4}$

The MOX fuel assemblies shall be secured within the packaging to prevent movement during transport. The shipping packages shall be designed to satisfy the containment requirements for fuels containing plutonium and to meet subcriticality and radiation exposure requirements under severe accident conditions identified in Chap. 3 of ORNL/TM-13526. ${ }^{4}$

The package shall be designed to have the fuel loaded and unloaded vertically, but to be shipped horizontally. The packaging shall include mechanical features to aid in upending the structural support for the fuel assemblies during loading/unloading operations. The package should also contain features that assist in the loading and unloading from SST [horizontally through the rear door of the trailer, without requiring powered equipment (e.g., forklifts) to enter SST]. 


\section{DESIGN REQUIREMENTS}

ORNL has developed a preliminary set of design requirements for a new, fresh MOX fuel transport package, as described in ORNL/TM-13526. ${ }^{4}$ Based on these requirements, ORNL developed several preliminary design concepts for such a package to determine whether the design requirements can be met, which would enable DOE to move forward with package design and certification activities. A general description of the design concepts is shown in Chap. 3 of this document.

A number of basic design requirements for a fresh MOX fuel transport package have been specified in ORNL/TM-13526. ${ }^{4}$ These requirements have been refined, augmented, and supplemented as project decisions and directions have evolved. Based on these design requirements, ORNL has developed two different packaging concepts identified as the end-loading concept and the double-strongback concept. ORNL has also completed some preliminary analyses of these concepts to determine their practicality as they relate to the basic design requirements.

Ultimately, there are a number of specific (final) package design requirements that cannot be identified until a consortium is selected and definitive fuel assembly designs have been chosen. Initiation of final design activities and development of the safety analysis report for packaging (SARP) for a new, fresh MOX fuel transport package, as well as review and certification of the package design by DOE, must, therefore, be delayed until other project decisions have been made, although the preliminary designs discussed in this document have the flexibility to provide the foundation and background for the final design concept.

Because of the substantial quantity of plutonium contained in the MOX fuel that will be delivered to selected reactor operators, DOE has determined that the package will be transported by an SST to provide adequate safeguards for the material during transport. SST has weight and tie-down limitations that will affect the package design. Only one package at a time will be shipped in an SST.

Currently, ORNL has completed an initial evaluation of the two preliminary design concepts as they relate to the design requirements. Some of the design requirements are listed below. The results of these evaluations are presented in Chap. 4 of this document.

Package Design: The package shall be certified by DOE as a Type B(U)F package in accordance with the requirements identified in DOE Order $460.1 \mathrm{~A} .5^{5}$ This order requires that the package design, as documented in SARP, must satisfy the requirements specified in 10 CFR 71.6

Criticality Safety: The package shall contain adequate nuclear poisons separating the fuel assemblies to ensure that under both normal and accident conditions, and under the conditions specified in $10 \mathrm{CFR}$ 71.55 and 10 CFR $71.59,{ }^{6}$ the effective neutron multiplication factor ( $\mathrm{k}_{\mathrm{eff}}$ ) of the package will never exceed 0.95 .

Containment: The package shall be designed to contain activity to the degree required by the regulations [10 CFR 71.51(a) ${ }^{6}$ under normal and accident conditions and have a sealing system that contains the contents and is testable. The current containment concept appears to satisfy these regulations.

Handling requirements: Lifting and tie-down points on the package shall meet these requirements noted in 10 CFR $71.45^{6}$ and be capable of being adequately secured inside an SST. The package shall have lifting and stabilizing attributes that permit it to be unloaded from an SST and handled safely at shipping and receiving facilities.

Weight limitation: The gross weight of the package shall be minimized, consistent with safety and security of the fuel. The maximum package weight shall not exceed 16,500 lb.

Capacity: The package capacity for carrying fresh MOX fuel assemblies shall be maximized. The MOX fuel program will benefit significantly from the development of packaging that can carry the maximum number of MOX fuel assemblies within the payload limitations of an SST. It appears that a package design for either four PWR or eight BWR fresh MOX fuel assemblies can be achieved.

Package handling and operation: The package shall be physically compatible with all facilities it must interface with, as well as the SST in which it will be transported.

Thermal: The maximum heat load from a single package shall not exceed $400 \mathrm{~W}$. Initial inspection of fuel characteristics for PWR and BWR fresh MOX fuel indicate that four PWR assemblies in a package will provide a decay heat load of $335 \mathrm{~W}$, while eight BWR assemblies would provide a heat load of about $260 \mathrm{~W}$. 
Shielding: The package, carrying MOX fuel assemblies or rods, will always be transported by SST under exclusive-use conditions. Under these conditions, the gamma plus neutron dose rate at the surface of the package shall not exceed $1000 \mathrm{mrem} / \mathrm{h}$; the dose rate at the surface of SST shall not exceed $200 \mathrm{mrem} / \mathrm{h}$ or $10 \mathrm{mrem} / \mathrm{h}$ at $2 \mathrm{~m}$ from the surface of SST. The dose rate in the cab of the tractor shall not exceed $2 \mathrm{mrem} / \mathrm{h}$.

Once the decisions have been made with regard to the specific reactors to be involved in the program, the information included in this document can be quickly refined, expanded as necessary, and focused on the development of a SARP, which will then be submitted to DOE. 


\section{DESIGN DESCRIPTION}

During the past several months, ORNL has been investigating a number of possible preliminary concepts for a MOX fuel package that would maximize the number of fuel bundles that could be carried in SST or SGT.

Initially, the existing shipping packages currently certified for transporting fresh MOX fuel assemblies were investigated for possible modifications. All of the existing shipping packages were eliminated from consideration because their existing carrying capacity was low (e.g., a maximum of one or two PWR assemblies), and modifying the packages to carry more fuel assemblies would cause them to exceed the weight limitation of SST/SGT.

Several preliminary concepts for the new shipping packages were derived from the existing package design. These concepts were also eliminated because of excessive weight and/or excessive manual labor required for package handling.

Finally, two preliminary package concepts were devised and placed under continued consideration. Both preliminary concepts are roughly rectangular in shape and are expected to carry four PWR or eight BWR fresh fuel assemblies. While the fuel assemblies will be loaded and unloaded vertically and the package will be transported in the horizontal position, both concepts have fundamentally different configurations. These two concepts are discussed below.

For each concept, the shipping package designs for both PWR and BWR MOX fuel assemblies are discussed. The fuel assembly design envelopes shown in Table 3.1 were applied for the PWR and BWR preliminary conceptual designs.

The materials to be used for the construction of the shipping containers are presented in Appendix E.

\subsection{END-LOADING CONCEPT}

The end-loading shipping package is designed to make the seal for the packaging closure as small as possible, which provides an operational benefit to help ensure that the seal can be made easily prior to each shipment. This goal was accomplished by having the design open on one end of the package, rather than continuing the clamshell design used for many of the current fresh fuel packages. Also, the end-loading package concept could minimize the time and personnel required during loading and unloading operations.

This package would require up-ending for vertical loading and unloading of the fuel assemblies. The up-ending characteristic for this concept will require that either (1) the package be positioned in a recessed (below grade) area or (2) the fuel assemblies be lifted more than $20 \mathrm{ft}$ above the floor, which could require changes to the elevation of fuel cranes in the involved sites, as well as additional safety analyses.

Shipping packages would be transported horizontally in SST and SGT trailers. The SST and SGT trailers have tie-down provisions that can be employed at specific points with limitations on the load transmitted by each tie-down element. This may influence the tie-down design for the shipping package. The details of the tie-downs in SST/SGT for this package have not been finalized.

Table 3.1. MOX fuel shipping package design envelope for PWR and BWR MOX fuel assembly and fuel assembly cavity

\begin{tabular}{lcccccr}
\hline & \multicolumn{2}{c}{ PWR } & & \multicolumn{2}{c}{ BWR } \\
\cline { 2 - 3 } \cline { 5 - 6 } & Assembly & Cavity & & Assembly & Cavity \\
\hline $\begin{array}{l}\text { Number of assemblies } \\
\text { per package }\end{array}$ & 4 & 4 & & 8 & 8 \\
$\begin{array}{l}\text { Assembly cavity length, in. } \\
\text { Assembly cavity width, in. }\end{array}$ & 178.3 & 180.0 & & 176.2 & 180.0 \\
Assembly maximum weight, lb & 1505.0 & 1505.0 & & 687.0 & 687.0 \\
Maximum total payload, lb & 6020.0 & 6020.0 & & 5500.0 & 5500.0 \\
\hline
\end{tabular}


The basic design of the MOX fuel shipping package is projected to be comprised of a square tubular cylinder that is $\sim 37 \mathrm{in}$. in width and height and $224 \mathrm{in}$. in length, made of 3/8-in.-thick austenitic stainless steel (Fig. 3.1). The overall height of the fuel shipping package is $\sim 42$ in. from the top to the bottom of the support structure.

The shipping package would rest on a support structure at all times except during loading and unloading operations. The support structure includes removable wheels to allow easy loading into SST as well as front-to-back movement for positioning of the packages inside SST (Fig. 3.2).

The space between the fuel assembly and the compartment wall will be occupied by a cushioning material. Final selection of the material and the design to stabilize the fuel assembly inside the compartment has not been made.

One of the end covers of the package would be removed for loading and unloading operations (Fig. 3.2). The MOX fuel assemblies would be lowered into the inner containment cavities and clamped in place. The removable end cover is designed to be bolted onto the flange at the end of the outer shell using 5/8-in. bolts; the bolt size has not been optimized. The other end of the cylinder could also be removed to facilitate maintenance and cleaning of the package.

The design parameters of the end-loading shipping packages for both PWR and BWR assemblies are summarized in Table 3.2 .

\subsubsection{PWR MOX End-Loading Fuel Shipping Package}

The new PWR MOX end-loading shipping package would carry four PWR MOX fuel assemblies (Figs. 3.2-3.4). Each fuel assembly would be loaded in its own separate square compartment fabricated of 1/8-in.-thick stainless steel. The compartment would also serve as the containment volume for the shipping package.

The four fuel compartment tubes would be assembled into a monolithic bundle with the criticality control mechanism in between. The 3/16-in.-thick $\mathrm{B}_{4} \mathrm{C}$ poison plates are placed in between the tubes with a 1-in. gap between them (Figs. B.2 and B.3 in Appendix B). The 1-in. gap will act as a neutron flux trap if it becomes filled with water during the severe accident conditions described in Chap. 3 of ORNL/TM-13526. ${ }^{4}$

ORNL 98-1499 EFG

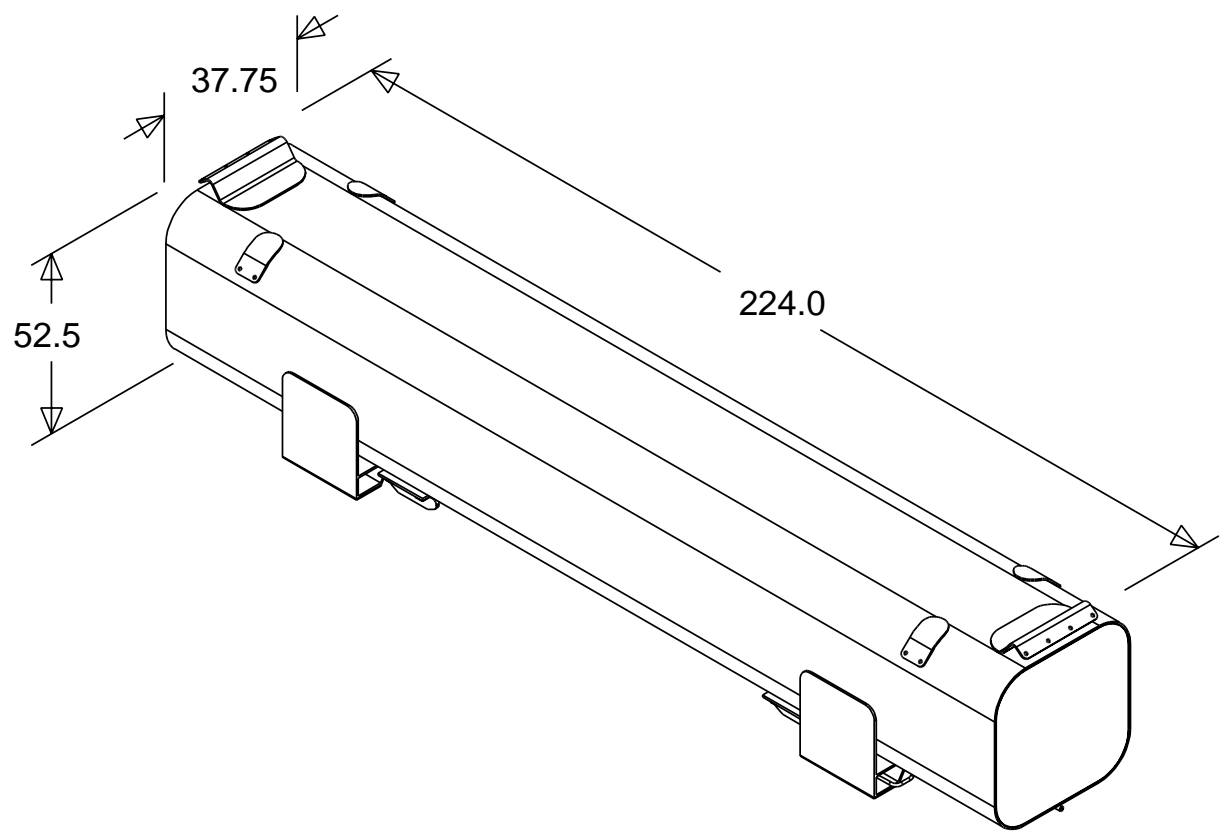

Fig. 3.1. Overall dimensions for end-loading concept (dimensions in inches). 


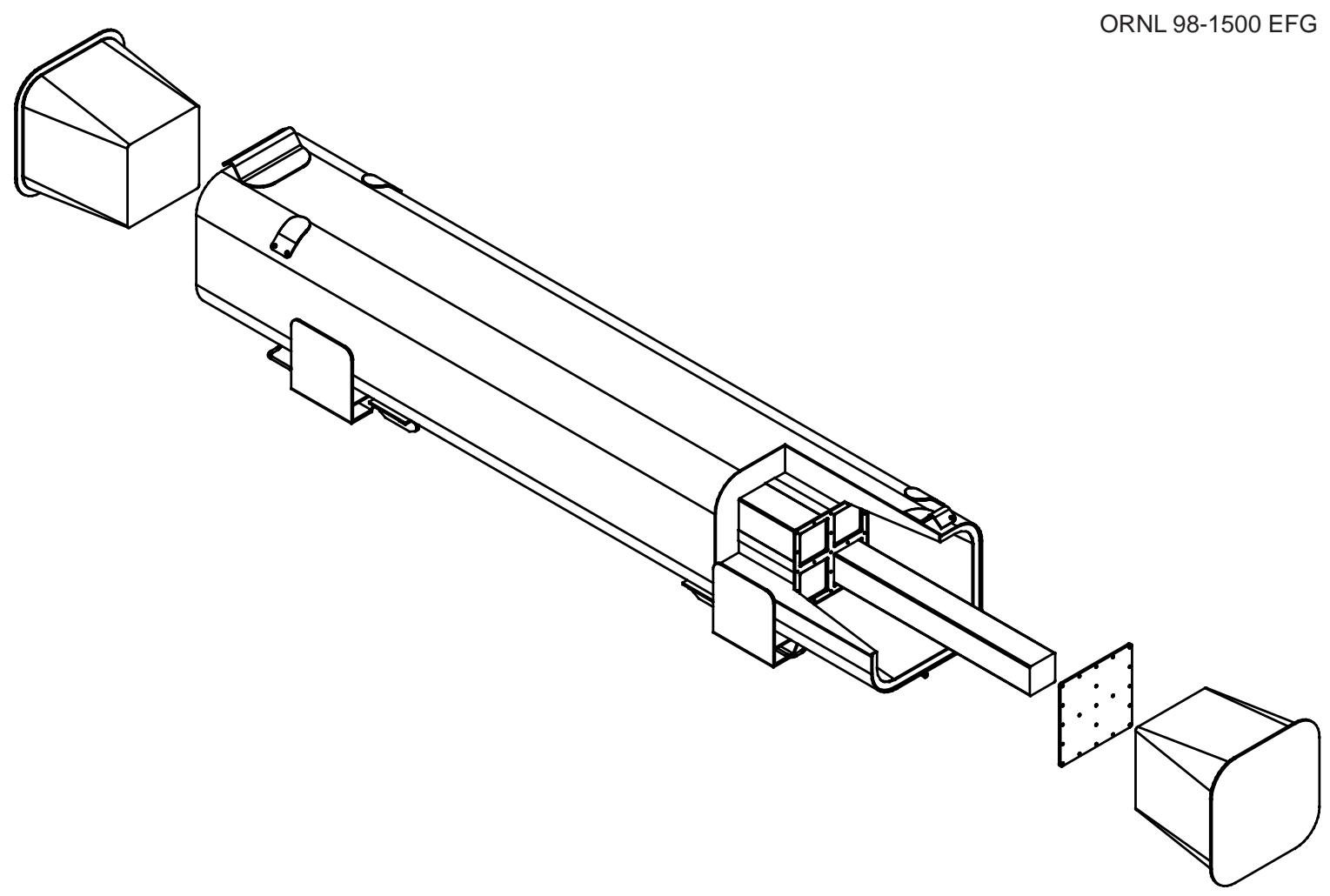

Fig. 3.2. Cutaway view of end-loading concept for PWR fuel.

Table 3.2. Design parameters of end-loading PWR and BWR fuel shipping packages

\begin{tabular}{lcc}
\hline & \multicolumn{2}{c}{ Fuel package } \\
\cline { 2 - 3 } \multicolumn{1}{c}{ Parameters } & PWR & BWR \\
\hline Length of package, in. & 224.0 & 224.0 \\
Height of package, in. & 36.75 & 36.75 \\
Width of package, in. & 36.75 & 36.75 \\
Overall height, in. & 52.5 & 42.125 \\
Number of fuel assemblies per package & 4 & 8 \\
Weight of fuel assemblies, lb & 6,020 & 5,500 \\
Total weight of package, lb & $\sim 13,000$ & $\sim 12,700$ \\
\hline
\end{tabular}

A $\mathrm{B}_{4} \mathrm{C}$ poison plate is sandwiched between a tube and the 5/16-in.-thick reinforcing structural member. The $\mathrm{B}_{4} \mathrm{C}$ poison plates are not designed to be load-bearing structures.

The monolithic fuel bundle tube assemblies are suspended and supported by low-density (LD) foam $\left(6 \mathrm{lb} / \mathrm{ft}^{3}\right)$ within the outer shell (Fig. 3.3). The LD foam that is designed to provide support for the containment volume during normal operations is also designed to absorb impact energy and prevent rupturing of the outer shell and the containment volume during the severe accident conditions described in Chap. 3 of ORNL/TM-13526. ${ }^{4}$

The outer shell is currently envisioned to be made of 3/8-in.-thick austenitic stainless steel but may be replaced with other materials that are stronger and lighter. 


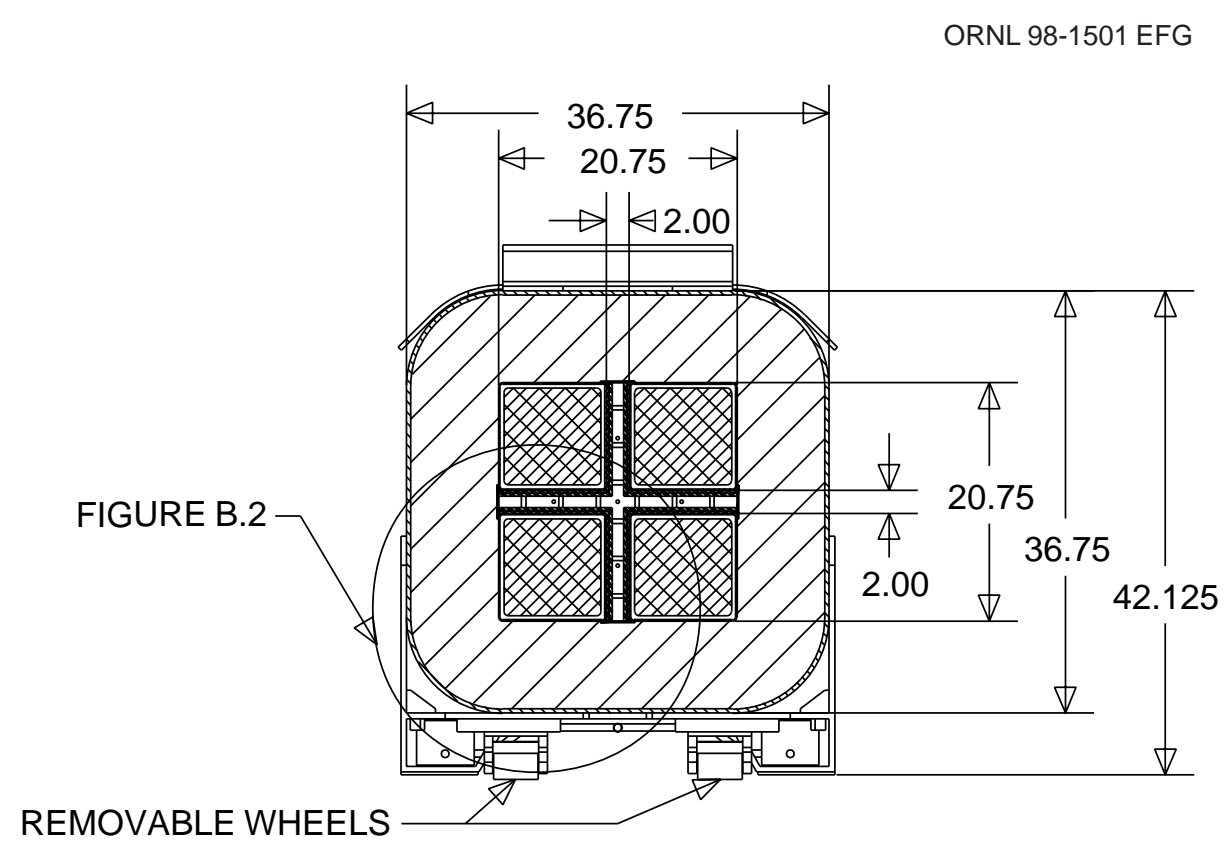

Fig. 3.3. Cross-sectional view of end-loading concept for PWR fuel (dimensions in inches).

ORNL 98-1502 EFG

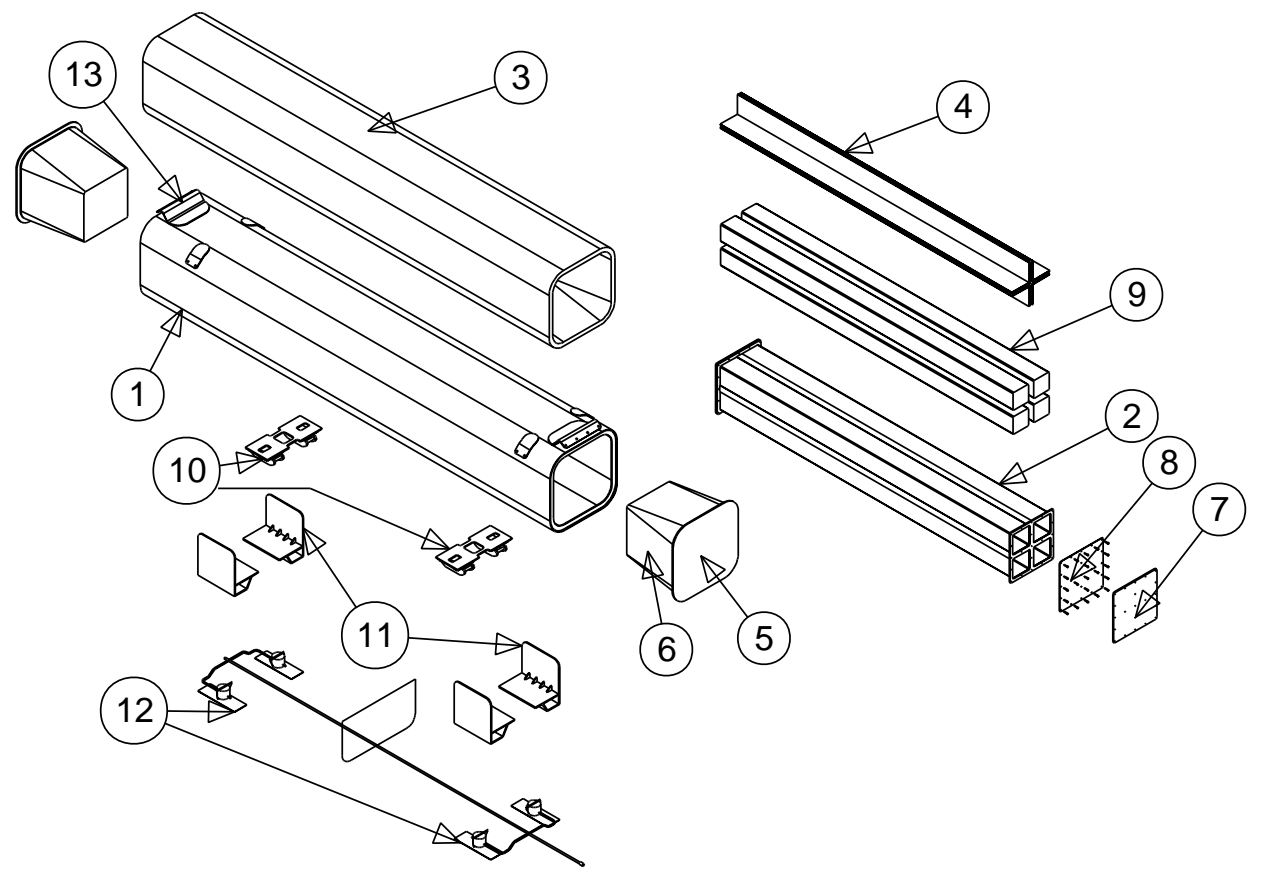

Fig. 3.4. Exploded view of end-loading shipping package for PWR fuel (see Table 3.3 for key to numbers). 
An exploded view of the end-loading shipping package design for PWR fuel assemblies is shown in Fig. 3.4. Total weight of the end-loading shipping package for the PWR fuel assemblies is currently estimated to be 13,000 lb. A summary of the weight of each component for an end-loading PWR shipping package is shown in Table 3.3.

\subsubsection{BWR MOX End-Loading Fuel Shipping Package}

The preliminary conceptual shipping package design for the BWR MOX fuel assemblies is very similar to the one for the PWR fuel assemblies except that eight BWR MOX fuel assemblies would be transported per package. On the outside, the BWR fuel shipping package concept is virtually identical to the PWR fuel shipping package concept. The differences between the two shipping package concepts, which are due to the characteristics of the fuel assemblies, are limited to the internals of the package and the total package weight.

The new BWR MOX end-loading fuel shipping package would carry eight BWR MOX fuel assemblies, which would be loaded in separate compartments made of $1 / 8$-in.-thick stainless steel (Figs. 3.5-3.7). Like the PWR package design, each compartment would also serve as the containment volume for the shipping package. These eight tubes would be assembled into a monolithic bundle. The 1/4-in.-thick $\mathrm{B}_{4} \mathrm{C}$ poison plates are placed in between the tubes with a 0.5-in. gap (Figs. B.5 and B.6 in Appendix B). The 0.5-in. gap will act as a neutron flux trap if it becomes filled with water during severe accident conditions.

The monolithic fuel bundle tube assemblies are suspended and supported by LD foam $\left(6 \mathrm{lb} / \mathrm{ft}^{3}\right)$ within the outer shell. The LD foam, which is designed to provide support for the containment volume during normal operations, is also designed to absorb impact energy and prevent rupturing of the outer shell and containment volume during the severe accident conditions described in Chap. 3 of ORNL/TM-13526. ${ }^{4}$

The outer shell is currently envisioned to be made of 3/8-in.-thick austenitic stainless steel but could be replaced with other materials that are stronger and lighter. An exploded view of the end-loading shipping package design for BWR fuel assemblies is shown in Fig. 3.7.

Total weight of the end-loading shipping package for the BWR fuel assemblies is estimated to be $\sim 12,700 \mathrm{lb}$. A summary of the weight of each component for the end-loading BWR shipping package design is shown in Table 3.4.

Table 3.3. End-loading design parameters for PWR fuel shipping package

\begin{tabular}{clllr}
\hline Key $a$ & \multicolumn{1}{c}{ Part name } & \multicolumn{1}{c}{ Material } & \multicolumn{1}{c}{$\begin{array}{c}\text { Thickness } \\
\text { (in.) }\end{array}$} & $\begin{array}{r}\text { Weight } \\
\text { (lb) }\end{array}$ \\
\hline 1 & Outer shell & Austenitic stainless steel & 0.375 & 3,265 \\
2 & Inner containment & Austenitic stainless steel & 0.125 & 1,130 \\
3 & LD foam & 6-lb/ft ${ }^{3}$ density foam & 7.625 & 550 \\
4 & B 4 C poison plate & B 4 C & 0.1875 & 550 \\
5 & Removable end cover & Austenitic stainless steel & 0.5 & 170 \\
6 & LD foam & 6-lb/ft ${ }^{3}$ density foam & 20.75 & 80 \\
7 & Inner containment flange & Austenitic stainless steel & 0.5 & 80 \\
8 & Inner containment gasket & Gasket to be determined & 0.125 & 20 \\
9 & PWR MOX fuel & Special nuclear material & N/A & 6,020 \\
& assemblies & (SNM) & & \\
10 & Removable wheels & N/A & N/A & 50 \\
11 & Support structure & Austenitic stainless steel & 0.5 & 610 \\
12 & Hydraulic system & N/A & N/A & 50 \\
13 & Tie-down components & Austenitic stainless steel & 0.375 to 0.5 & 100 \\
\hline
\end{tabular}

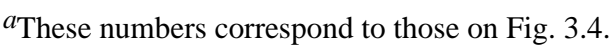




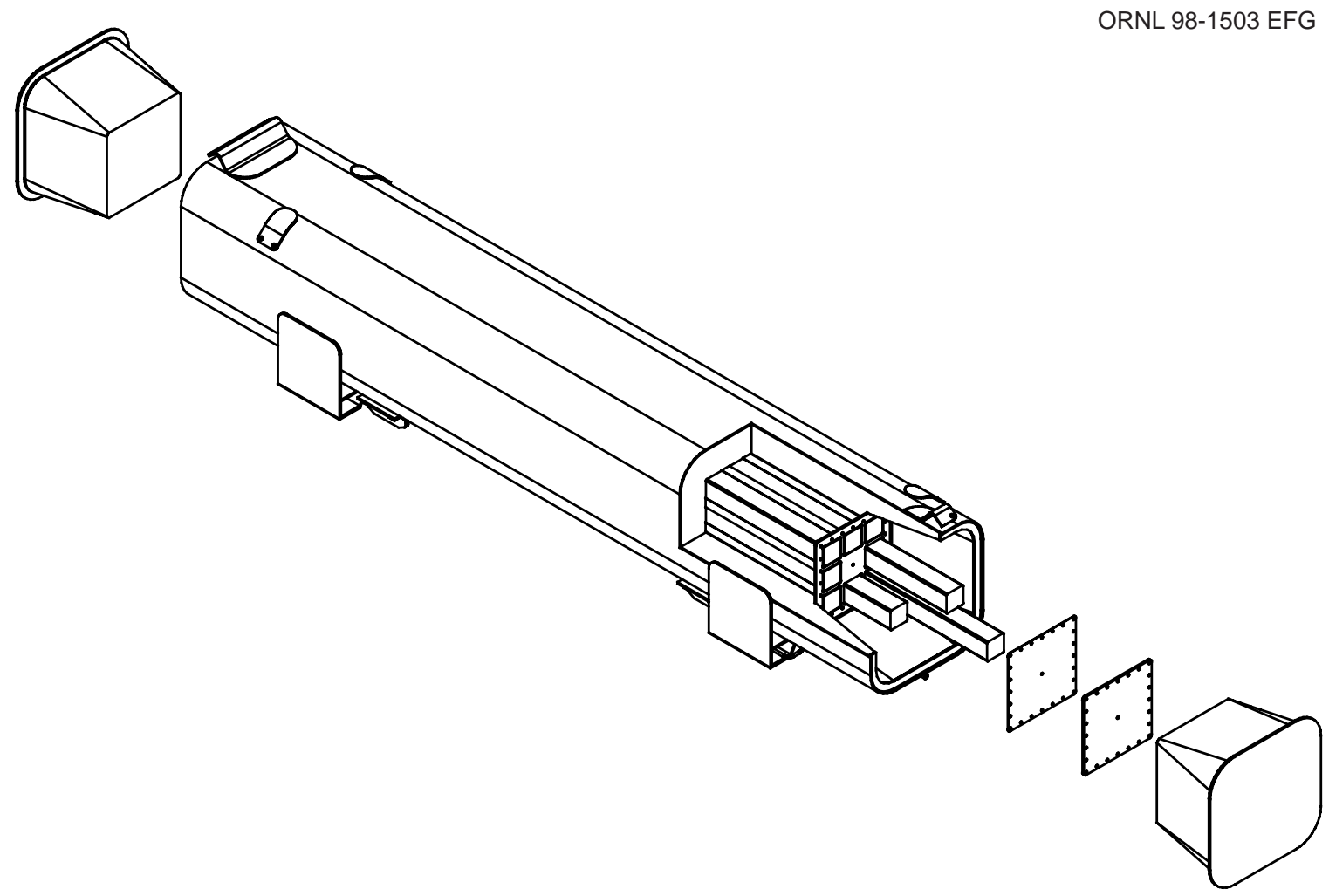

Fig. 3.5. Cutaway view of end-loading concept for BWR fuel.

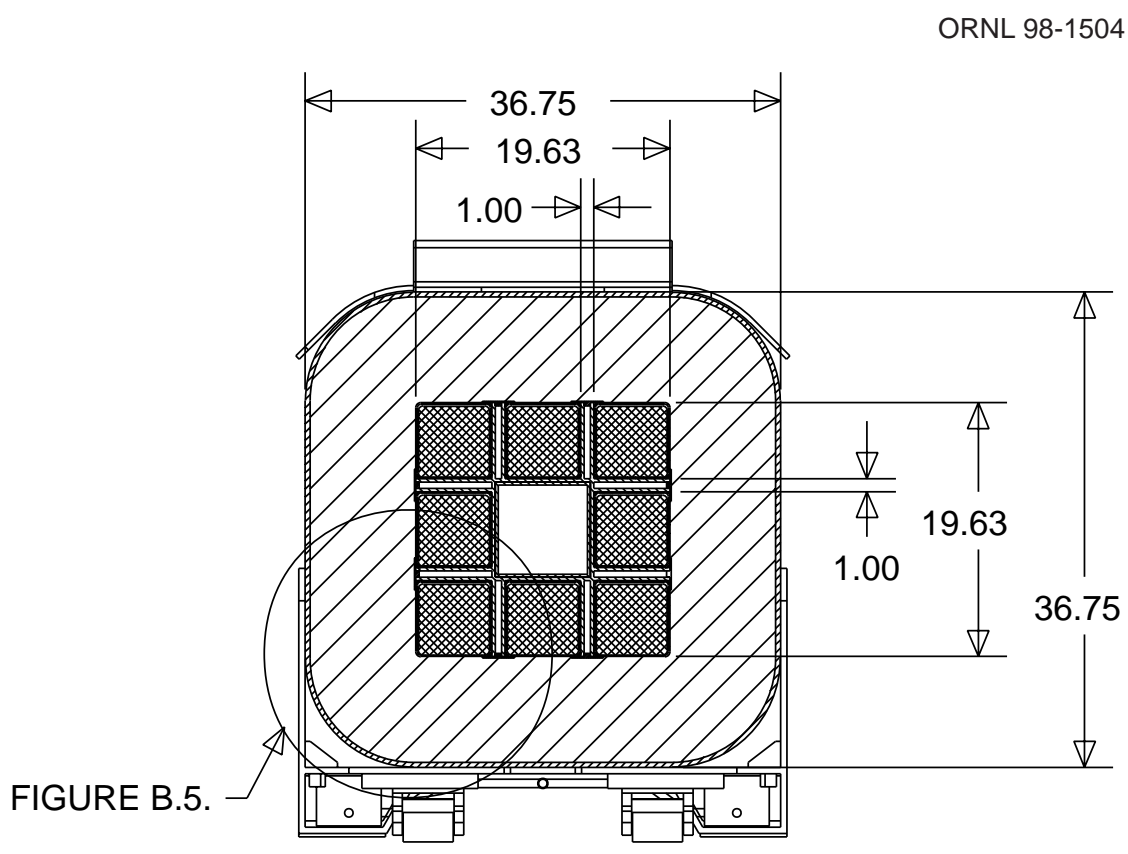

Fig. 3.6. Cross-sectional view of end-loading concept for BWR fuel (dimensions in inches). 


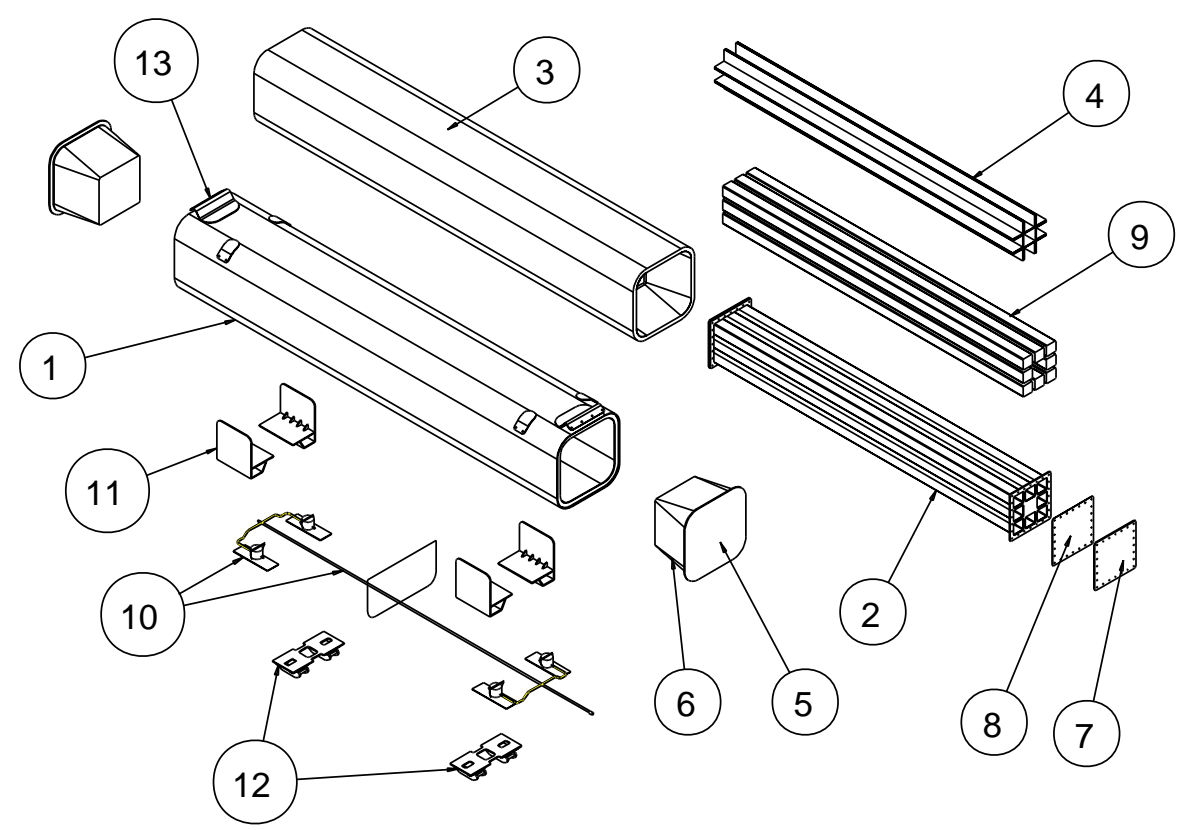

Fig. 3.7. Exploded view of end-loading concept for BWR fuel (see Table 3.4 for key to numbers).

Table 3.4. End-loading design parameters for BWR fuel shipping package

\begin{tabular}{|c|c|c|c|c|}
\hline $\mathrm{Key}^{a}$ & Part name & Material & $\begin{array}{l}\text { Thickness } \\
\text { (in.) }\end{array}$ & $\begin{array}{l}\text { Weight } \\
\text { (lb) }\end{array}$ \\
\hline 1 & Outer shell & Austenitic stainless steel & 0.375 & 3,265 \\
\hline 2 & Inner containment volume & Austenitic stainless steel & 0.125 & 1,520 \\
\hline 3 & LD foam & $6-1 \mathrm{~b} / \mathrm{ft}^{3}$ density foam & N/A & 595 \\
\hline 4 & $\mathrm{~B}_{4} \mathrm{C}$ poison plate & $\mathrm{B}_{4} \mathrm{C}$ & 0.25 & 555 \\
\hline 5 & Removable end cover & $\begin{array}{l}\text { Austenitic stainless steel } \\
\text { plate }\end{array}$ & 0.5 & 170 \\
\hline 6 & LD foam & $6-1 b / \mathrm{ft}^{3}$ density foam & 20.625 & 80 \\
\hline 7 & Inner containment flange & Austenitic stainless steel & 0.5 & 80 \\
\hline 8 & Inner containment gasket & Gasket & 0.125 & 20 \\
\hline 9 & $\begin{array}{l}\text { BWR MOX fuel } \\
\text { assembly }\end{array}$ & SNM & N/A & 5,500 \\
\hline 10 & Hydraulic line system & N/A & N/A & $\sim 35$ \\
\hline 11 & Support structure & Austenitic stainless steel & 0.5 & 610 \\
\hline 12 & Removable wheels & N/A & N/A & $\sim 50$ \\
\hline 13 & Tie-down components & Austenitic stainless steel & 0.375 to 0.5 & 100 \\
\hline
\end{tabular}

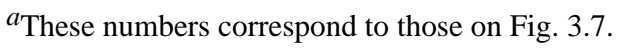

\subsection{DOUBLE-STRONGBACK CONCEPT}

Although the end-loading concept discussed in Sect. 3.1 appears promising, it could require some undetermined additional expense to the nuclear utility in additional equipment and changes to procedures 
and the utility's safety analysis report. Therefore, a different shipping package design was developed to minimize possible impacts on the package handling at potential commercial PWRs and BWRs.

The double-strongback shipping package preliminary concept was developed to minimize impact on the existing loading and unloading operations while increasing the capacity to carry more MOX fuel assemblies. This goal was accomplished by utilizing a strongback concept that is similar to that of the existing MO-1 shipping package. This new strongback concept includes a completely sealed inner box (containment volume) that contains two separate strongbacks that can be raised vertically to accommodate the existing procedure for vertical loading and unloading of the MOX fuel assemblies (Figs. 3.8-3.11). Once raised to the vertical position, the strongbacks would be braced during loading and unloading operations. Each strongback would hold two PWR or four BWR assemblies.

The double-strongback shipping packages would be transported horizontally in the SST and SGT trailers. The SST and SGT trailers have tie-down provisions that can be employed at specific points with limitations on the load transmitted by each tie-down element. This may influence the tie-down design for the shipping package. The details of the tie-downs in SST/SGT have not been finalized.

The basic design of the double-strongback shipping package is projected to be comprised of a containment volume that contains two double strongbacks; LD foam, which surrounds the containment volume; and the outer shell (Fig. 3.12). The containment volume and outer shell have removable covers that can be opened while in a horizontal position (Fig. 3.8).

Both the containment volume cover and the shell cover are removed for loading and unloading operations. The MOX fuel assemblies are placed into the strongback and clamped in place. The removable end covers are designed to be bolted onto their respective flanges using a 5/8-in.-bolt; the bolt sizes have not been optimized. Gaskets will be used to provide a complete seal to satisfy the containment design requirement.

The containment volume structure is suspended and supported by LD foam $\left(6 \mathrm{lb} / \mathrm{ft}^{3}\right)$ within the outer shell. The LD foam, which is designed to provide support for the containment volume during normal

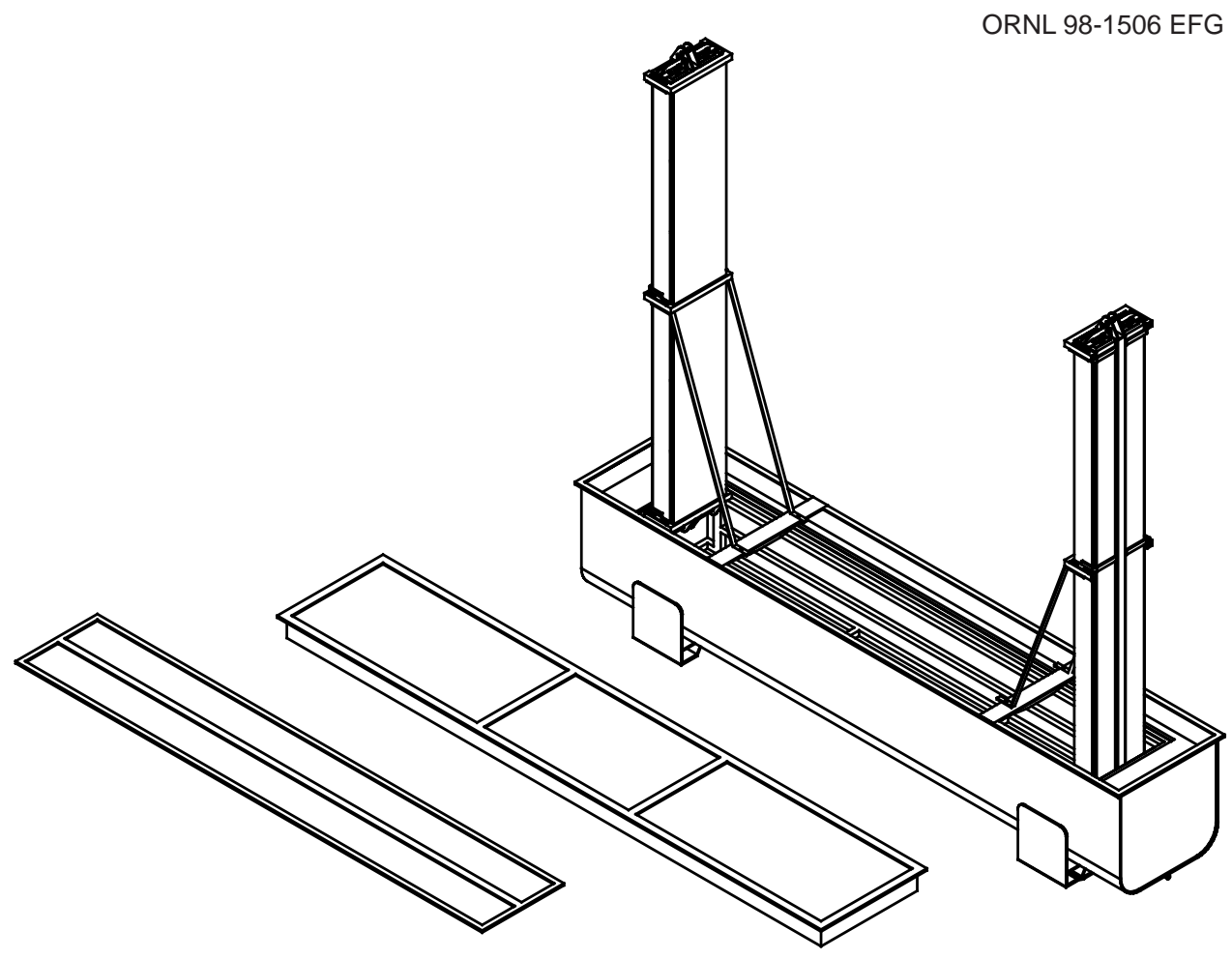

Fig. 3.8. Double-strongback concept for PWR fuel. 


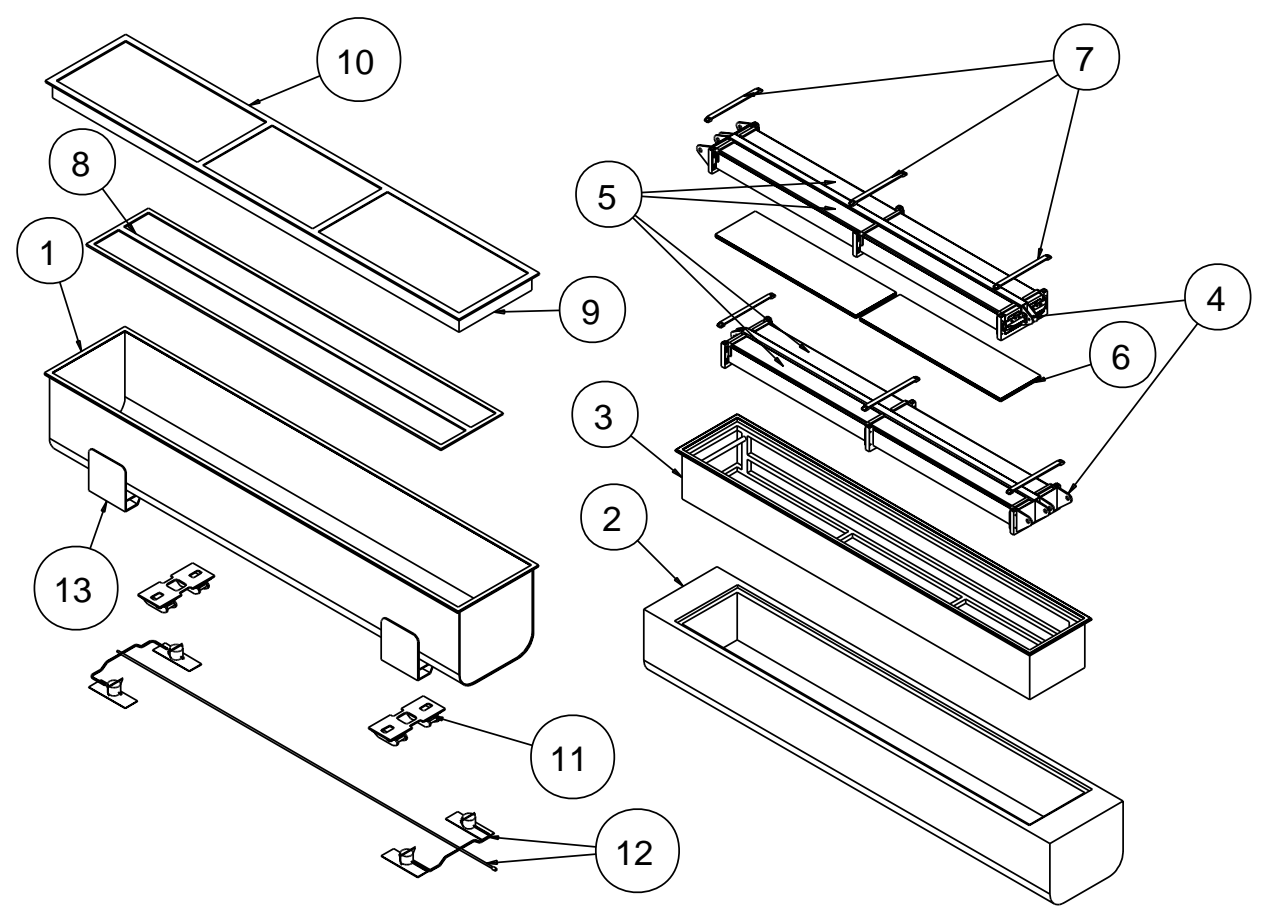

Fig. 3.9. Exploded view of double-strongback concept for PWR fuel (see Table 3.6 for key to numbers).

ORNL 98-1508 EFG

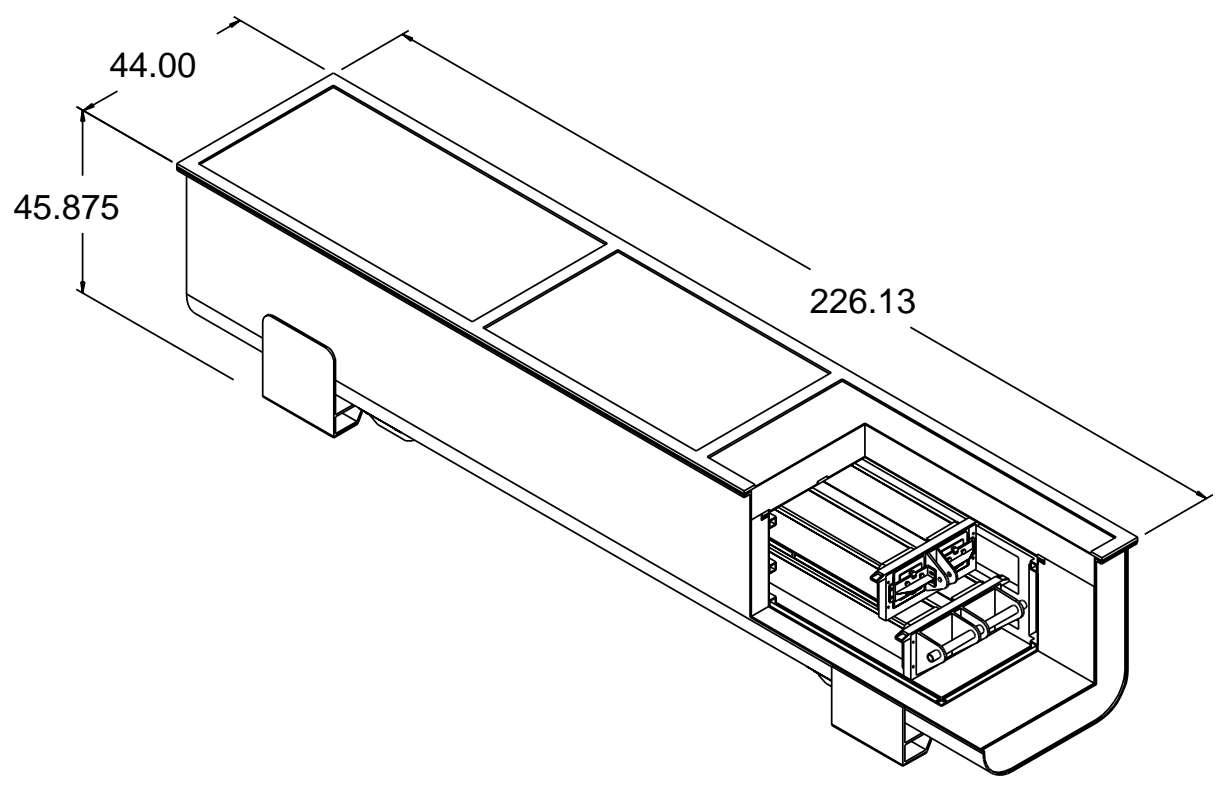

Fig. 3.10. Cutaway view of double-strongback concept for PWR fuel (dimensions in inches). 

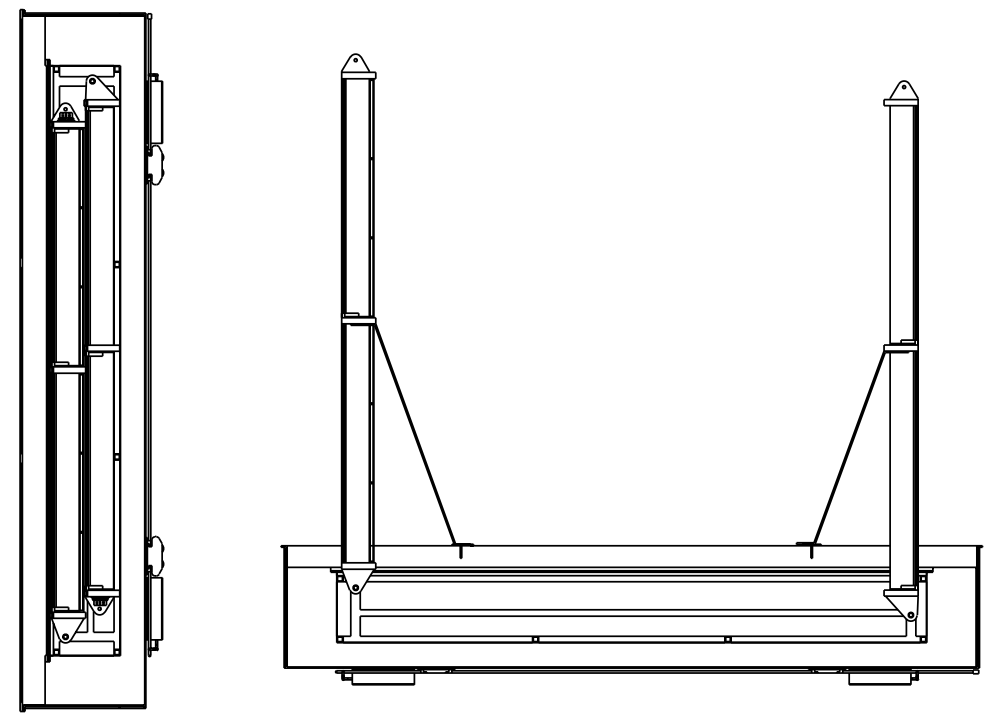

Fig. 3.11. Double-strongback concept for PWR fuel.

ORNL 98-1510 EFG

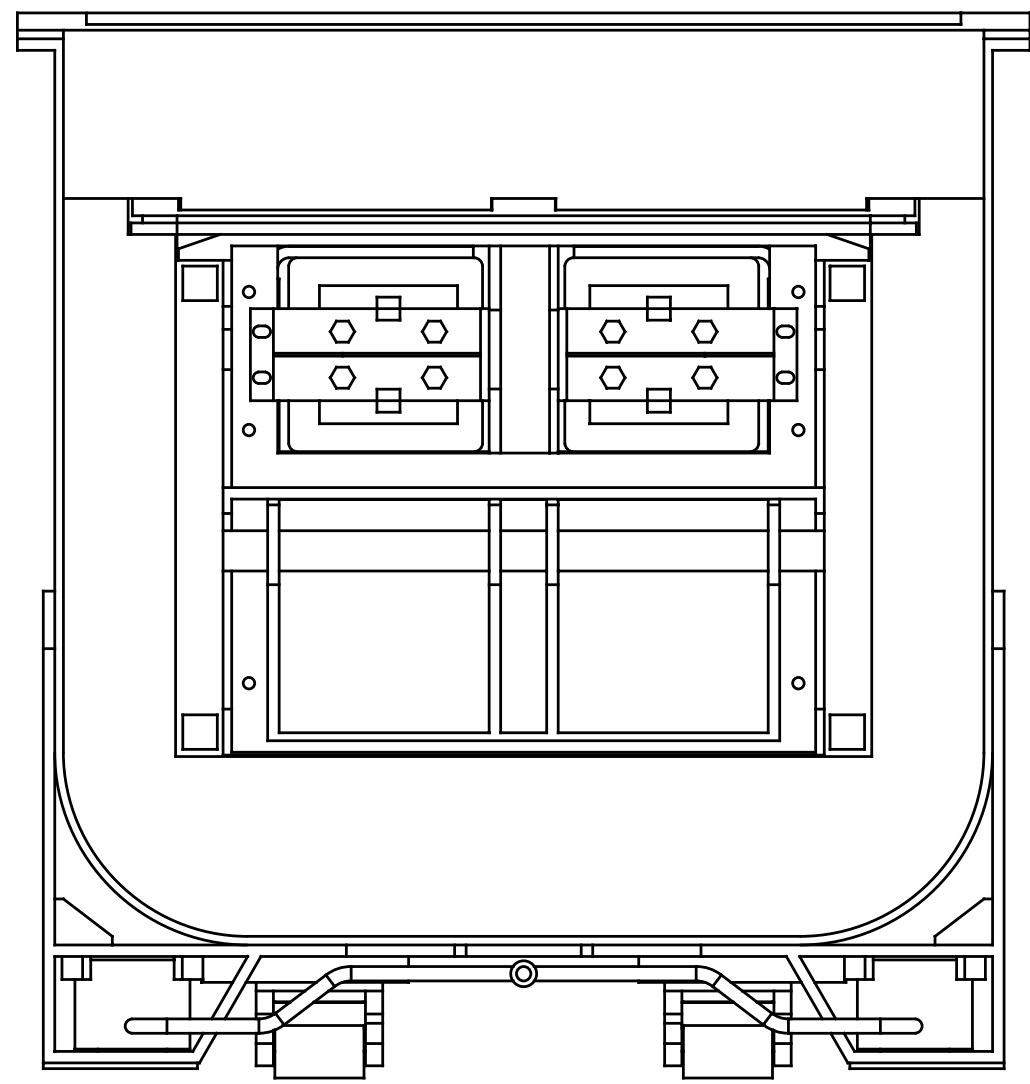

Fig. 3.12. Cross-sectional view of double-strongback concept for PWR fuel. 
operations, is also designed to absorb impact energy and prevent rupturing of the outer shell and the containment volume during the severe accident conditions described in Chap. 3 of ORNL/TM-13526. ${ }^{4}$

The shipping package would rest on a support structure except during the loading and unloading operation into SST. The support structure is envisioned to include lightweight removable wheels (Fig. 3.12) to allow easy loading into SST as well as front-to-back movement for positioning of the packages inside SST. A hydraulic jack system (Fig. 3.12) will be used to elevate the shipping containers during installation and removal of the wheels.

The design parameters of the double-strongback shipping packages for both PWR and BWR assemblies are summarized in Table 3.5.

\subsubsection{PWR MOX Double-Strongback Fuel Shipping Package}

The new double-strongback shipping package concept is envisioned to carry four PWR MOX fuel assemblies (Figs. 3.8-3.10).

An exploded view of the double-strongback shipping package design for PWR fuel assemblies is shown in Fig. 3.9. Total weight of the package is estimated to be $\sim 14,200 \mathrm{lb}$. A summary of the weight of each component is shown in Table 3.6.

Table 3.5. Design parameters of double-strongback shipping packages for PWR and BWR fuel

\begin{tabular}{lcc}
\hline \multirow{2}{*}{\multicolumn{1}{c}{ Parameters }} & \multicolumn{2}{c}{ Fuel package } \\
\cline { 2 - 3 } \multicolumn{1}{c}{ PWR } & BWR \\
\hline Length of package, in. & 226.125 & 226.0 \\
Height of package, in. & 40.50 & 35.25 \\
Width of package, in. & 44.0 & 49.50 \\
Overall height, in. & $\sim 46.0$ & $\sim 41.0$ \\
Number of fuel assemblies per package & 4 & 8 \\
Weight of fuel assemblies, lb & 6,020 & 5,500 \\
Total weight of package, lb & $\sim 14,200$ & $\sim 14,750$ \\
\hline
\end{tabular}

Table 3.6. Double-strongback design parameters for PWR fuel shipping package

\begin{tabular}{|c|c|c|c|c|}
\hline $\mathrm{Key}^{a}$ & Part name & Material & $\begin{array}{l}\text { Thickness } \\
\text { (in.) }\end{array}$ & $\begin{array}{l}\text { Weight } \\
\text { (lb) }\end{array}$ \\
\hline 1 & Outer shell & Austenitic stainless steel & 0.5 & 3,120 \\
\hline 2 & LD foam & $6-\mathrm{lb} / \mathrm{ft}^{3}$ density foam & N/A & 440 \\
\hline 3 & Containment volume & Austenitic stainless steel & 0.375 & 865 \\
\hline 4 & Strongback assemblies (2) & Austenitic stainless steel & N/A & 910 \\
\hline 5 & $\begin{array}{c}\text { PWR MOX fuel } \\
\text { assemblies (4) }\end{array}$ & SNM & N/A & 6,020 \\
\hline 6 & $\mathrm{~B}_{4} \mathrm{C}$ poison plates & $\mathrm{B}_{4} \mathrm{C}$ & 0.25 & 230 \\
\hline 7 & Strongback hold-down clamp & Austenitic stainless steel & 0.5 & 270 \\
\hline 8 & Removable inner cover & Austenitic stainless steel & 0.125 and 0.25 & 530 \\
\hline 9 & $\mathrm{LD}$ foam & $6-\mathrm{lb} / \mathrm{ft}^{3}$ density foam & 7.3125 & 235 \\
\hline 10 & Removable outer cover & Austenitic stainless steel & 0.25 and 0.5 & 1,030 \\
\hline 11 & Removable wheels & N/A & N/A & $\sim 50$ \\
\hline 12 & Hydraulic jack system & N/A & N/A & $\sim 50$ \\
\hline 13 & Support structure & Austenitic stainless steel & 0.375 to 0.5 & 400 \\
\hline
\end{tabular}

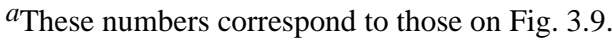


The outer shell is $\sim 44$ in. in width, 46 in. in height, and 226 in. in length and is made of 3/8-in.-thick austenitic stainless steel (Fig. 3.10). Other materials that are stronger and lighter could be used in place of the austenitic stainless steel. The removable cover for the outer shell would be bolted onto the flange at the top of the outer shell. The overall height of the fuel shipping package is $\sim 46$ in. from the top to the bottom of the support structure. This overall height could change, if required in the future.

The containment volume is $23.5 \mathrm{in}$. in height, $30 \mathrm{in}$. in width, and $190 \mathrm{in}$. in length and is made of 1/16-in.-thick austenitic stainless steel (Fig. 3.13). The structural frame of the containment volume is made of 1/4-in.-thick steel square tubing. The frame is strong enough to provide support for the strongbacks during transportation and for the pivoting of the strongbacks during loading and unloading operations. The containment volume is completely sealed during transportation by the removable cover (Fig. 3.9).

Each fuel assembly would be loaded in its own separate compartment made of thin stainless steel sheet metal supported by a strongback frame made of steel tubes (Figs. 3.14 and 3.15). Unlike the endloading concept, the compartment does not serve as a containment volume but rather as a holding tray.

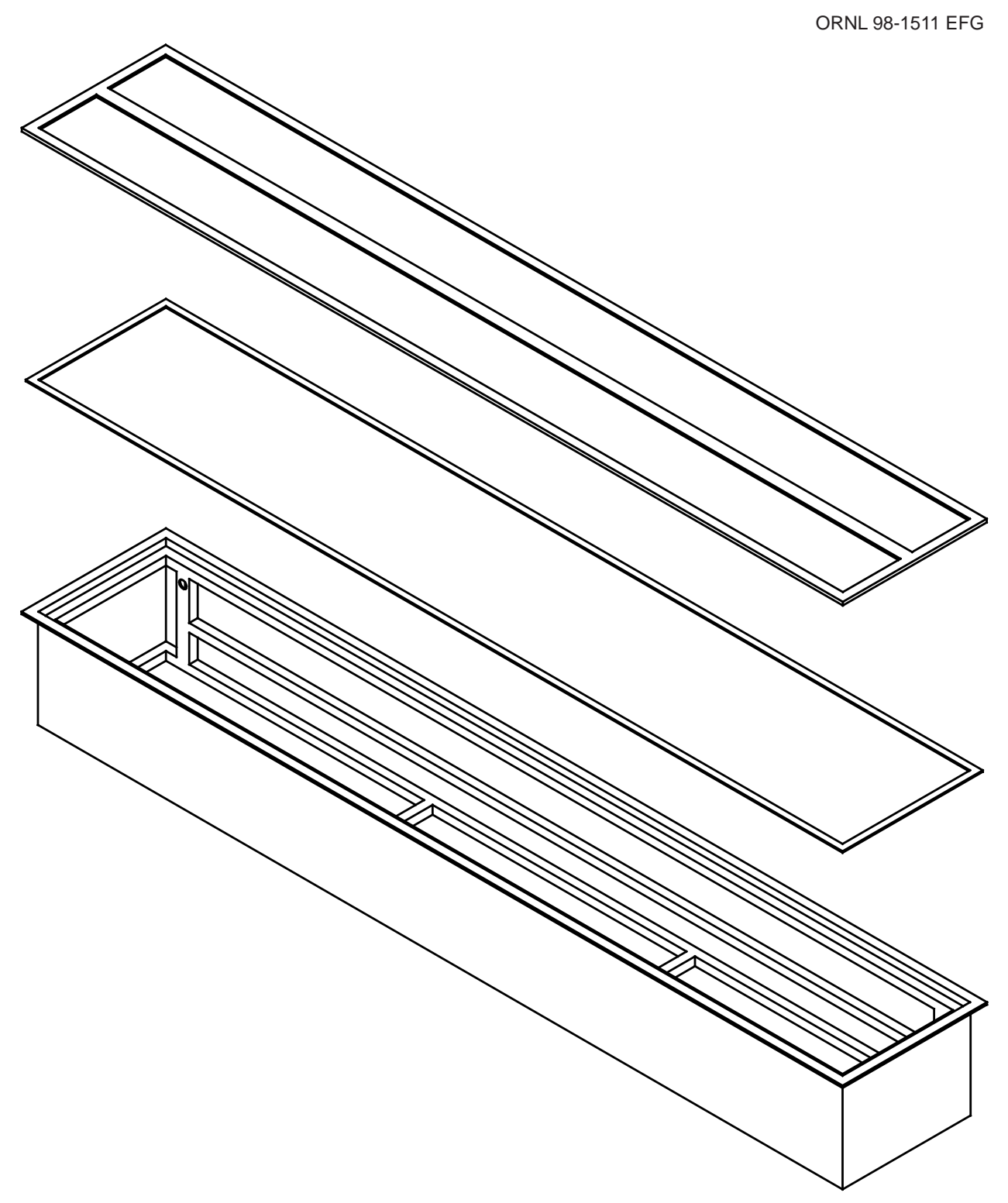

Fig. 3.13. Containment volume for double-strongback concept. 
Each strongback has two compartments for PWR fuel assemblies; 3/16-in.-thick $\mathrm{B}_{4} \mathrm{C}$ poison plates are placed between the two compartments with a 2 5/8-in. gap between them. Each compartment is separated by the strongback frame, which is made of 3/16-in.-thick steel tubing. The $\mathrm{B}_{4} \mathrm{C}$ poison plates, with a 1-in. gap in between, are installed to control nuclear criticality during hypothetical accident conditions (HAC). Detailed drawings (Figs. C.1-C.5) are presented in Appendix C.

Once placed in the compartment, each MOX fuel assembly will be secured to prevent vibration during transportation using mechanical clamps and soft pads along the length of the fuel assembly as well as at the top (Fig. 3.14).

\subsubsection{BWR MOX Double-Strongback Fuel Shipping Package}

The new double-strongback shipping package concept is envisioned to carry eight BWR MOX fuel assemblies (Figs. 3.16-3.19). The outer shell is $~ 50$ in. in width, $41 \mathrm{in.}$ in height, and $226 \mathrm{in.}$ in length and is made of 3/8-in.-thick austenitic stainless steel. Other materials that are stronger and lighter could be used in place of the austenitic stainless steel. The removable cover for the outer shell would be bolted onto the flange at the top of the outer shell. The overall height of the fuel shipping package is $\sim 41 \mathrm{in}$. from the top to the bottom of the support structure, but this overall height could change, if required in the future.

An exploded view of the double-strongback shipping package design for BWR fuel assemblies is shown in Fig. 3.17. Total weight of the package is estimated to be $\sim 13,588 \mathrm{lb}$. A summary of the weight of each component is shown in Table 3.7.

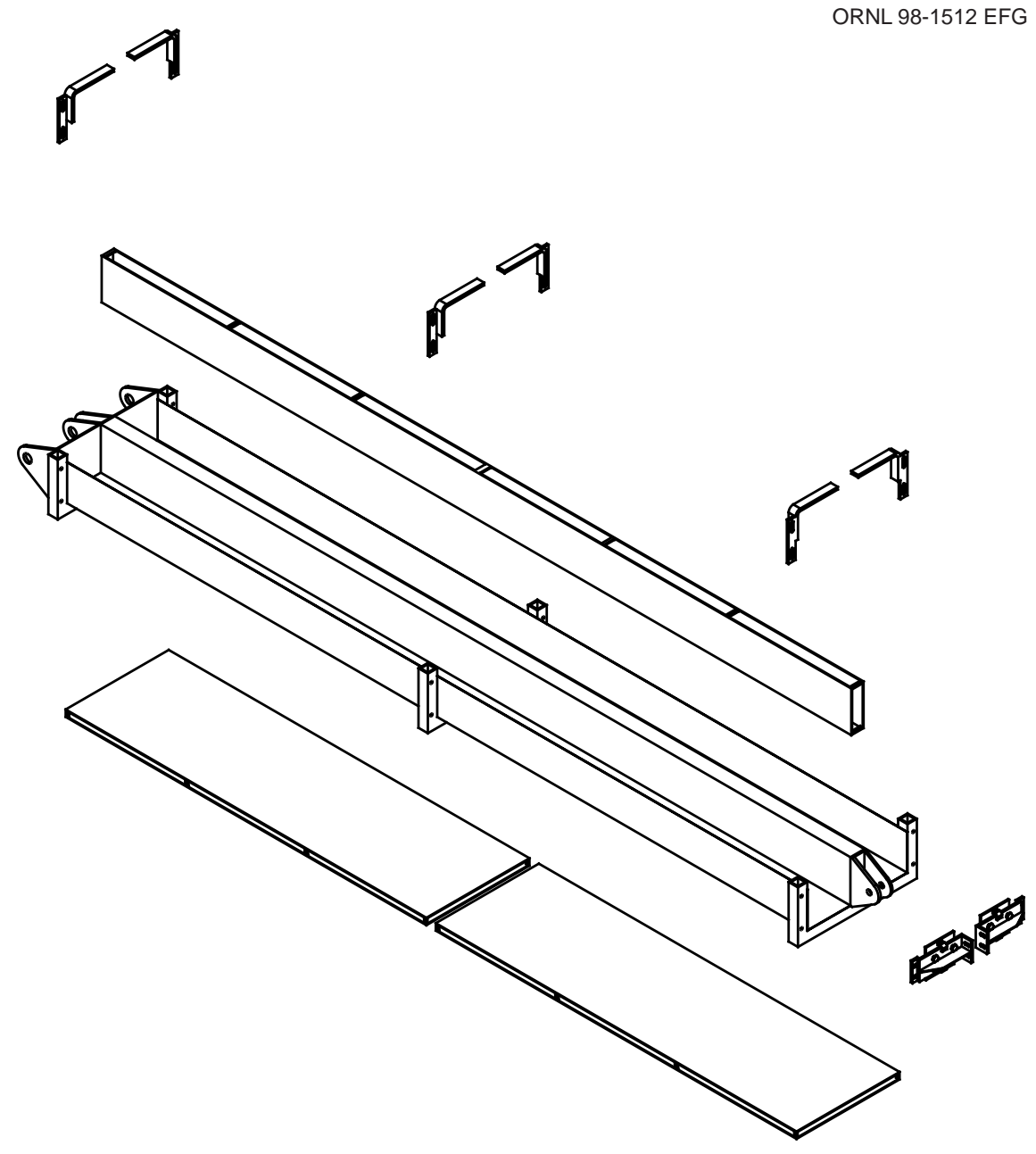

Fig. 3.14. Strongback frame for double-strongback concept. 


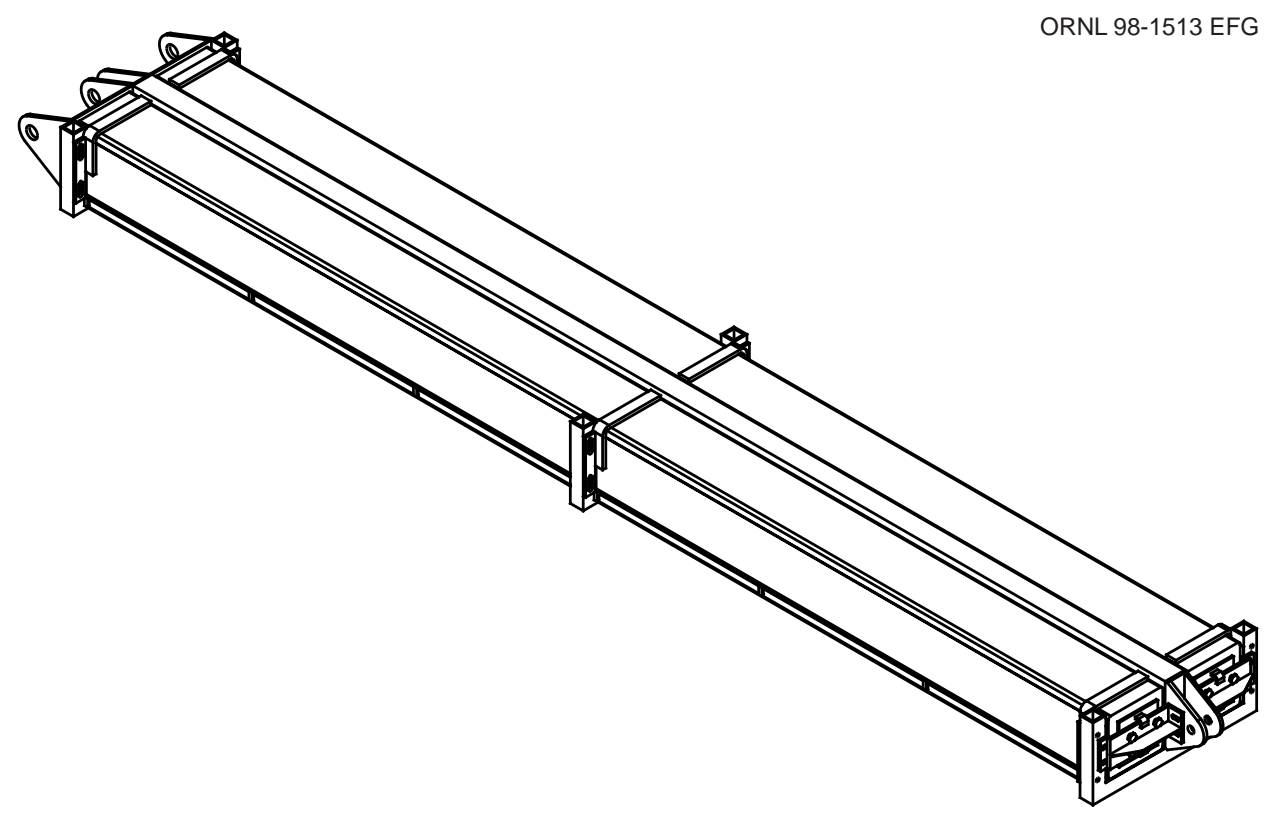

Fig. 3.15. Secured PWR fuel assemblies in strongback concept.

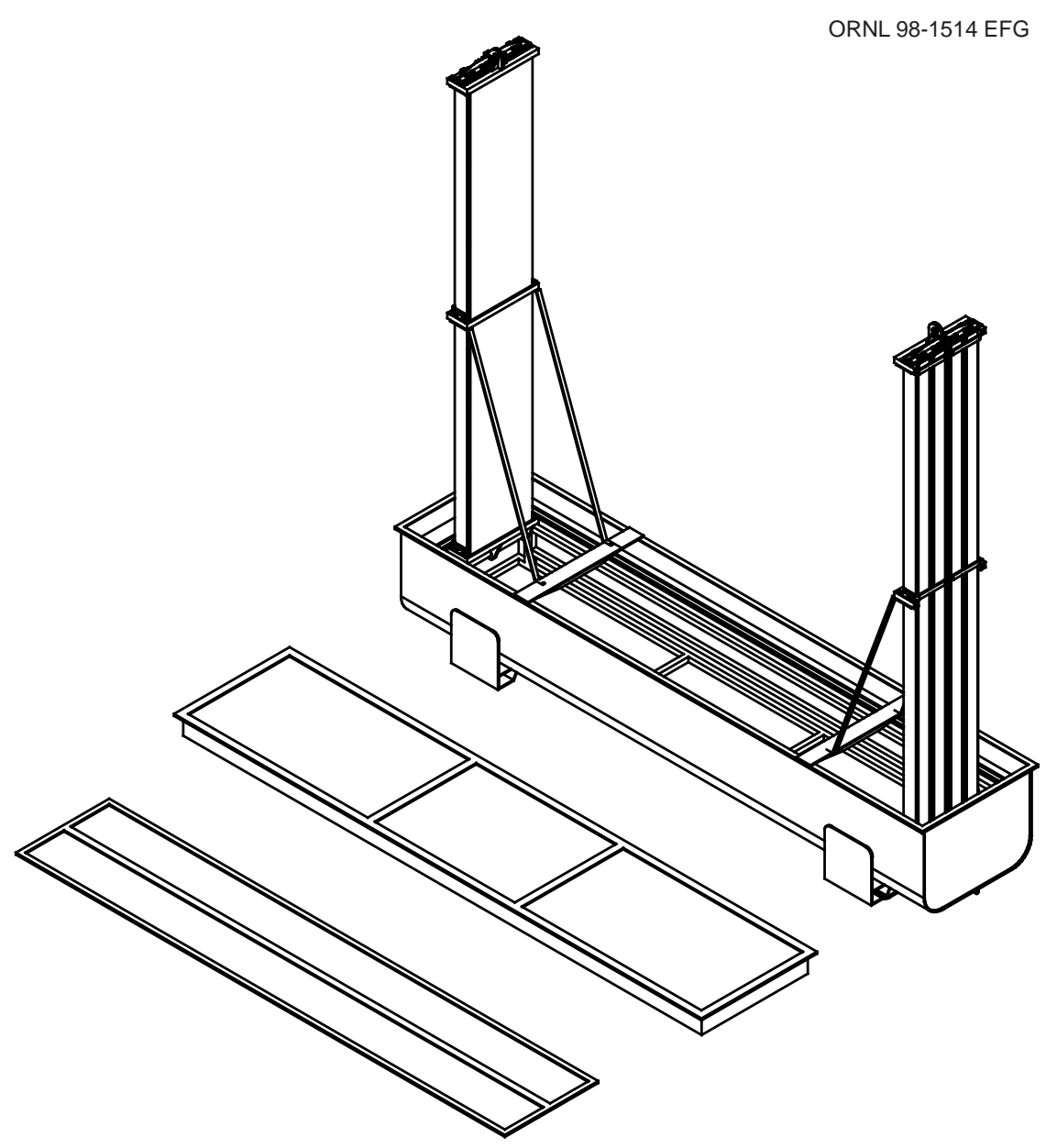

Fig. 3.16. Double-strongback concept for BWR fuel. 

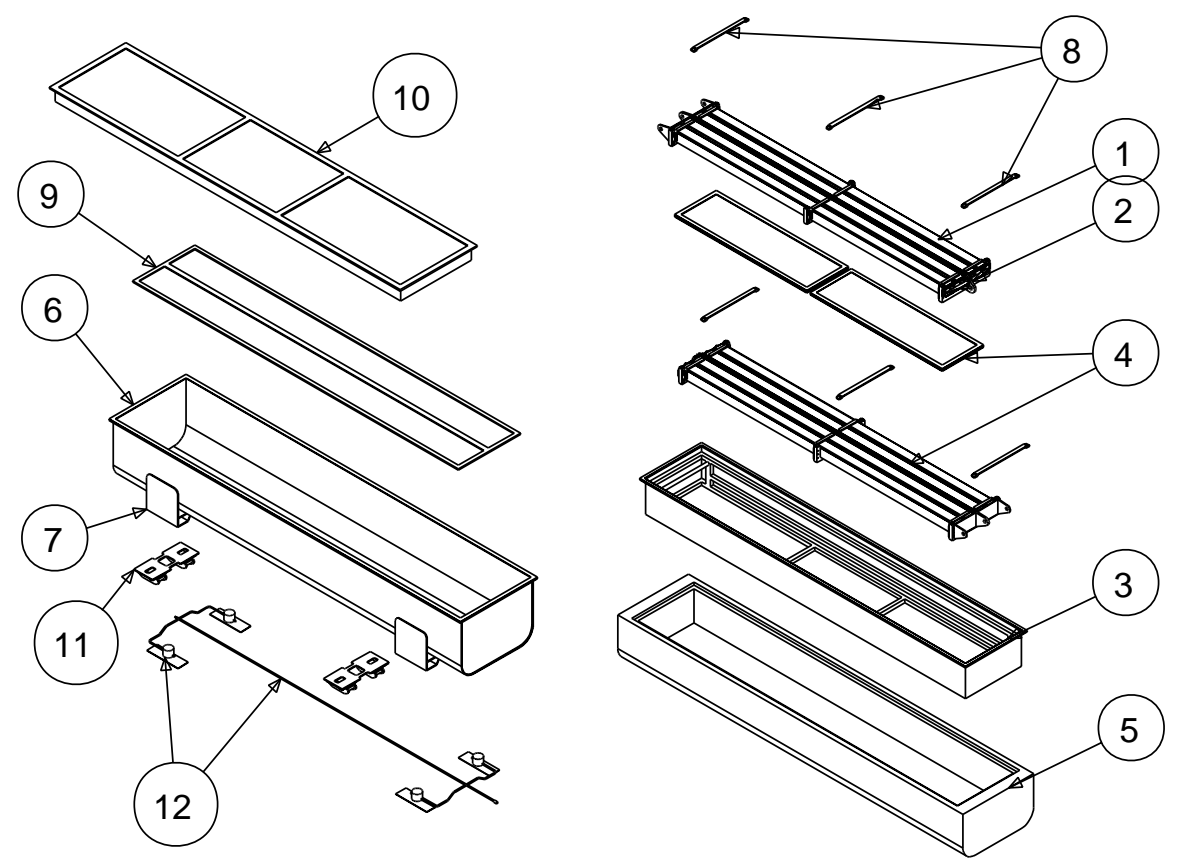

Fig. 3.17. Exploded view of double-strongback concept for BWR fuel (see Table 3.7 for key to numbers).

ORNL 98-1516 EFG

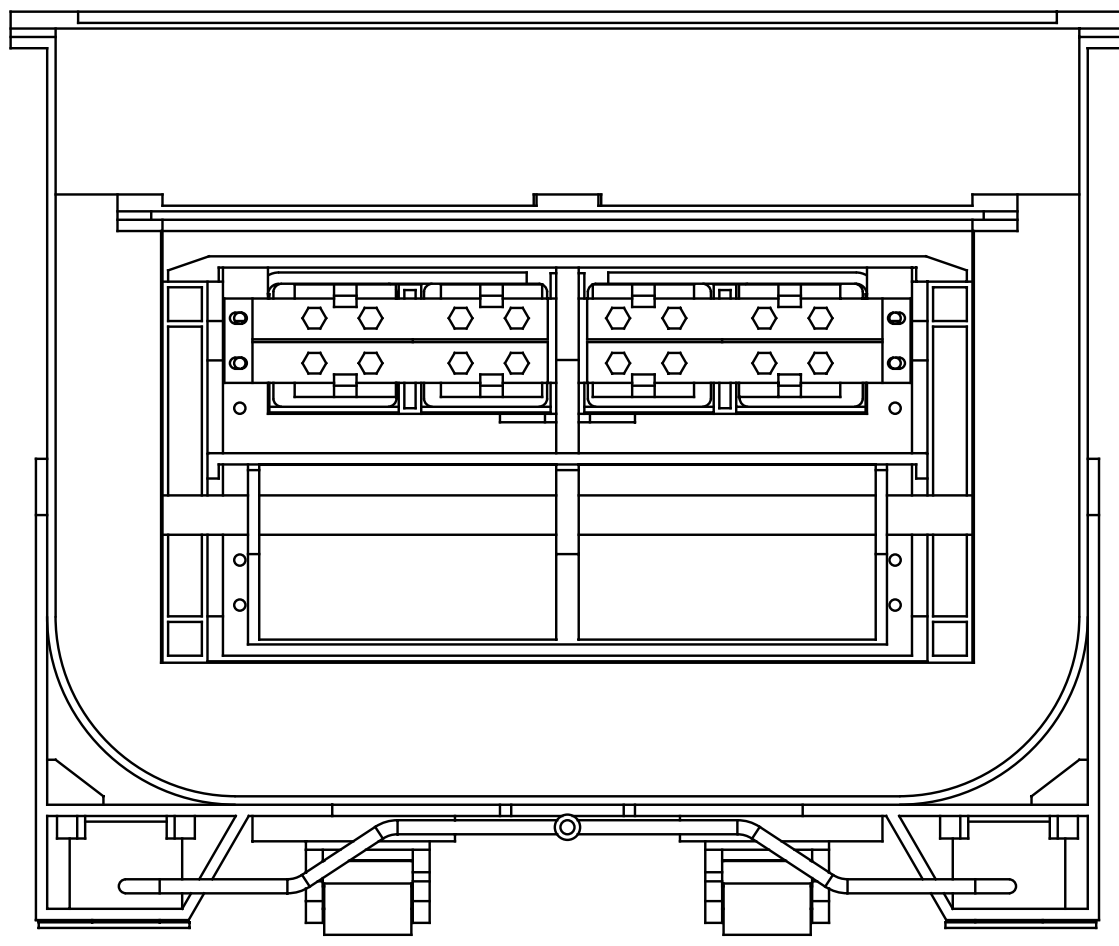

Fig. 3.18. Cross-sectional view of strongback concept for BWR fuel. 


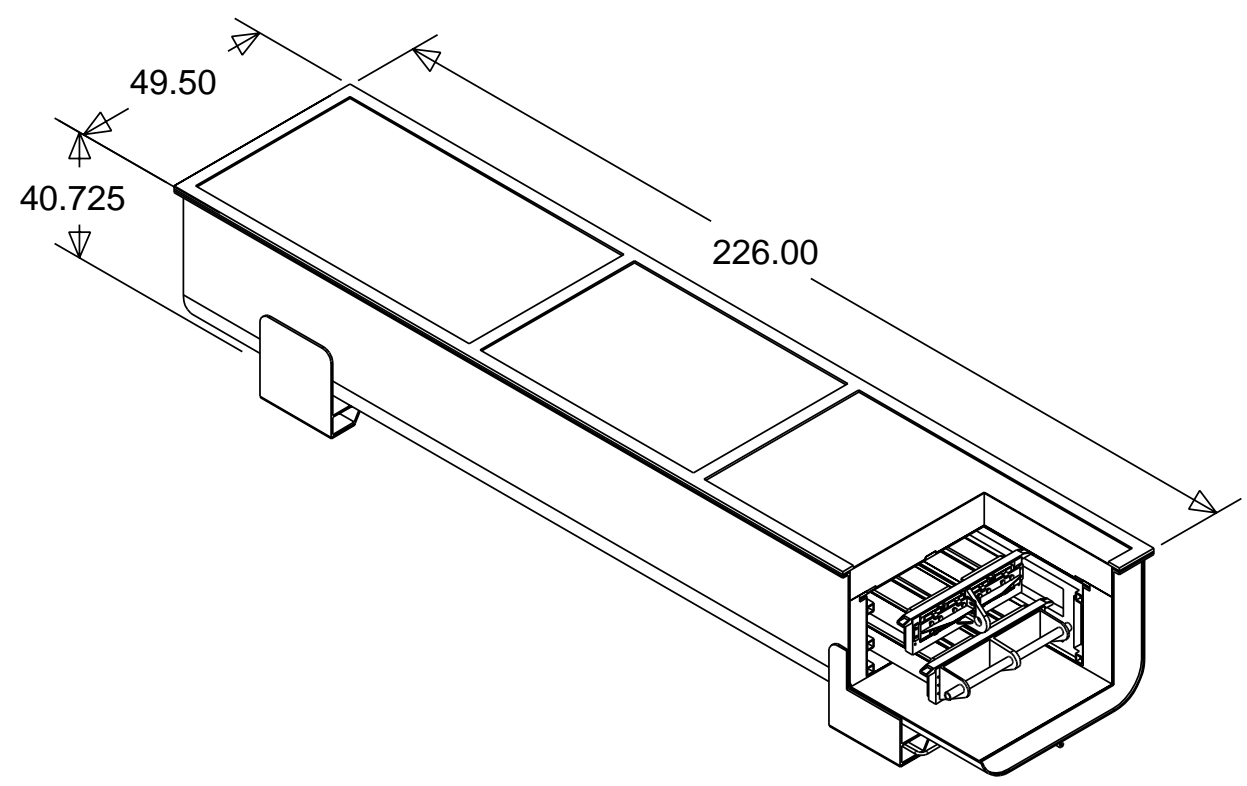

Fig. 3.19. Cutaway view of double-strongback concept for BWR fuel.

Table 3.7. Double-strongback design parameters for BWR fuel shipping package

\begin{tabular}{rlllr}
\hline Key ${ }^{a}$ & \multicolumn{1}{c}{ Part name } & \multicolumn{1}{c}{ Material } & \multicolumn{1}{c}{$\begin{array}{c}\text { Thickness } \\
\text { (in.) }\end{array}$} & $\begin{array}{c}\text { Weight } \\
\text { (lb) }\end{array}$ \\
\hline 1 & $\begin{array}{l}\text { BWR MOX fuel } \\
\text { assemblies (8) }\end{array}$ & SNM & N/A & 5,500 \\
2 & Strongback assemblies (2) & Austenitic stainless steel & N/A & 800 \\
3 & Containment volume & Austenitic stainless steel & 0.125 & 820 \\
4 & B 4 C poison plates & B 4 & N/A & 230 \\
5 & LD foam & 6-lb/ft ${ }^{3}$ density foam & N/A & 490 \\
6 & Outer shell & Austenitic stainless steel & 0.375 & 3,158 \\
7 & Support structure & Austenitic stainless steel & 0.5 & 500 \\
8 & Hold-down clamps & Austenitic stainless steel & 0.5 & 100 \\
9 & Removable inner lid & Austenitic stainless steel & 0.125 and 0.25 & 590 \\
10 & Removable outer lid & Austenitic stainless steel & 0.25 and 0.5 & 1,300 \\
& & and 6-lb/ft ${ }^{3}$ density foam & & \\
11 & Removable wheels & N/A & N/A & $\sim 50$ \\
12 & Hydraulic jack system & N/A & N/A & $\sim 50$ \\
\hline
\end{tabular}

${ }^{a}$ These numbers correspond to those on Fig. 3.17.

The containment volume is $\sim 20 \mathrm{in}$. in height, $36 \mathrm{in}$. in width, and $205 \mathrm{in.} \mathrm{in} \mathrm{length} \mathrm{and} \mathrm{is} \mathrm{made} \mathrm{of}$ 1/16-in.-thick austenitic stainless steel (see Figs. C.6-C.9 in Appendix C for details). The structural frame of the containment volume is made of 1/4-in.-thick steel square tubing. The frame is strong enough to provide support for the strongbacks during transportation and for the pivoting of the strongbacks during loading and unloading operations. The containment volume is completely sealed during transportation by the removable cover (Fig. 3.19).

Each fuel assembly would be loaded in its own separate compartment made of thin stainless steel sheet metal supported by a strongback frame made of steel tubes (Figs. 3.20 and 3.21). Each strongback has 

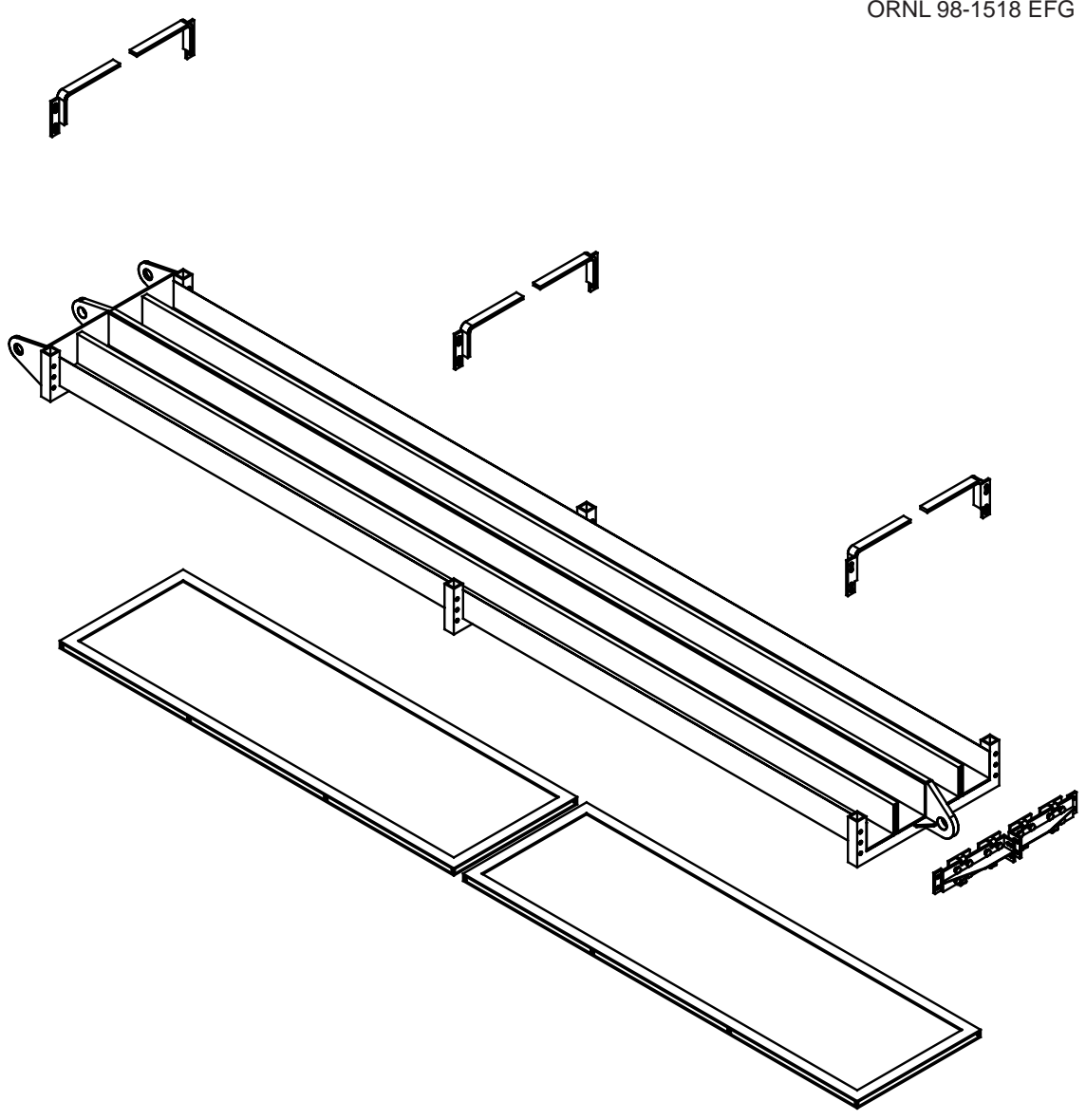

Fig. 3.20. Strongback frame concept for BWR fuel.

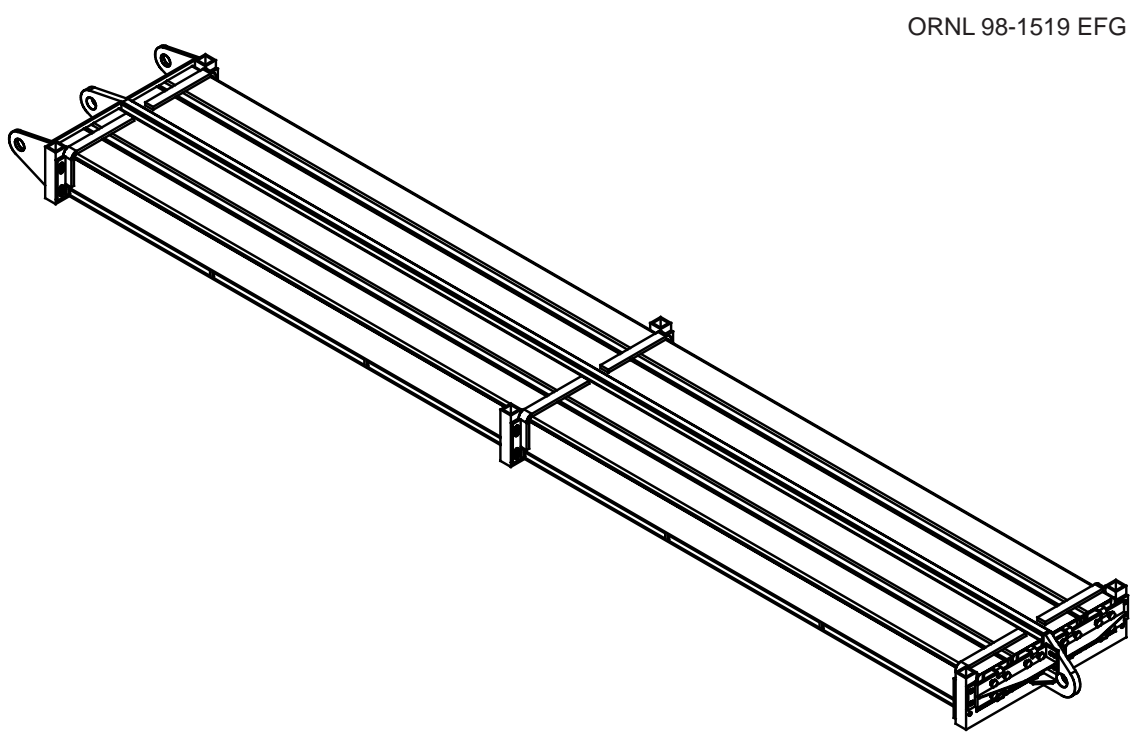

Fig. 3.21. Secured BWR fuel in strongback concept. 
four compartments for BWR fuel assemblies. Each compartment is separated by the strongback frame, which is made of 3/16-in.-thick steel tubing. The $\mathrm{B}_{4} \mathrm{C}$ poison plates, with a minimum 0.5-in. gap in between, are installed between the fuel assemblies to control criticality during HAC.

Once placed in the compartment, each MOX fuel assembly will be secured to prevent vibration during transportation using mechanical clamps and soft pads along the length of the fuel assembly as well as at the top (Figs. 3.20 and 3.21). 


\section{PRELIMINARY DESIGN ANALYSIS}

Because of time constraints, the MOX fuel shipping containers have not been analyzed for the accident conditions specified in 10 CFR $71 .{ }^{6}$ However, many similar types of fuel shipping containers have been analyzed previously by engineering personnel at ORNL using a number of state-of-the-art finite element analysis (FEA) codes. The FEA codes are described in more detail in the following section with an example of a previous analysis. These ORNL tools and personnel will be used for analyzing the MOX fuel containers in the future.

The complete array of accident condition impacts specified in 10 CFR 71 can be modeled using LS-Dyna ${ }^{7}$ for the MOX shipping containers. Impact configurations of a shipping container typically include the side, end, center of gravity over corner, and the slapdown impacts onto a rigid surface. LS-Dyna is a nonlinear dynamic finite element code often used for impact simulations because of its computational efficiency and its extensive material model library. The model library includes, but is not limited to, material models such as elastic, elastic-plastic, and power law models. A honeycomb model allows the modeling of foams that exhibit hardening as the material compresses, until all voids in the material collapse. A piecewise linear model allows the specification of the stress-strain curve up to a defined point of failure. As elements reach the failure point, they are deleted from the model.

The preprocessors such as Ingrid ${ }^{8}$ and/or True Grid $^{9}$ will be used in conjunction with LS-Dyna for modeling complex initial geometries and impact configurations. The different parts and materials of the mechanical system can be modeled as separate masses. Contact surfaces can be defined between adjacent parts and materials such that the components may bear and slide relative to each other, but not penetrate the adjacent surface. The result is a realistic simulation of the bearing and sliding of components within a complex system.

The results of the LS-Dyna analysis can be reviewed using the postprocessor software Taurus. Taurus allows the analyst to extract time history, deformation, stress, and strain data at various times during the impact.

As an example of the capability of LS-Dyna to evaluate complex package designs that have been built to transport fissile material, the program was used to analyze the dynamic impact of the horizontal shipping container (HSC) when dropped from $9 \mathrm{~m}$ onto a solid unyielding surface. A summary of the analysis is provided in Appendix F. This is the same type of analysis that will need to be performed on the end-loading and the double-strongback package concepts.

\subsection{STRUCTURAL ANALYSIS}

Structural analysis will be completed for both normal conditions of transportation (NCT) and HAC as specified in Sect. 3.2 of ORNL/TM-13526. ${ }^{4}$

\subsubsection{Normal Load Condition}

Normal load conditions will be completed for NCT as specified in Sect. 3.2.1 of ORNL/TM-13526. ${ }^{4}$

\subsubsection{Ambient thermal conditions}

Steady-state heat transfer analysis will be performed using FEA methods.

\subsubsection{External/internal pressure}

Static FEA analysis will be performed with external pressure on the outer shell surface varying from 25 to $140 \mathrm{kPa}$ absolute to evaluate the effects of different external pressures. 


\subsubsection{Vibration}

The FEA method and/or experimental methods will be used to evaluate the effects of vibration on the package.

\subsubsection{Water spray}

Experimental methods will not be applied to determine the effect of water spray. A reasoned argument that the water would not affect the performance of the stainless steel package will be used.

\subsubsection{Free drop}

Two free drops will be performed per Sect. 3.2.1.5 of ORNL/TM-13526. ${ }^{4}$ Large deformation nonlinear analysis will be performed using the LS-Dyna nonlinear dynamic FEA program.

\subsubsection{Compression}

Static analysis will be performed using an FEA program.

\subsubsection{Penetration}

Penetration analysis will be performed per Sect. 3.2.1.7 of ORNL/TM-13526. ${ }^{4}$ Large deformation nonlinear analysis will be performed using the LS-Dyna nonlinear dynamic FEA program.

\subsubsection{HAC}

HAC will be completed as specified in Sect. 3.2.3 of ORNL/TM-13526. ${ }^{4}$

\subsubsection{Initial test conditions}

Initial test conditions will be developed at a later time to meet the needs of FMDP.

\subsubsection{Free drop test condition}

The free drop test will be performed as specified in Sect. 3.2.3.2 of ORNL/TM-13526. ${ }^{4}$ Large deformation nonlinear analysis will be performed using the LS-Dyna nonlinear dynamic FEA program. Testing of a prototype may be required and is currently recommended.

\subsubsection{Puncture drop test condition}

As discussed in the beginning of this section, detailed large deformation nonlinear analyses to verify the design adequacy against the puncture drop test condition have not been performed on the design concepts discussed here because of the time constraint. Large deformation nonlinear analyses will be performed using a nonlinear dynamic FEA program to simulate the puncture drop test condition at a later date.

However, preliminary analyses were performed using FEA methods to determine whether the new shipping package design is reasonable. Preliminary analyses were performed for the end-loading design concept only. The analyses were performed according to the requirements of 10 CFR 71.73(c)(3), ${ }^{6}$ which requires dropping of the shipping package from a 40-in. height onto a 6-in.-diam pole with an edge round no more than 0.25 in.

Preliminary analyses were performed using the ABAQUS and Cosmos/M nonlinear codes. Results indicate that the outer shell made of 3/8-in.-thick stainless steel deforms $\sim 5 \mathrm{in}$., but the punch did not break through the outer wall. Figure 4.1 shows the result of the analysis using the ABAQUS nonlinear program. 


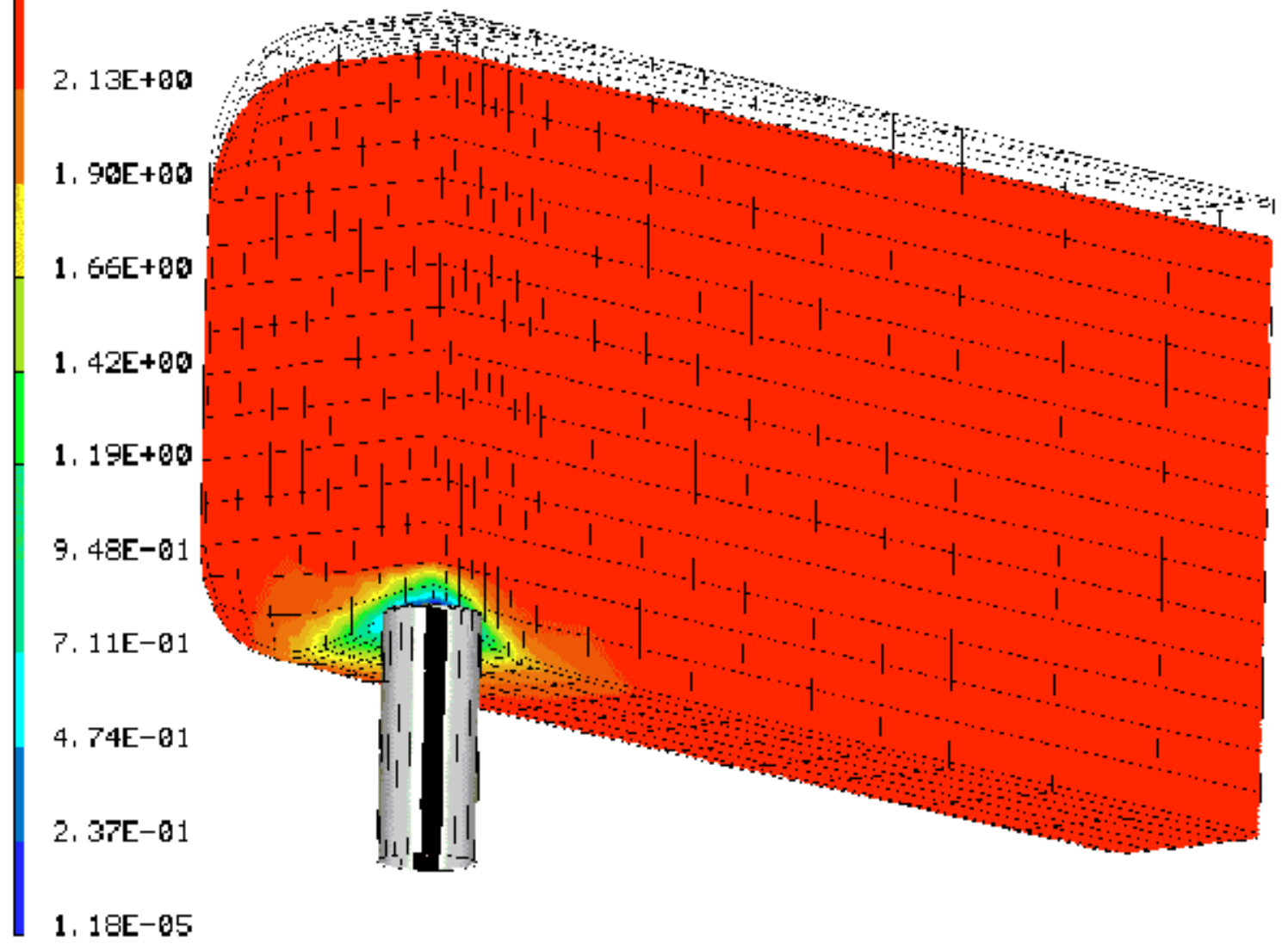

Fig. 4.1. ABAQUS nonlinear 3-ft drop analysis results.

Figure 4.2 shows the close-up view of the local region where contact occurs between the outer shell of the shipping package and the pole.

Testing of a prototype may be required and is currently recommended.

\subsubsection{Thermal test condition}

Transient heat transfer analyses will be performed using an FEA method such that the design satisfies the HAC requirements specified in Sect. 3.2.3.4 of ORNL/TM-13526. ${ }^{4}$

Testing of a prototype may be required.

\subsubsection{General immersion test condition}

Static FEA analysis will be performed with an external pressure equivalent to a hydrostatic pressure of $15 \mathrm{~m}$ on the outer shell surface as specified in Sect. 3.2.3.6 of ORNL/TM-13526. ${ }^{4}$

Testing of a prototype may be required and is currently recommended.

\subsubsection{Experimental Stress Analysis (Testing)}

Experimental stress analysis or testing will be performed to provide collateral support for analytical results on drop tests. The schedule is to be decided. 


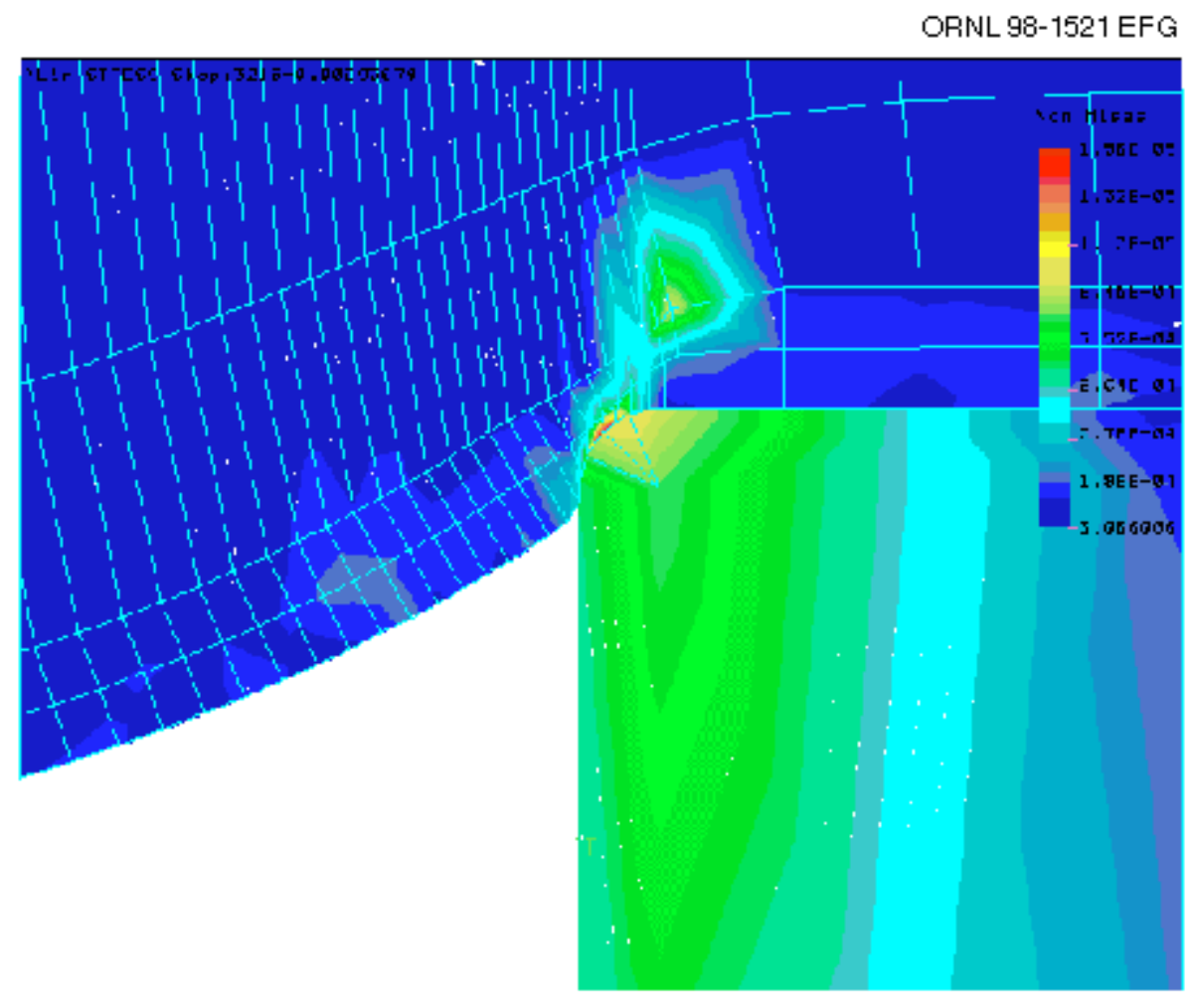

Fig. 4.2. Cosmos/M nonlinear 3-ft drop analysis results—close-up of contact region.

\subsection{NUCLEAR SAFETY ANALYSIS}

Computational analyses have been performed to assess the adequacy of the MOX fresh fuel package design for criticality safety and radiation shielding. Although the analyses considered potential loss of the LD foam because of an HAC (fire) and water in-leakage, no tests or analyses have been performed to evaluate actual changes in the package materials or configuration based on an HAC. Thus, the analyses here are representative of the more comprehensive safety analyses (as specified in Sect. 3.4 of ORNL/TM- $13526^{4}$ needed for the final design.

Two package concepts (end loading and double strongback) for transport of MOX PWR and BWR assemblies were investigated. As described in the previous section, the payloads are four assemblies for the PWR containers and eight assemblies for the BWR containers. The SCALE computer code system ${ }^{10}$ was used in the criticality safety and shielding analyses.

The results of the analysis for both the end-loading and double-strongback concepts with baskets based on a flux-trap design indicate that the subcriticality condition for the single-package evaluations required by 10 CFR 71.55 can be satisfied by all four packages.

\subsubsection{Criticality Safety Analysis}

A nuclear criticality safety analysis has been performed for the four MOX fresh fuel shipping package concepts, which include the end-loading and double-strongback containers for MOX PWR and BWR assemblies. The analysis assumed the most reactive credible configuration consistent with NCT and undamaged HAC and close-fitting, full reflection of the package by water. Results of the analysis demonstrate that the subcriticality condition for the single-package evaluations required by 10 CFR $71.55^{6}$ is satisfied by all four packages for undamaged conditions. A transport index (TI) has been derived for each 
package from an analysis of a $2 \times 2$ array of the corresponding package. Results of the analysis indicate that the radiation dose limits specified under 10 CFR $71.47^{6}$ are not exceeded for NCT and, under 10 CFR 71.51(a)(2), ${ }^{6}$ are not exceeded for undamaged HAC.

Effective neutron multiplication factors $\left(\mathrm{k}_{\mathrm{eff}}\right)$ of the packages were calculated with the CSAS25 calculational sequence of the SCALE code system ${ }^{10}$ using the 44-group ENDF/B-V cross-section library. ${ }^{11}$ A $30.48-\mathrm{cm}$ close-fitting water reflector was employed on all sides of the packages in the calculations to model full reflection. The MOX fuels for both the PWR and the BWR were assumed to consist of 6 wt $\% \mathrm{PuO}_{2}$ with 93.8 wt $\%{ }^{239} \mathrm{Pu}$, and the balance was made up of depleted $\mathrm{UO}_{2}$. Details of calculational models and material compositions are described separately in Appendixes D and E.

In the preliminary design for the end-loading concept, as described in Sect. 3.1, the fuel assemblies (PWR or BWR) were contained within inner steel cans that were separated by a basket material. The basket material was a $20 \% \mathrm{~B}_{4} \mathrm{C}$-loaded foam with a density of $30 \mathrm{lb} / \mathrm{ft}^{3}$ [borated high-density (HD) foam]. The material surrounding the fuel region was an unborated foam with a density of $6 \mathrm{lb} / \mathrm{ft}^{3}$ (LD foam). Outside the $\mathrm{LD}$ foam was a steel outer shell 0.953 -cm $\left(0.375\right.$-in.) thick. Values of $\mathrm{k}_{\mathrm{eff}}$ for the end-loading packages with the HD foam basket were calculated for PWR and BWR MOX assemblies and are presented in Table 4.1. As far as nuclear criticality is concerned, the PWR bundles require at least $6.35 \mathrm{~cm}$ (2.5 in.) of HD foam, and the BWR assemblies need about $1.22 \mathrm{~cm}(0.48$ in.). In comparing the two packages, the PWR package has a much higher reactivity because it contains significantly more fissile material.

Because of a concern about the integrity of the HD foam, other basket designs were examined. The concept of a neutron flux trap ${ }^{12}$ was adopted by adding neutron poison plates to the inner steel can surfaces within the basket while leaving the basket interior empty. The poison plates used in the packages are stainless-steel-clad $\mathrm{B}_{4} \mathrm{C}$. Under dry conditions, the poison plates have little or no effect because boron absorbs primarily thermal neutrons, and no moderator is present. Note that no poison is needed under these conditions because the reactivity is very low. However, when the container is flooded with water, an excellent moderator, a flux trap, is created in which fast neutrons are thermalized in the water, and the thermal neutrons are absorbed by the boron as they attempt to diffuse toward neighboring fuel assemblies. The thickness of the steel clad of the poison plates was fixed at $0.03 \mathrm{~cm}$, and $\mathrm{B}_{4} \mathrm{C}$ thicknesses of 0.1 and $0.2 \mathrm{~cm}$ were studied, giving a total poison plate thicknesses of $0.16 \mathrm{~cm}$ and $0.26 \mathrm{~cm}$, respectively. Using this basket design, the spacing between the inner steel cans with no poison plates is $2.54 \mathrm{~cm}$ for the PWR (reduced from $6.35 \mathrm{~cm}$ for the HD foam case) and $1.22 \mathrm{~cm}$ for the BWR. For the PWR package, the poison plates also covered the inner steel can surfaces adjacent to the LD foam. This was necessary to minimize the reactivity increase because of neutron reflection from the LD foam during water flooding.

Table 4.2 clearly shows that for the end-loading concept, the PWR package calculates subcritical for the undamaged flooded case with $0.16-\mathrm{cm}$ poison plates (interior condition 4), and the BWR package calculates subcritical even with no poison (interior condition 3). An additional advantage of this design is that the package weight will be less than the HD foam design because of the reduction of the basket size. Table 4.2 also includes calculations for the PWR package with different amounts of water in the LD foam. These calculations examine the reactivity change because of water flooding of the package and the disappearance of the LD foam under HAC. The results from interior conditions 5-10 (wet basket with 0.26$\mathrm{cm}$ poison plates) illustrate the competing phenomena of neutron moderation, absorption, and reflection.

Table 4.1. The $k_{\text {eff }}$ values for MOX fuel end-loading concept with HD foam basket

\begin{tabular}{cccc}
\hline $\begin{array}{c}\text { Fuel assembly } \\
\text { type }\end{array}$ & $\begin{array}{c}\text { HD foam thickness } \\
(\mathrm{cm})\end{array}$ & $\mathrm{k}_{\mathrm{eff}}$ & $1 \sigma^{a}$ \\
\hline PWR & 5.08 & 0.94213 & 0.00216 \\
PWR & 6.35 & 0.92246 & 0.00213 \\
BWR & 1.22 & 0.74866 & 0.00193 \\
\hline
\end{tabular}

${ }^{a}$ One standard deviation. 
Interior conditions 6 and 7 show that with full-density water, the presence or absence of LD foam has little effect on moderation. Comparison of the results for interior conditions 6-10 to that for interior condition 5 (essentially no change in $\mathrm{k}_{\mathrm{eff}}$ ) shows that the reflected neutrons are so thermalized that they are all absorbed by the poison plates between the assemblies and the LD foam. On the other hand, for the BWR package, the presence of water in the LD foam increases the $\mathrm{k}_{\mathrm{eff}}$ from 0.64 to 0.68 , as is evident by comparing the result of interior condition 5 to those of interior conditions 6 and 7. This increase is caused by the extra neutron reflection from the LD foam region to the fuel assemblies because poison plates do not exist between the two regions in the BWR package.

The only basket design examined for the double-strongback concept also uses the neutron flux trap concept previously described for the end-loading concept. As described in Sect. 3.2, the double-strongback PWR package holds four assemblies in a $2 \times 2$ array. The horizontal spacing without poison plates between assemblies is $7.62 \mathrm{~cm}$ ( 3 in.), and the vertical spacing is $5.08 \mathrm{~cm}$ ( $2 \mathrm{in}$.). The double-strongback BWR package holds eight assemblies in a $4 \times 2$ array. The horizontal spacing without poison plates is $3.81 \mathrm{~cm}$ ( 1.5 in.) between the middle two assemblies and $2.54 \mathrm{~cm}$ (1 in.) between the outer assemblies. The vertical spacing is about $7.62 \mathrm{~cm}$ (3 in.). The results of the analysis for this design are given in Table 4.3. Again, the designs calculate subcritical for the flooded PWR package, even if the thinner $0.16-\mathrm{cm}$ poison plates are used (interior condition 4). Note that the flooded BWR package no longer calculates subcritical without poison plates, perhaps because there is more interaction between the rows of neighboring assemblies than in the end-loading concept. For this concept, the effect of reflection from the LD foam with and without water is even smaller than for the end-fitting concept because of the extra space between the fuel region and the LD foam.

Table 4.4 presents the results of the analyses for $2 \times 2$ arrays of packages for each concept. For the end-loading concept, the presence of full-density water in the LD foam neutronically isolates the packages

Table 4.2. The $k_{\text {eff }}$ values for MOX fuel end-loading concept with steel-clad $\mathrm{B}_{4} \mathrm{C}$ poison plates

\begin{tabular}{|c|c|c|c|c|c|}
\hline & \multirow[b]{2}{*}{ Interior condition } & \multicolumn{2}{|c|}{$\mathrm{PWR}^{a}$} & \multicolumn{2}{|c|}{$\mathrm{BWR}^{b}$} \\
\hline & & $\mathrm{k}_{\mathrm{eff}}$ & $1 \sigma^{c}$ & $\mathrm{k}_{\mathrm{eff}}$ & $1 \sigma$ \\
\hline 1 & $\begin{array}{l}\text { Dry basket and LD foam, } \\
\text { no poison }\end{array}$ & 0.36125 & 0.00096 & \multicolumn{2}{|c|}{ N/A } \\
\hline 2 & $\begin{array}{l}\text { Dry basket and LD foam, } \\
0.26-\mathrm{cm} \text { plates }\end{array}$ & \multicolumn{2}{|c|}{ N/A } & 0.28179 & 0.00080 \\
\hline 3 & $\begin{array}{l}\text { Wet basket, dry LD foam, } \\
\text { no poison }\end{array}$ & 1.06522 & 0.00194 & 0.88075 & 0.00177 \\
\hline 4 & $\begin{array}{l}\text { Wet basket, dry LD foam, } \\
\text { 0.16-cm plates }\end{array}$ & 0.90717 & 0.00211 & 0.65681 & 0.00182 \\
\hline 5 & $\begin{array}{l}\text { Wet basket, dry LD foam, } \\
0.26 \text {-cm plates }\end{array}$ & 0.89672 & 0.00179 & 0.64016 & 0.00174 \\
\hline 6 & $\begin{array}{l}\text { Wet basket, no LD foam, } \\
1.0-\mathrm{g} / \mathrm{cm}^{3} \mathrm{H}_{2} \mathrm{O}, 0.26-\mathrm{cm} \text { plates }\end{array}$ & 0.89345 & 0.00235 & 0.68516 & 0.00183 \\
\hline 7 & $\begin{array}{l}\text { Wet basket, } \mathrm{LD} \text { foam with } \\
1.0-\mathrm{g} / \mathrm{cm}^{3} \mathrm{H}_{2} \mathrm{O}, 0.26-\mathrm{cm} \text { plates }\end{array}$ & 0.89242 & 0.00199 & 0.68481 & 0.00200 \\
\hline 8 & $\begin{array}{l}\text { Wet basket, } \mathrm{LD} \text { foam with } \\
0.75-\mathrm{g} / \mathrm{cm}^{3} \mathrm{H}_{2} \mathrm{O}, 0.26-\mathrm{cm} \text { plates }\end{array}$ & 0.89683 & 0.00210 & \multicolumn{2}{|c|}{ N/A } \\
\hline 9 & $\begin{array}{l}\text { Wet basket, LD foam with } \\
0.5-\mathrm{g} / \mathrm{cm}^{3} \mathrm{H}_{2} \mathrm{O}, 0.26-\mathrm{cm} \text { plates }\end{array}$ & 0.89581 & 0.00208 & \multicolumn{2}{|c|}{ N/A } \\
\hline 10 & $\begin{array}{l}\text { Wet basket, } \mathrm{LD} \text { foam with } \\
0.25-\mathrm{g} / \mathrm{cm}^{3} \mathrm{H}_{2} \mathrm{O}, 0.26-\mathrm{cm} \text { plates }\end{array}$ & 0.89644 & 0.00191 & \multicolumn{2}{|c|}{ N/A } \\
\hline
\end{tabular}

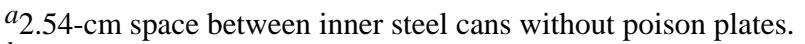

$b_{1}$.22-cm space between inner steel cans without poison plates.

${ }^{c}$ One standard deviation. 
Table 4.3. The $k_{\text {eff }}$ values for MOX fuel double-strongback concept with steel-clad $\mathrm{B}_{4} \mathrm{C}$ poison plates

\begin{tabular}{|c|c|c|c|c|c|}
\hline & \multirow[b]{2}{*}{ Interior condition } & \multicolumn{2}{|c|}{ PWR } & \multicolumn{2}{|c|}{ BWR } \\
\hline & & $\mathrm{k}_{\mathrm{eff}}$ & $1 \sigma^{a}$ & $\mathrm{k}_{\mathrm{eff}}$ & $1 \sigma$ \\
\hline 1 & $\begin{array}{l}\text { Dry basket and LD foam, } \\
\text { no poison }\end{array}$ & 0.37384 & 0.00111 & N/A & \\
\hline 2 & $\begin{array}{l}\text { Dry basket and LD foam, } \\
0.26-\mathrm{cm} \text { plates }\end{array}$ & N/A & & 0.24296 & 0.00088 \\
\hline 3 & $\begin{array}{l}\text { Wet basket, dry LD foam, } \\
\text { no poison }\end{array}$ & 1.11052 & 0.00193 & 1.01992 & 0.00179 \\
\hline 4 & $\begin{array}{l}\text { Wet basket, dry LD foam, } \\
\text { 0.16-cm plates }\end{array}$ & 0.89030 & 0.00182 & 0.64188 & 0.00177 \\
\hline 5 & $\begin{array}{l}\text { Wet basket, dry LD foam, } \\
0.26-\mathrm{cm} \text { plates }\end{array}$ & 0.88495 & 0.00208 & 0.63136 & 0.00174 \\
\hline 6 & $\begin{array}{l}\text { Wet basket, no LD foam, } \\
1.0-\mathrm{g} / \mathrm{cm}^{3} \mathrm{H}_{2} \mathrm{O}, 0.26-\mathrm{cm} \text { plates }\end{array}$ & 0.88922 & 0.00188 & 0.63098 & 0.00175 \\
\hline 7 & $\begin{array}{l}\text { Wet basket, } \mathrm{LD} \text { foam with } \\
1.0-\mathrm{g} / \mathrm{cm}^{3} \mathrm{H}_{2} \mathrm{O}, 0.26-\mathrm{cm} \text { plates }\end{array}$ & 0.89460 & 0.00190 & 0.62922 & 0.00183 \\
\hline
\end{tabular}

${ }^{a}$ One standard deviation.

Table 4.4. The $k_{\text {eff }}$ values for MOX fuel $2 \times 2$ arrays of packages with steel-clad $\mathrm{B}_{4} \mathrm{C}$ poison plates

\begin{tabular}{|c|c|c|c|c|}
\hline \multirow[b]{2}{*}{ Package description } & \multicolumn{2}{|c|}{ PWR } & \multicolumn{2}{|c|}{ BWR } \\
\hline & $\mathrm{k}_{\mathrm{eff}}$ & $1 \sigma^{a}$ & $\mathrm{k}_{\mathrm{eff}}$ & $1 \sigma$ \\
\hline \multicolumn{5}{|c|}{ End-loading concept } \\
\hline $\begin{array}{l}\text { Wet basket, LD foam with } 1.0-\mathrm{g} / \mathrm{cm}^{3} \\
\mathrm{H}_{2} \mathrm{O}, 0.26-\mathrm{cm} \text { plates }\end{array}$ & 0.89710 & 0.00068 & 0.68659 & 0.00079 \\
\hline $\begin{array}{l}\text { Wet basket, } \mathrm{LD} \text { foam with no } \mathrm{H}_{2} \mathrm{O} \text {, } \\
0.26 \text {-cm plates }\end{array}$ & 0.91532 & 0.00093 & 0.70062 & 0.00074 \\
\hline \multicolumn{5}{|c|}{ Double-strongback concept } \\
\hline $\begin{array}{l}\text { Wet basket, } \mathrm{LD} \text { foam with } 1.0-\mathrm{g} / \mathrm{cm}^{3} \\
\mathrm{H}_{2} \mathrm{O}, 0.26-\mathrm{cm} \text { plates }\end{array}$ & 0.89194 & 0.00080 & 0.63167 & 0.00067 \\
\hline $\begin{array}{l}\text { Wet basket, } \mathrm{LD} \text { foam with no } \mathrm{H}_{2} \mathrm{O} \text {, } \\
0.26-\mathrm{cm} \text { plates }\end{array}$ & 0.89315 & 0.00081 & 0.63281 & 0.00083 \\
\hline
\end{tabular}

${ }^{a}$ One standard deviation.

from each other. Examination of Tables 4.2-4.4 shows that the array $\mathrm{k}_{\mathrm{eff}}$ is nearly identical to the singlepackage $k_{\text {eff }}$ for the cases of LD foam with full-density water. Because the $2 \times 2$ arrays all calculate subcritical, the TI for criticality control is calculated to be 63 , indicating that the packages may only be shipped by exclusive use vehicles.

To investigate the reactivity of the $2 \times 2$ package arrays under extreme HAC, an analysis was performed for the end-loading PWR packages. This case is representative of an HAC that results in the loss of $\mathrm{LD}$ foam, flooding of the system, and shifting of the assemblies toward the middle of the array. The endloading PWR package was selected because it is the most reactive of the four containers. A computergenerated model of this problem is shown in Figs. D.2-D.6 in Appendix D. The $\mathrm{k}_{\text {eff }}$ was calculated to be $0.99717 \pm 0.00093$. The result of this case emphasizes the importance of maintaining the fuel assemblies' 
positions inside the package during and after HAC. To prevent the fuel assemblies from shifting under HAC, additional structural members besides the LD foam may be needed between the fuel assemblies and the outer shell of the package.

The results of the analysis for both the end-loading and double-strongback concepts with baskets based on a flux-trap design indicate that the subcriticality condition for the single-package evaluations required by 10 CFR 71.55 can be satisfied by all four packages. The basis for this statement is as follows. According to NUREG/CR-5661, 13 the upper subcritical limit (USL) can be expressed as

$$
\mathrm{USL}=0.95-\Delta \mathrm{k}_{\mathrm{u}}+\bar{\beta}
$$

where $\Delta \mathrm{k}_{\mathrm{u}}$ is the calculational uncertainty, and $\bar{\beta}$ is the calculational bias $\left(\mathrm{k}_{\mathrm{c}}-1\right)$ established by the calculation of $\mathrm{k}_{\mathrm{c}}$ for an applicable set of critical benchmark experiments. Although no benchmark calculations were performed during the present analysis, information could be used from NUREG/CR-6361 14 and from ORNL/MD/LTR-80 15 to compute $k_{c}$ for these types of packages. The greatest $\mathrm{k}_{\mathrm{eff}}$ calculated for the conceptual design (0.907 for the end-loading package with PWR fuel under undamaged HAC) allows for the uncertainty and bias term $-\Delta \mathrm{k}_{\mathrm{u}}+\bar{\beta}$ to be as great as 0.04 . During design of the actual packages, if calculations using available data from benchmark experiments indicate that the uncertainty and bias term is greater than 0.04 , there is adequate space in the end-loading PWR package to use thicker poison plates and more water for increased moderation.

It is recommended that the 0.26 - $\mathrm{cm}$-thick $\mathrm{B}_{4} \mathrm{C}$ poison plates be used for the conceptual design because NUREG/CR-5661 ${ }^{13}$ recommends that for packages with fixed neutron absorbers, no more than $75 \%$ of the minimum neutron absorber content should be assumed effective. This is based on concerns that potential "streaming" of neutrons can occur because of nonuniformities in the boron distribution. Details can be found in Sect. 3.1.3 of NUREG/CR-5661. ${ }^{13}$ Note that even if only one-half of the neutron absorber content is effective, which corresponds to the calculations for the $0.16-\mathrm{cm}$ poison plates, the package is still subcritical. The analysis for the design of the actual packages must be performed as specified in Sect. 3.4 of ORNL/TM-13526, ${ }^{4}$ that is, by using the guidance provided in NUREG/CR-5661, 13 establishing the USL with the methodology of NUREG/CR-6361, ${ }^{14}$ and using a 5\% margin of subcriticality. The present analysis for the conceptual design shows that the design of safe packages is an achievable goal and provides a sound basis for the design of the actual packages.

\subsubsection{Shielding Analysis}

A nuclear shielding analysis has been performed for the four MOX fresh-fuel shipping packages, which include the end-loading and double-strongback containers carrying MOX PWR and BWR assemblies. Results of the analysis indicate that the radiation dose limits specified under 10 CFR $71.47^{6}$ are not exceeded for NCT and, under 10 CFR 71.51(a)(2), ${ }^{6}$ are not exceeded for undamaged HAC.

Dose rates at the surface of the packages and at distances of 1 and $2 \mathrm{~m}$ from the surface were computed with the SAS4 calculational sequence of the SCALE code system, ${ }^{7}$ using the coupled 27 -group neutron/18-group gamma-ray cross section library. The dose-rate response functions used for the calculations were obtained from the ANSI/ANS-6.1.1-1977 standard. ${ }^{16}$ All dose rates were computed using point-detector next-event estimators. The location of the surface estimators is actually about $1 \mathrm{~cm}$ from the surface to avoid the $\left(1 / \mathrm{r}^{2}\right)$ singularity possible with a point-detector next-event estimator. The SAS4 module performs a Monte Carlo shielding analysis using an automated biasing procedure and is used extensively by the U.S. Nuclear Regulatory Commission (NRC) and the nuclear industry to evaluate radiation doses of spent-fuel shipping and storage containers.

As for the criticality analysis, the MOX fuel was assumed to consist of 6 wt $\% \mathrm{PuO}_{2}$, enriched to 93.8 wt $\%{ }^{239} \mathrm{Pu}$, and the balance was made up of depleted uranium. For the shielding analysis, $6000 \mathrm{ppm}$ ${ }^{241} \mathrm{Am}$ and $25 \mathrm{ppb}{ }^{236} \mathrm{Pu}$ impurities were assumed to be present in the fuel. The alpha particles emitted by ${ }^{241} \mathrm{Am}$ are an important contributor to $(\alpha, \mathrm{n})$ sources from the oxide fuel. The ${ }^{208} \mathrm{Tl}$ decay daughter of ${ }^{236} \mathrm{Pu}$ has a $2.6-\mathrm{MeV}$ gamma ray that is a significant gamma-ray source. The sources from the fuel 
(including the impurities) were computed with the ORIGEN-S module of the SCALE system and specified as fixed sources for the SAS4 calculations. Radiation sources from induced fission reactions are accounted for explicitly (fission neutrons) or implicitly (prompt fission gamma rays) in a fixed-source SAS4 calculation. The only source not modeled is the delayed gamma rays from induced fission, but this omission is not significant (as discussed in this section). Details of the calculational models and material compositions are described in Appendixes D and E, respectively.

The dose rate limits of 10 CFR $71.47^{6}$ specify that for NCT, the surface dose rate may not exceed 2 $\mathrm{mSv} / \mathrm{h}(200 \mathrm{mrem} / \mathrm{h})$, and that the dose rate at any point $2 \mathrm{~m}$ from the outer lateral surfaces of a package may not exceed $0.1 \mathrm{mSv} / \mathrm{h}(10 \mathrm{mrem} / \mathrm{h})$. The dose rate limits of $10 \mathrm{CFR} 71.51(\mathrm{a})(2)^{6}$ specify that for HAC, the dose rate at a point $1 \mathrm{~m}$ from the outer surfaces of a package may not exceed $10 \mathrm{mSv} / \mathrm{h}(1 \mathrm{rem} / \mathrm{h})$.

Dose rates are presented here only for the final basket designs using the neutron flux trap concept. The dose rates for the HD foam designs and for a borated steel liner model in the end-loading concept are given in Appendix D. Those results show clearly that including the $25 \mathrm{ppb}{ }^{236} \mathrm{Pu}$ impurity increases the primary gamma-ray dose rate by a factor of 2 to 3 . For the end-loading concept, the spacing between the inner steel cans in the basket was $5.08 \mathrm{~cm}(2.0$ in.) for the PWR package and $1.27 \mathrm{~cm}(0.5 \mathrm{in}$.) for the BWR package. Also, for the PWR package the poison plates between the fuel region and the LD foam were not modeled in the shielding calculations. The dose rates for the end-loading concept packages are shown in Tables 4.5 and 4.6 for dry and wet conditions, respectively. The dose rates for the double-strongback concept packages are given in Tables 4.7 and 4.8. All tables give individual dose rate components (neutron, primary gamma, and secondary gamma) as well as total dose rate. In general, the uncertainty in an individual dose rate component, as represented by the fractional standard deviation (fsd), is quite good (about 5\%) for dry conditions and acceptable (about 10\%) for wet conditions. However, uncertainties for surface dose rates are higher than those for the 1- and 2-m locations because of occasionally large $\left(1 / \mathrm{r}^{2}\right)$ contributions to the point-detector next-event estimators from nearby locations within the package. Uncertainties presented for secondary gamma-ray dose rates under wet conditions are often larger than those presented for dry conditions because time did not allow running more histories for the wet cases.

In summary, total dose rates at the package surfaces are always at least a factor of 7 less than the regulatory limit of $2 \mathrm{mSv} / \mathrm{h}(200 \mathrm{mrem} / \mathrm{h})$. At the $2-\mathrm{m}$ location, the total dose rates are at least a factor of 3 less than the limit of $0.1 \mathrm{mSv} / \mathrm{h}(10 \mathrm{mrem} / \mathrm{h})$. Generally, the neutron dose rate is larger than that for gamma rays, particularly for dry conditions.

Clearly, all the dose rates are well within the limits required by 10 CFR 71.47 and 10 CFR 71.51(a)(2). ${ }^{6}$ The secondary gamma dose rates include contributions from prompt fission gamma rays (because of induced fission), as well as that from neutron capture. Because the delayed fission gammaray energy (about $7 \mathrm{MeV}$ per fission) and spectrum are comparable to those of the prompt fission gamma rays, it is clear that inclusion of the delayed gamma rays from induced fissions will have a very small impact on the total dose rates. In fact, it is obvious that the dose rates will remain well under the necessary limits. The present analysis shows that meeting regulatory limits on dose rates is readily achievable, and, as for the criticality analysis, provides a sound basis for further design efforts. 
Table 4.5. Dose rates at side of container for MOX fuel end-loading concept, dry, with $0.26-\mathrm{cm}$ steel-clad $\mathrm{B}_{4} \mathrm{C}$ poison plates

\begin{tabular}{|c|c|c|c|c|c|c|c|}
\hline \multirow[t]{2}{*}{ Location } & \multicolumn{2}{|c|}{ Neutron dose rate } & \multicolumn{2}{|c|}{$\begin{array}{c}\text { Primary gamma } \\
\text { dose rate }\end{array}$} & \multicolumn{2}{|c|}{$\begin{array}{c}\text { Secondary gamma } \\
\text { dose rate }\end{array}$} & \multirow[t]{2}{*}{ Total } \\
\hline & $\mathrm{mrem} / \mathrm{h}$ & $\mathrm{fsd}^{a}$ & $\mathrm{mrem} / \mathrm{h}$ & fsd & $\mathrm{mrem} / \mathrm{h}$ & fsd & \\
\hline \multicolumn{8}{|c|}{$P W R(5.08-c m$ spacing) } \\
\hline Surface & 13.719 & 0.051 & 8.747 & 0.156 & 0.075 & 0.051 & 22.541 \\
\hline $1 \mathrm{~m}$ & 3.389 & 0.018 & 1.963 & 0.049 & 0.018 & 0.025 & 5.370 \\
\hline $2 \mathrm{~m}$ & 1.500 & 0.016 & 0.846 & 0.027 & 0.008 & 0.025 & 2.354 \\
\hline \multicolumn{8}{|c|}{$B W R$ (1.27-cm spacing) } \\
\hline Surface & 11.518 & 0.058 & 5.845 & 0.047 & 0.072 & 0.195 & 17.435 \\
\hline $1 \mathrm{~m}$ & 2.747 & 0.012 & 1.705 & 0.027 & 0.016 & 0.046 & 4.468 \\
\hline $2 \mathrm{~m}$ & 1.233 & 0.010 & 0.764 & 0.023 & 0.007 & 0.032 & 2.004 \\
\hline
\end{tabular}

${ }^{a}$ Fractional standard deviation: one standard deviation divided by the calculated mean.

Table 4.6. Dose rates at side of container for MOX fuel end-loading concept, wet, with $0.26-\mathrm{cm}$ steel-clad $\mathrm{B}_{4} \mathrm{C}$ poison plates

\begin{tabular}{|c|c|c|c|c|c|c|c|}
\hline \multirow[t]{2}{*}{ Location } & \multicolumn{2}{|c|}{ Neutron dose rate } & \multicolumn{2}{|c|}{$\begin{array}{c}\text { Primary gamma } \\
\text { dose rate }\end{array}$} & \multicolumn{2}{|c|}{$\begin{array}{c}\text { Secondary gamma } \\
\text { dose rate }\end{array}$} & \multirow[t]{2}{*}{ Total } \\
\hline & $\mathrm{mrem} / \mathrm{h}$ & $\mathrm{fsd}^{a}$ & $\mathrm{mrem} / \mathrm{h}$ & fsd & $\mathrm{mrem} / \mathrm{h}$ & fsd & \\
\hline \multicolumn{8}{|c|}{ PWR (5.08-cm spacing) } \\
\hline Surface & 22.337 & 0.317 & 6.002 & 0.135 & 0.381 & 0.115 & 28.720 \\
\hline $1 \mathrm{~m}$ & 4.356 & 0.127 & 1.503 & 0.029 & 0.245 & 0.245 & 6.104 \\
\hline $2 \mathrm{~m}$ & 1.962 & 0.107 & 0.694 & 0.027 & 0.090 & 0.304 & 2.746 \\
\hline \multicolumn{8}{|c|}{$B W R(1.27-c m$ spacing) } \\
\hline Surface & 8.732 & 0.125 & 5.901 & 0.110 & 0.107 & 0.122 & 14.740 \\
\hline $1 \mathrm{~m}$ & 1.904 & 0.024 & 1.505 & 0.030 & 0.029 & 0.082 & 3.438 \\
\hline $2 \mathrm{~m}$ & 0.860 & 0.020 & 0.682 & 0.026 & 0.014 & 0.091 & 1.556 \\
\hline
\end{tabular}

${ }^{a}$ Fractional standard deviation: one standard deviation divided by the calculated mean. 
Table 4.7. Dose rates for MOX fuel double-strongback concept, dry, with 0.26-cm steel-clad $\mathrm{B}_{4} \mathrm{C}$ poison plates

\begin{tabular}{|c|c|c|c|c|c|c|c|}
\hline \multirow[t]{2}{*}{ Location } & \multicolumn{2}{|c|}{ Neutron dose rate } & \multicolumn{2}{|c|}{$\begin{array}{c}\text { Primary gamma } \\
\text { dose rate }\end{array}$} & \multicolumn{2}{|c|}{$\begin{array}{c}\text { Secondary gamma } \\
\text { dose rate }\end{array}$} & \multirow[t]{2}{*}{ Total } \\
\hline & $\mathrm{mrem} / \mathrm{h}$ & $\mathrm{fsd}^{a}$ & $\mathrm{mrem} / \mathrm{h}$ & fsd & $\mathrm{mrem} / \mathrm{h}$ & fsd & \\
\hline \multicolumn{8}{|c|}{$P W R^{b}$} \\
\hline Surface & 14.575 & 0.078 & 9.717 & 0.161 & 0.094 & 0.200 & 24.386 \\
\hline $1 \mathrm{~m}$ & 3.589 & 0.011 & 2.094 & 0.022 & 0.015 & 0.028 & 5.698 \\
\hline $2 \mathrm{~m}$ & 1.594 & 0.009 & 0.970 & 0.034 & 0.006 & 0.026 & 2.570 \\
\hline \multicolumn{8}{|c|}{$B W R^{c}$} \\
\hline Surface & 16.547 & 0.089 & 9.069 & 0.110 & 0.068 & 0.278 & 25.684 \\
\hline $1 \mathrm{~m}$ & 3.799 & 0.010 & 2.781 & 0.022 & 0.016 & 0.033 & 6.596 \\
\hline $2 \mathrm{~m}$ & 1.660 & 0.008 & 1.218 & 0.019 & 0.007 & 0.026 & 2.885 \\
\hline
\end{tabular}

${ }^{a}$ Fractional standard deviation: one standard deviation divided by the calculated mean.

${ }^{b}$ Dose rates for PWR are at side of package.

${ }^{c}$ Dose rates for BWR are at bottom of package.

Table 4.8. Dose rates for MOX fuel double-strongback concept, wet, with $0.26-\mathrm{cm}$ steel-clad $\mathrm{B}_{4} \mathrm{C}$ poison plates

\begin{tabular}{|c|c|c|c|c|c|c|c|}
\hline \multirow[t]{2}{*}{ Location } & \multicolumn{2}{|c|}{ Neutron dose rate } & \multicolumn{2}{|c|}{$\begin{array}{c}\text { Primary gamma } \\
\text { dose rate }\end{array}$} & \multicolumn{2}{|c|}{$\begin{array}{c}\text { Secondary gamma } \\
\text { dose rate }\end{array}$} & \multirow[t]{2}{*}{ Total } \\
\hline & $\mathrm{mrem} / \mathrm{h}$ & $\mathrm{fsd}^{a}$ & $\mathrm{mrem} / \mathrm{h}$ & fsd & $\mathrm{mrem} / \mathrm{h}$ & fsd & \\
\hline \multicolumn{8}{|c|}{$P W R^{b}$} \\
\hline Surface & 3.903 & 0.371 & 3.699 & 0.116 & 0.396 & 0.126 & 7.998 \\
\hline $1 \mathrm{~m}$ & 0.923 & 0.074 & 1.015 & 0.031 & 0.175 & 0.090 & 2.113 \\
\hline $2 \mathrm{~m}$ & 0.448 & 0.063 & 0.473 & 0.027 & 0.073 & 0.081 & 0.994 \\
\hline \multicolumn{8}{|c|}{$B W R^{c}$} \\
\hline Surface & 5.647 & 0.265 & 5.557 & 0.072 & 0.310 & 0.257 & 11.514 \\
\hline $1 \mathrm{~m}$ & 1.155 & 0.033 & 1.840 & 0.019 & 0.121 & 0.348 & 3.116 \\
\hline $2 \mathrm{~m}$ & 0.535 & 0.032 & 0.825 & 0.015 & 0.051 & 0.318 & 1.411 \\
\hline
\end{tabular}

${ }^{a}$ Fractional standard deviation: one standard deviation divided by the calculated mean.

$b_{\text {Dose rates for PWR are at side of package. }}$

${ }^{c}$ Dose rates for BWR are at bottom of package. 
Page Intentionally Blank 


\section{SUMMARY}

This report provides the latest information about the status of the preliminary conceptual designs for two different fresh MOX fuel package design alternatives that have undergone analysis and revision since the initial concepts were developed in 1997. The two different concepts are the end-loading concept and the double-strongback concept.

Refinements to both designs have included changes to structural designs (to improve package strength and provide a more sound engineering design). This has resulted in a minor increase in the package gross weight. Based on recent activities undertaken by ORNL and DOE/MD, the payload capacity limitation for the SST and SGT may be relaxed to the SST-2 limit of 16,500 lb. This will permit either of the new package designs to be acceptable for transport within an SST-2.

Major revisions have occurred to the criticality safety design. Initially, the conceptual designs utilized a highdensity, boron-impregnated foam material to provide criticality control for the multiple fuel assembly package designs. Upon review, however, it was determined that the foam should not be relied on to provide more than a single function (i.e., structural integrity plus criticality control). Therefore, stainless steel plates over a $\mathrm{B}_{4} \mathrm{C}$ sandwich were added to the package design. This addition resulted in a slight increase in the package gross weight but will ultimately lead to a more defensible design.

Because of the need to provide a summary of the package designs (this report) in support of the issuance of the final RFP (planned for a March 1998 release date), additional analyses (structural and thermal performance under accident conditions, etc.) have not been performed. Ultimately, continued analyses will result in additional revisions to the package designs, and will lead to development of information needed to be included in the SARP that will be submitted to DOE to obtain certification of the new MOX fresh fuel transport package as a Type B(U)F package design. 
Page Intentionally Blank 


\section{REFERENCES}

1. Program Acquisition Strategy for Obtaining Mixed-Oxide Fuel Fabrication and Reactor Irradiation Services, U.S. Department of Energy, July 17, 1997.

2. S. B. Ludwig et al., Transportation and Packaging Issues Involving the Disposition of Surplus Plutonium as MOX Fuel in Commercial LWRs, ORNL/TM-13427, Lockheed Martin Energy Research Corp., Oak Ridge National Laboratory, August 1997.

3. U.S. Department of Energy, Mixed Oxide (MOX) Fuel Fabrication and Reactor Irradiation Services, Request for Proposals No. DE-RP02-98CH10888, November 21, 1997.

4. S. B. Ludwig et al., Programmatic and Technical Requirements for the FMDP MOX Fresh Fuel Transport Package, ORNL/TM-13526, Lockheed Martin Energy Research Corp., Oak Ridge National Laboratory, December 1997.

5. DOE Order 460.1A, Packaging and Transportation Safety, October 2, 1996.

6. 10 CFR 71, "Packaging and Transportation of Radioactive Materials."

7. LS-Dyna 3d, Version 936.02, Livermore Software Technology Corp., December 1995.

8. INGRID, Version 3.3, Lawrence Livermore National Laboratory, July 1992.

9. TrueGrid, Version 1.3.9, XYZ Scientific Applications, Inc., March 1997.

10. SCALE: A Modular Code System for Performing Standardized Computer Analyses for Licensing Evaluation, Vols. I-III, NUREG/CR-0200, Rev. 4 (ORNL/NUREG/CSD-2/R4), U.S. Nuclear Regulatory Commission, April 1995.

11. M. D. DeHart and S. M. Bowman, Validation of the SCALE Broad Group Structure 44-Group ENDF/B-V Cross-Section Library for Use in Criticality Safety Analyses, ORNL/TM-12460, Martin Marietta Energy Systems, Inc., Oak Ridge National Laboratory, September 1994.

12. J. A. Bucholz, Scoping Design Analyses for Optimized Shipping Casks Containing 1-, 2-, 3-, 5-, 7-, or 10-Year-Old PWR Spent Fuel, ORNL/CSD/TM-149, Union Carbide Corp., Oak Ridge National Laboratory, January 1983.

13. H. R. Dyer and C. V. Parks, Recommendations for Preparing the Criticality Safety Evaluation of Transportation Packages, NUREG/CR-5661 (ORNL/TM-11936), U.S. Nuclear Regulatory Commission, April 1997.

14. J. J. Lichtenwalter et al., Criticality Benchmark Guide for Light-Water-Reactor Fuel in Transportation and Storage Packages, NUREG/CR-6361 (ORNL/TM-13211), U.S. Nuclear Regulatory Commission, March 1997.

15. J. J. Lichtenwalter et al., Neutronics Benchmarks for the Utilization of Mixed Oxide Fuel, ORNL/MD/LTR-80, Lockheed Martin Energy Research Corp., Oak Ridge National Laboratory, in publication.

16. ANSI/ANS-6.1.1-1977, "Neutron and Gamma-Ray Flux-to-Dose-Rate Factors," American Nuclear Society, LaGrange Park, Illinois, 1977. 
Page Intentionally Blank 


\section{Appendix A BACKGROUND INFORMATION}

On January 14, 1997, the Department of Energy (DOE) announced the formal Record of Decision (ROD) for the storage and disposition of weapons-usable fissile materials. ${ }^{1}$ To pursue the mixed-oxide (MOX) fuel portion of the dual approach, ROD stated that the United States would pursue the use of domestic light-water reactors (LWRs) to irradiate MOX fuel assemblies.

Thus, an integral part of the MOX fuel approach is acquisition of MOX fuel fabrication and reactor irradiation services from the private sector. As outlined in the Program Acquisition Strategy for Obtaining Mixed-Oxide (MOX) Fuel Fabrication and Reactor Irradiation Services (PAS), ${ }^{2}$ released on July 17, 1997, DOE provided a description of the technical approach that it intends to use to implement fuel fabrication, reactor irradiation, and associated services. In PAS, DOE provided certain assumptions and outlined various responsibilities that would be undertaken by DOE and the selected consortium. With regard to transportation of plutonium, DOE stated the following assumption: "Plutonium oxide and unirradiated MOX fuel elements will be transported by DOE via Safe Secure Trailers (SSTs)." ${ }^{2}$ With regard to responsibilities, PAS stated that DOE would

1. provide a certified package design for the transport of fresh MOX fuel from the MOX fuel fabrication facility to the reactor sites, and

2. transport plutonium oxide powder to the MOX fuel fabrication facility and transport fresh fuel assemblies between the fuel facility and the reactors.

PAS also stated that the consortium would "[p]rocure and maintain fresh MOX fuel transportation packages." Because of a paucity of transport packages certified in the United States to transport fresh MOX fuel, DOE assigned the Oak Ridge National Laboratory (ORNL) the responsibility to develop and certify a new package design for the transport of MOX fuel assemblies. This will allow MOX shipments to commence at the earliest possible date (2004), and no later than 2007.

PAS was followed up by release of a draft Request for Proposals (RFP) in November 1997. ${ }^{3}$ In addition to providing DOE's vision for how it intends to proceed with disposition of surplus plutonium via reactor-based alternatives, the draft RFP placed the burden of developing and certifying the new MOX fuel package design with the private-sector "consortium" that would be selected through a procurement process. In support of the draft RFP, ORNL issued a report describing the technical and programmatic requirements for the new, fresh MOX fuel transport package. ${ }^{4}$ The intention is that the package design requirements, coupled with the concepts and analyses provided here, will provide the consortium a foundation for continued development and certification of a new package design for the shipment of fresh MOX fuel assemblies.

Since the draft RFP was released in November 1997, ORNL has continued to refine its preliminary conceptual designs and resolve issues related to the package certification process and plans that fresh MOX fuel would be shipped via DOE's SST to provide the necessary materials safeguards for the fresh MOX fuel.

This report provides the latest information about the status of the preliminary conceptual designs for two different fresh MOX fuel package design alternatives that have undergone analysis and revision since the initial concepts were developed. Refinements have included changes to structural designs (to improve strength and provide a more sound engineering design). Major revisions have occurred to the criticality safety design. Initially, the conceptual designs utilized a high-density, boron-impregnated foam material to provide criticality control for the multiple fuel assembly package designs. Upon review, however, it was determined that the foam should not be relied on to provide more than a single function (i.e., structural integrity plus criticality control). Therefore, borated steel plates were added to the design. This resulted in a slight increase in the package gross weight, but will ultimately lead to a more defensible design. Because of the need to provide this information in support of the issuance of the final RFP (planned for a February 1998 release date), additional analyses (structural and thermal performance under accident conditions, etc.) have not been performed. Ultimately, continued analyses will result in additional revisions to the package designs. 
With regard to the package certification process, ORNL and the DOE Office of Fissile Materials Disposition (DOE/MD) staff met with the DOE Certifying Official (M. Wangler, DOE/EM-76) on January 15,1998 . Wangler provided clear confirmation that the new MOX fuel package, because it was being developed by DOE (or by a DOE-funded contractor), would be certified by DOE. This confirmed information received by DOE/MD in discussions with the Nuclear Regulatory Commission (NRC). Previously, the draft RFP had indicated that NRC would certify the package design. Wangler also stated that any foreign MOX package design (if a suitable foreign package would meet the needs of the disposition program and had never been certified in the United States) would also need to be certified by DOE for use in the United States. In such an instance, the foreign package design would be treated the same as a "new" design, with regard to the certification process. The MOX package would need to be certified as a Type $\mathrm{B}(\mathrm{U}) \mathrm{F}$ package and would need to meet all the regulations of the Department of Transportation [49 Code of Federal Regulations (CFR) 171 through 178] ${ }^{5}$ and NRC (10 CFR 71). ${ }^{6}$ Responsibilities for the DOE Certifying Official are outlined in DOE Orders 460.1A and 460.2.7,8

Because of the large quantity of plutonium that will be contained in each package and because the plutonium in the package is a Category IID material (see DOE Order 5633.3B), ${ }^{9}$ the shipments are expected to be made in SSTs or the recently developed safeguards transport (SGT). On February 5, 1998, ORNL and Sandia National Laboratories (SNL) staff supported DOE/MD in providing a briefing to the DOE Transportation Safeguards Division (TSD) in Albuquerque, New Mexico. The purpose of the briefing was to provide TSD with a snapshot of the volume of shipments needed to support the disposition mission during the next 15 years. ORNL provided its latest information about MOX fuel package designs and plans for shipping these packages using SSTs. TSD confirmed (based on the quantity of plutonium in each package) that DOE Orders required use of the SSTs to provide the physical protection for the materials in transit. Clearly, the MOX fuel contained sufficient material to warrant this shipment strategy. TSD provided DOE/MD with its latest information about future plans for the SST fleet, in terms of numbers of trailers that would be available in the future. TSD also stated that it expects to support the DOE/MD mission using only SSTs, while reserving the newer SGTs for use in support of DOE's Defense Programs. As a result, the payload capacity for the new MOX fuel package design can be relaxed to the SST-2 limit of $16,500 \mathrm{lb}$.

\section{REFERENCES}

1. Record of Decision for the Storage and Disposition of Weapons-Usable Fissile Materials Final Programmatic Environmental Impact Statement, U.S. Department of Energy, January 14, 1997.

2. Program Acquisition Strategy for Obtaining Mixed-Oxide Fuel Fabrication and Reactor Irradiation Services, U.S. Department of Energy, July 17, 1997.

3. U.S. Department of Energy, Mixed-Oxide (MOX) Fuel Fabrication and Reactor Irradiation Services, Request for Proposals No. DE-RP02-98CH10888, November 21, 1997.

4. S. B. Ludwig et al., Programmatic and Technical Requirements for the FMDP MOX Fresh Fuel Transport Package, ORNL/TM-13526, Lockheed Martin Energy Research Corp., Oak Ridge National Laboratory, December 1997.

5. 49 CFR 171-178, "Shippers-General Requirements for Shipping and Packaging."

6. 10 CFR 71, "Packaging and Transportation of Radioactive Materials."

7. DOE Order 460.1A, Packaging and Transportation Safety, October 2, 1996.

8. DOE Order 460.2, "Departmental Materials Transportation and Packaging Management," September 27, 1995.

9. DOE Order 5633.3B, "Control and Accountability of Nuclear Materials," September 7, 1994. 


\section{Appendix B \\ END-LOADING CONCEPT DETAILS}

ORNL 98-1522 EFG

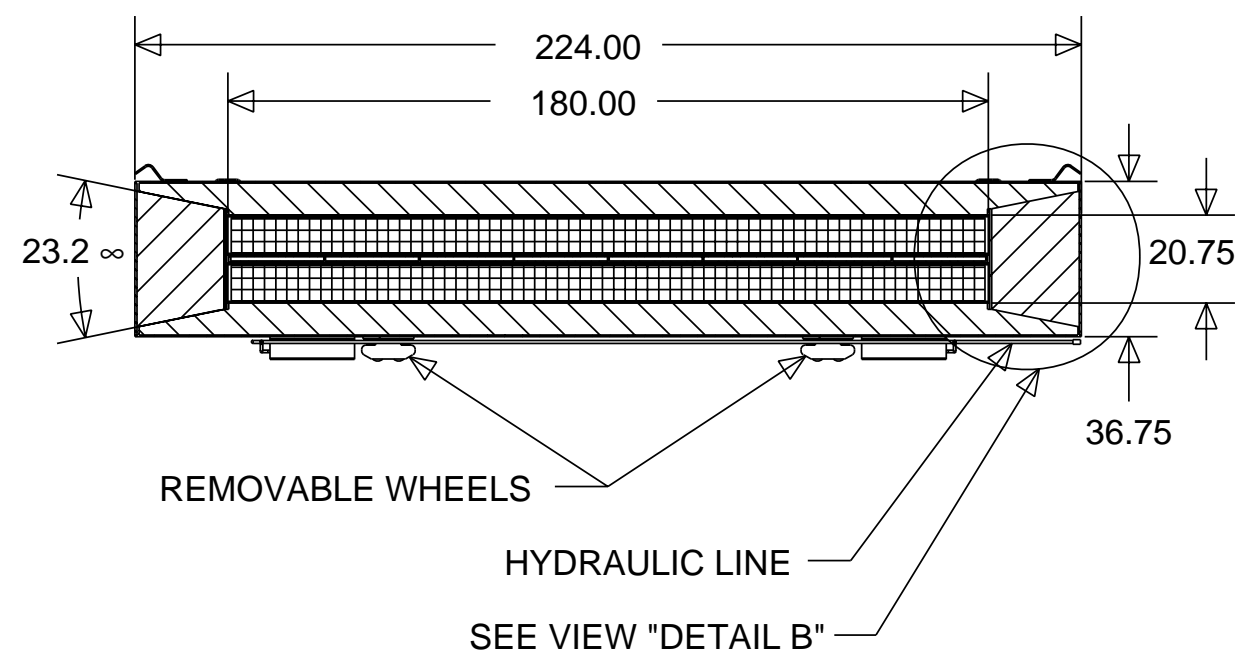

Fig. B.1. PWR fuel shipping package—end-loading option (dimensions in inches).

ORNL 98-1523 EFG

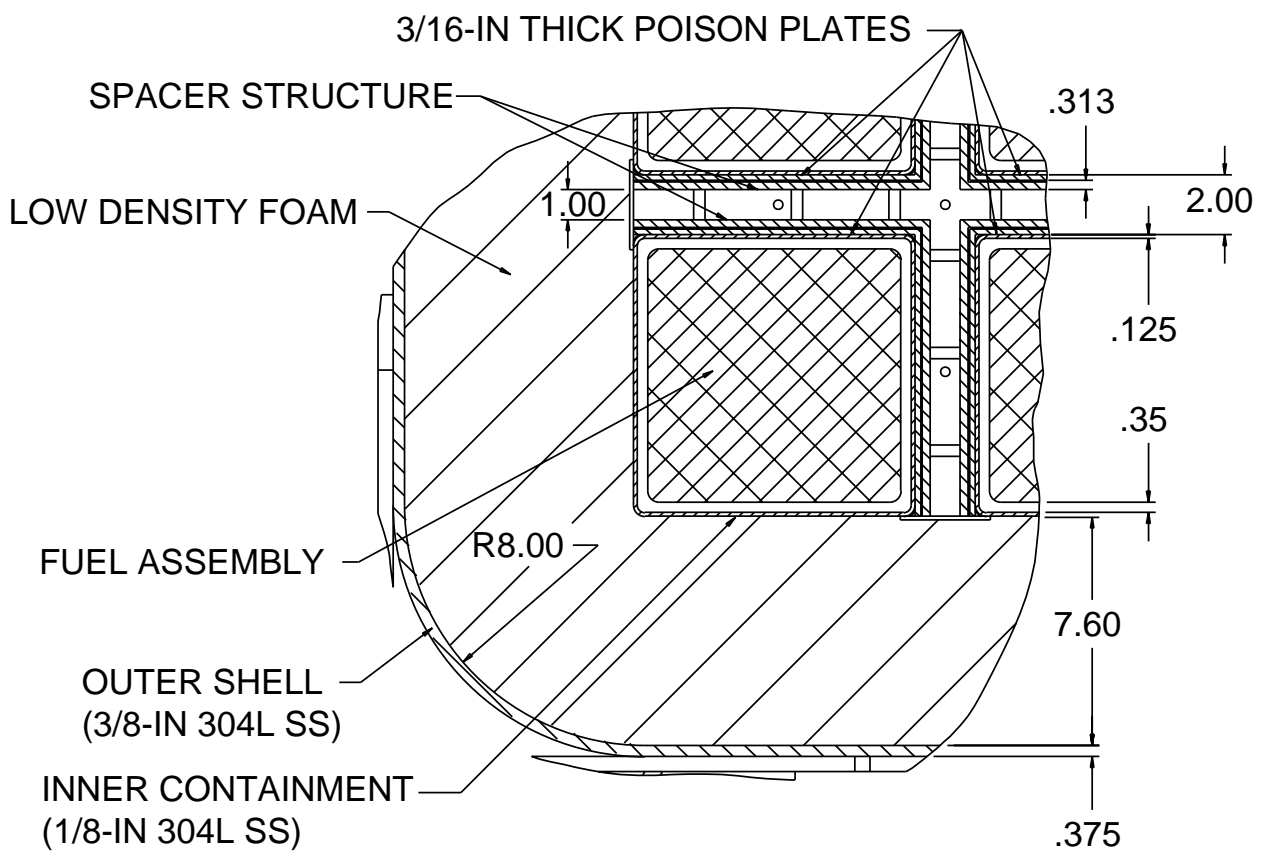

Fig. B.2. View of detail A-PWR package (dimensions in inches). 


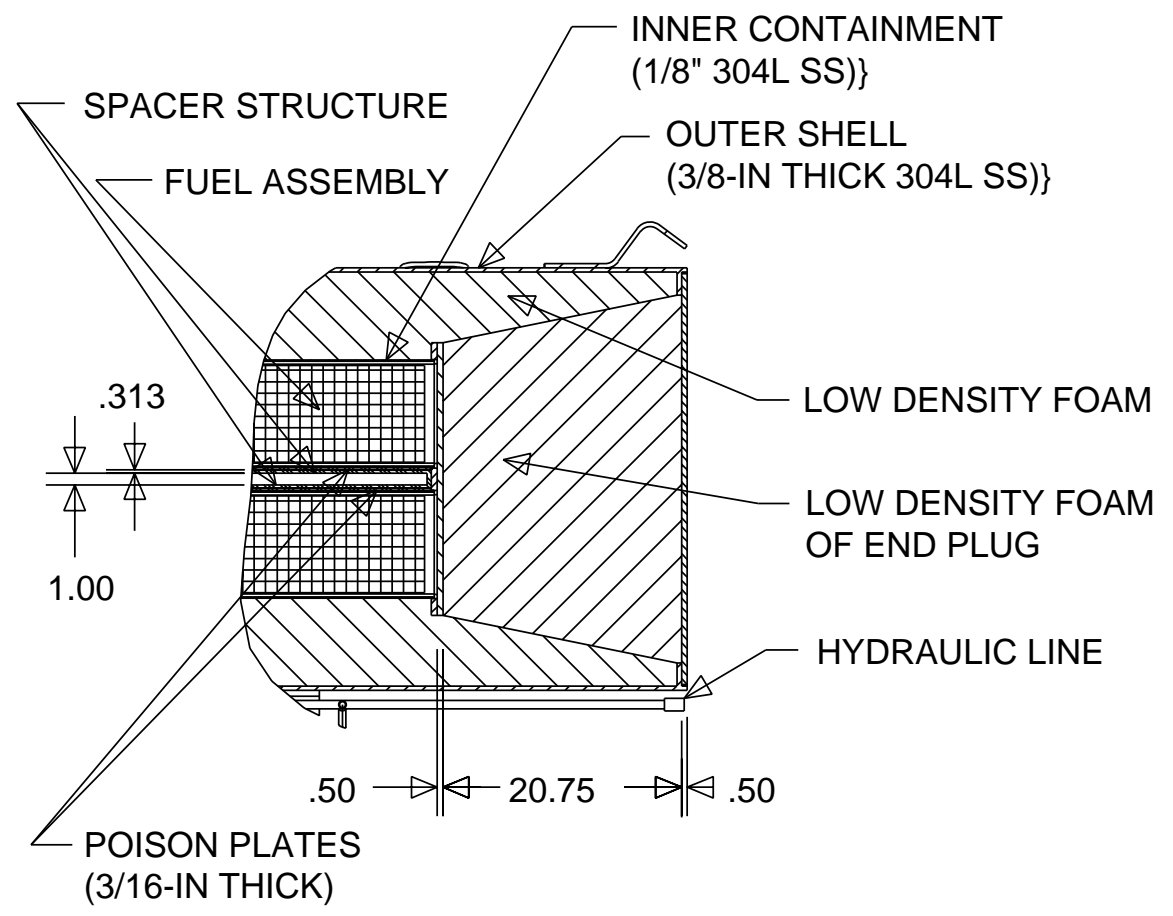

Fig. B.3. View of detail B-PWR package (dimensions in inches).

ORNL 98-1525 EFG

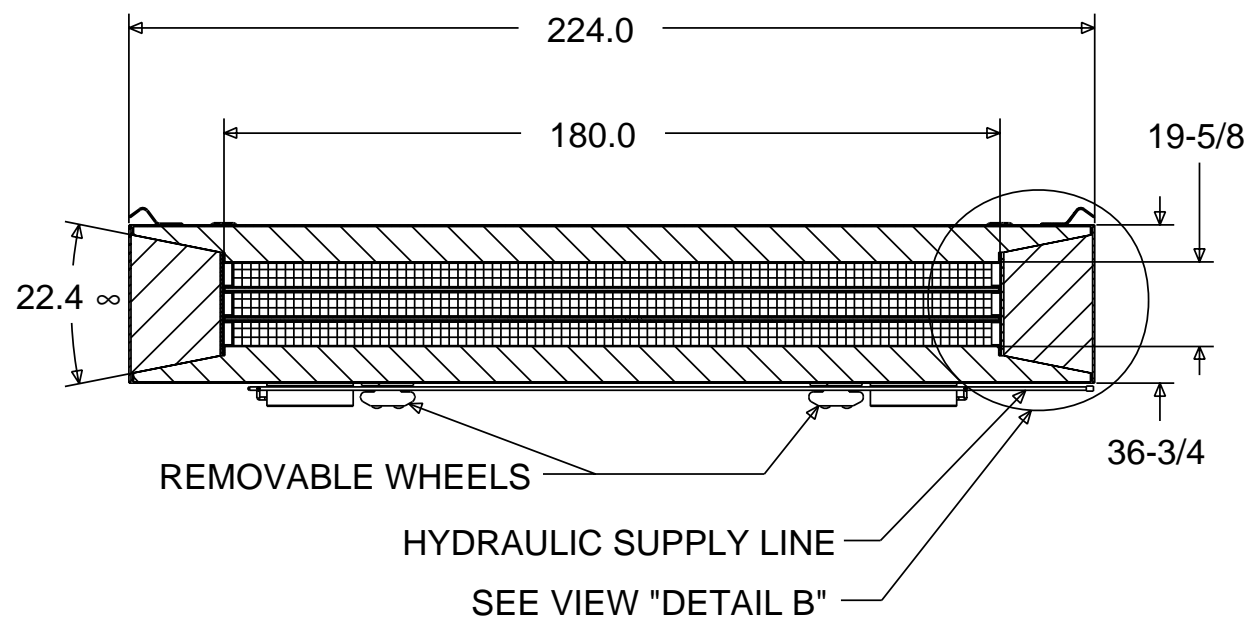

Fig. B.4. BWR fuel shipping package—end-loading option (dimensions in inches). 


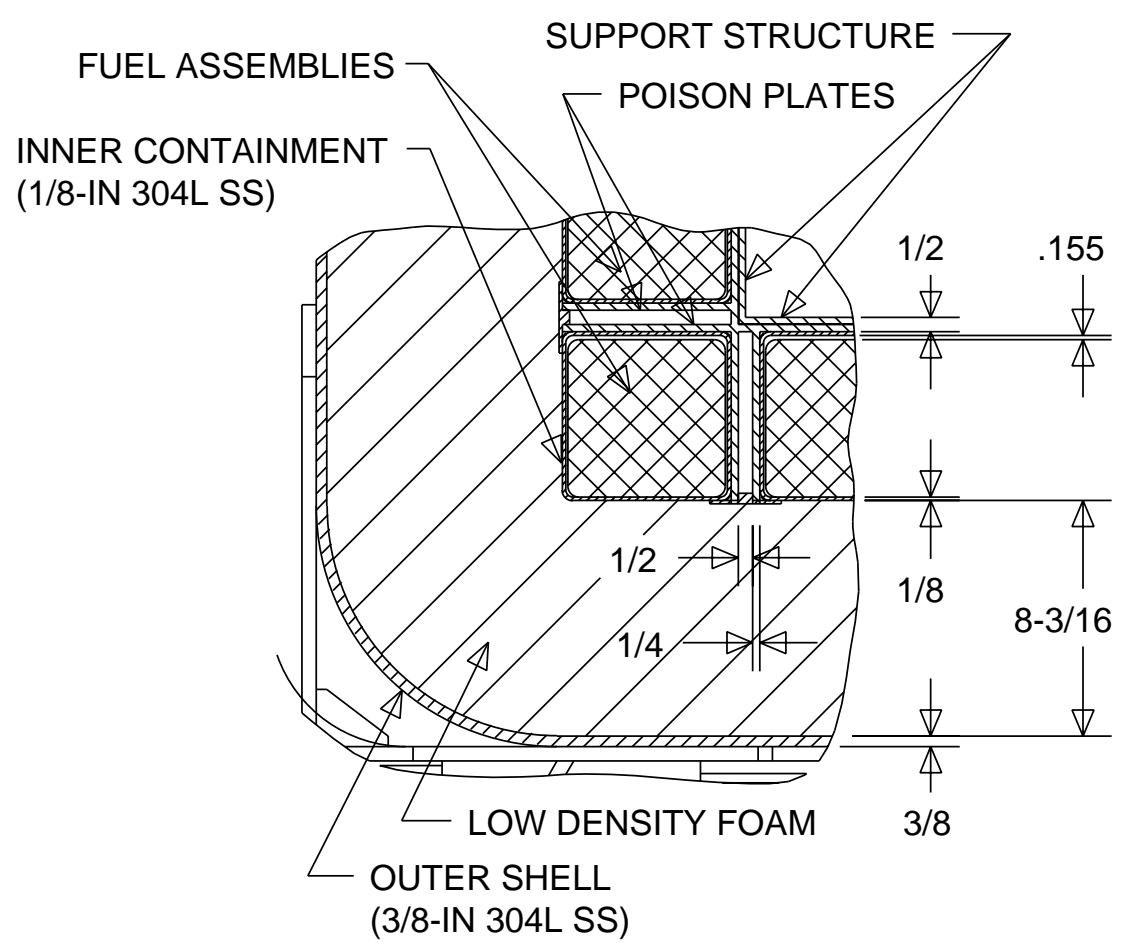

Fig. B.5. View of detail A-BWR shipping container (dimensions in inches).

ORNL 98-1527 EFG

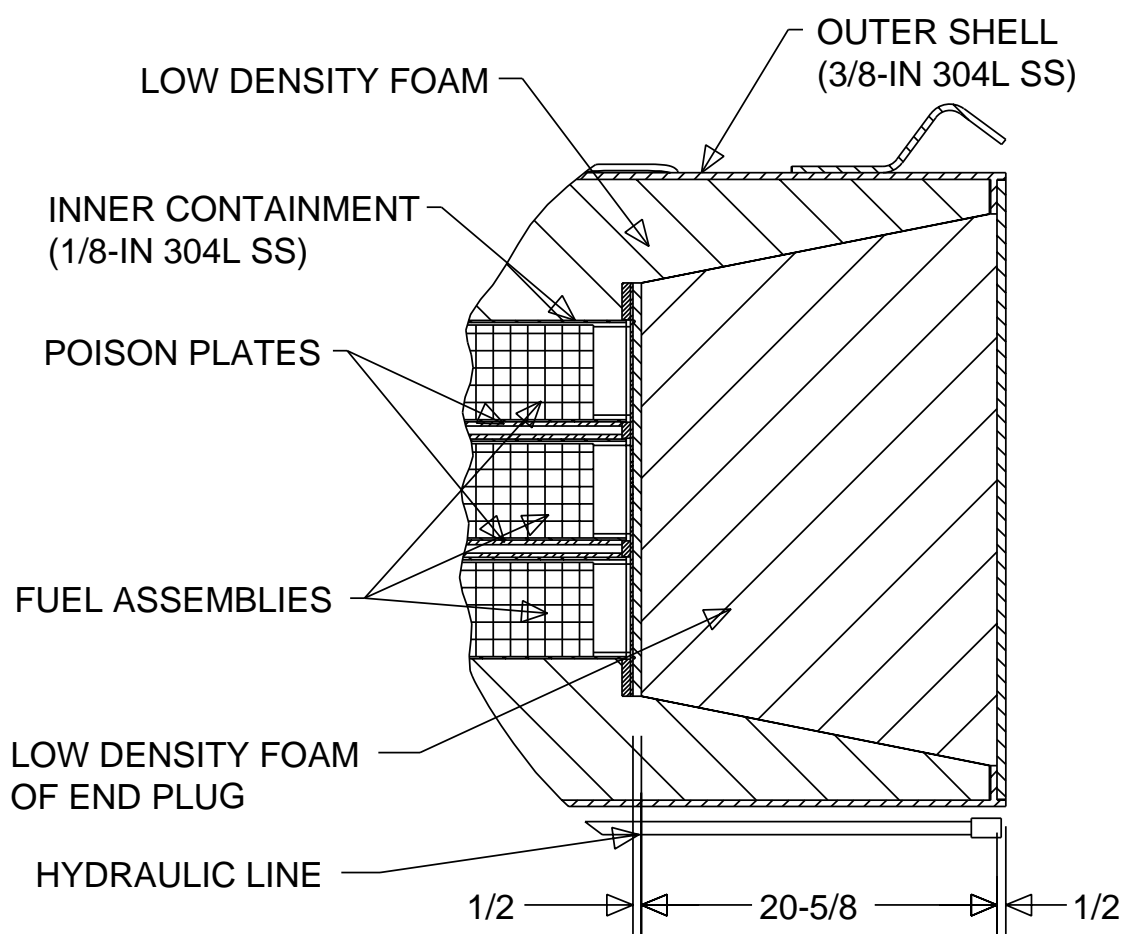

Fig. B.6. View of detail B-BWR shipping container (dimensions in inches). 
Page Intentionally Blank 


\section{Appendix C \\ STRONGBACK CONCEPT DETAILS}

ORNL 98-1528 EFG

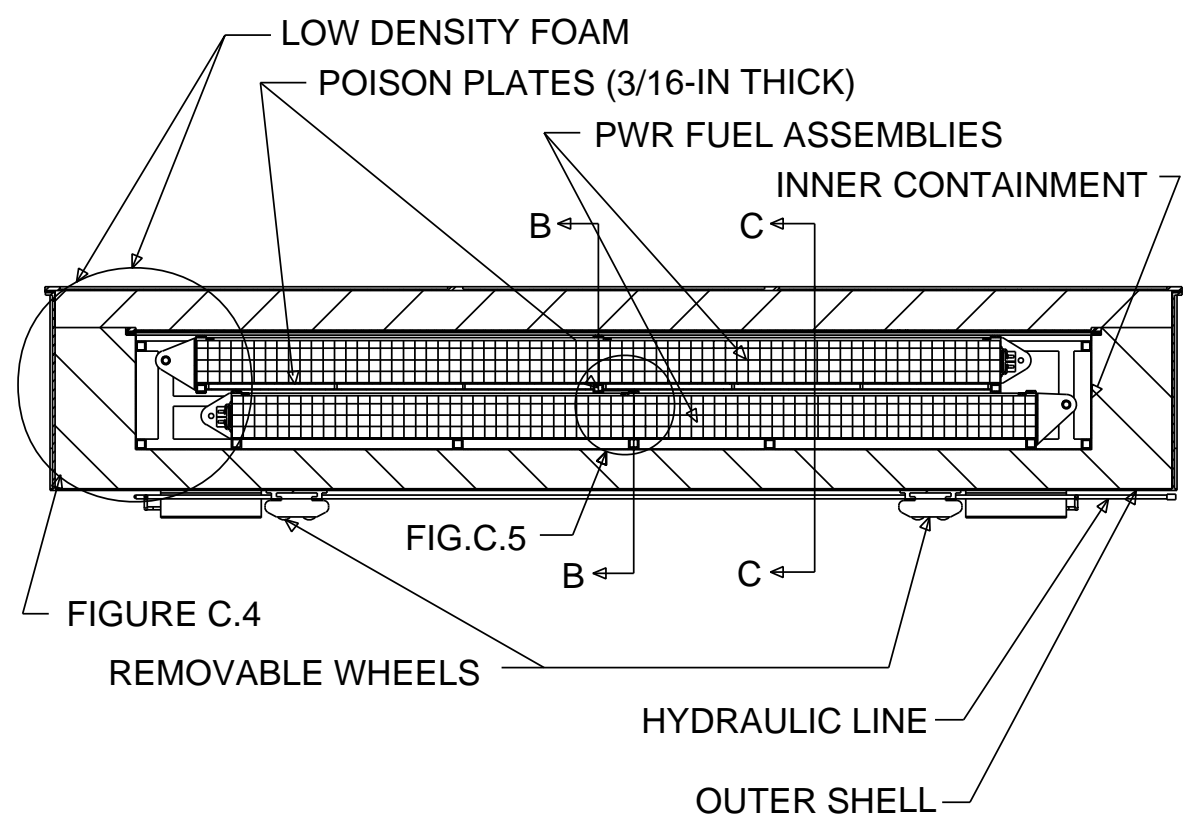

Fig. C.1. Cross-sectional view A-A of PWR shipping container (dimensions in inches).

ORNL 98-1529 EFG

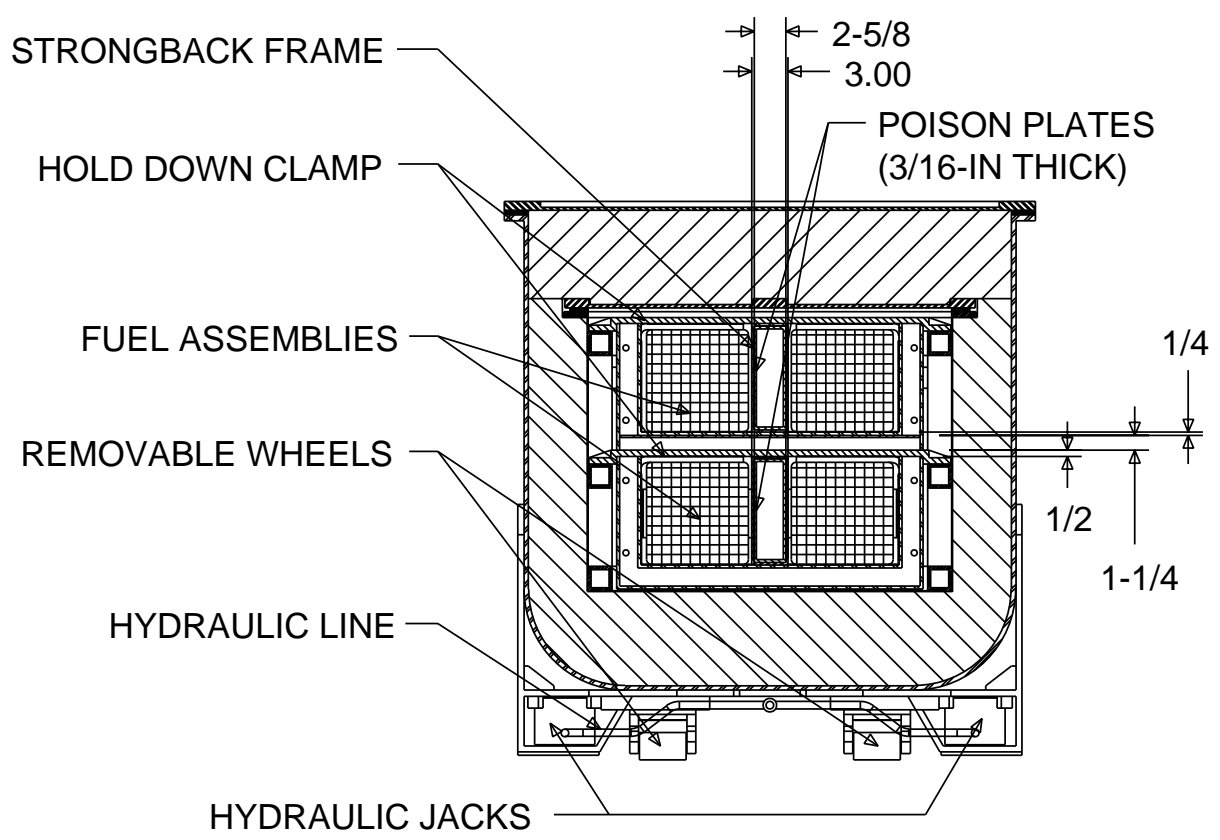

Fig. C.2. Cross-sectional view B-B of PWR shipping container (dimensions in inches). 
ORNL 98-1530 EFG

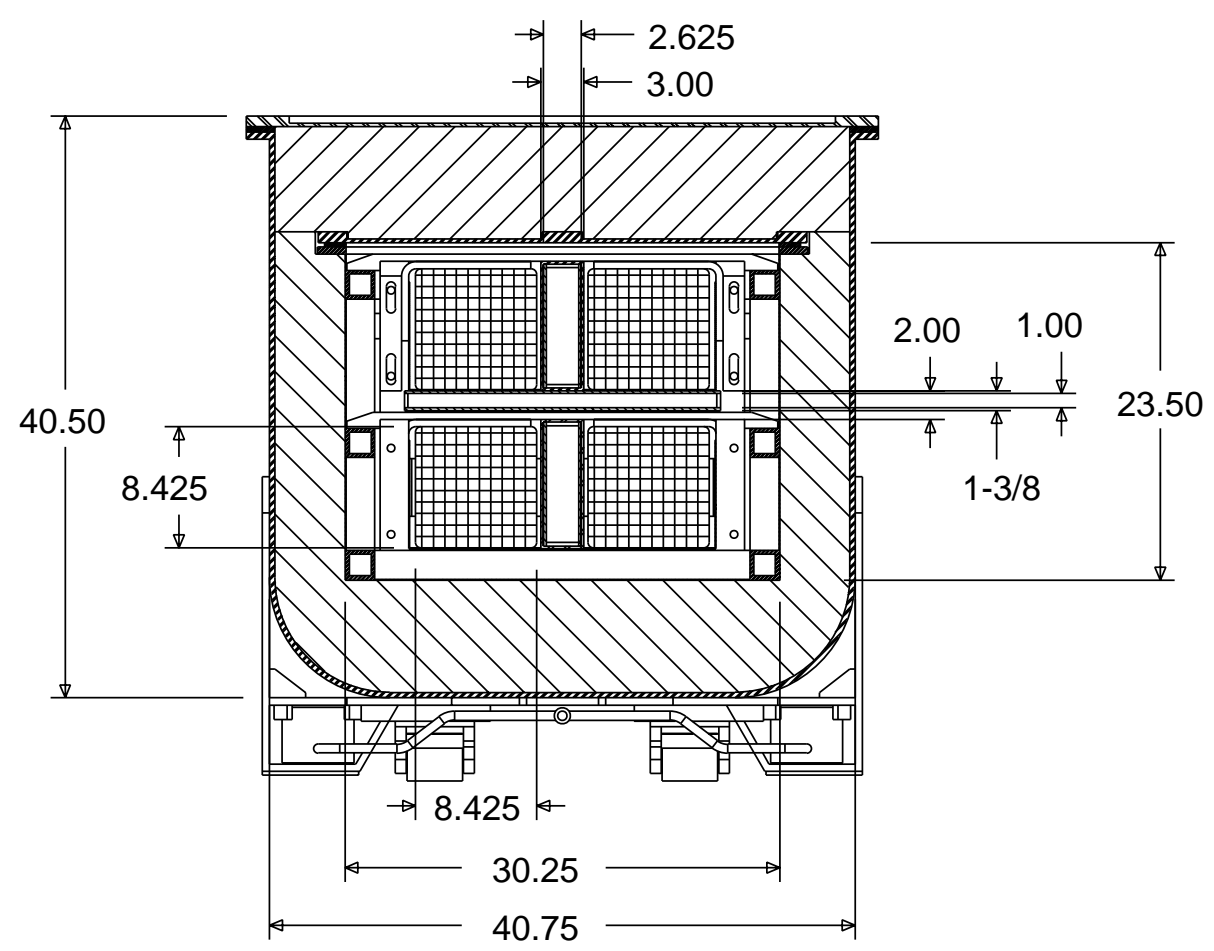

Fig. C.3. Cross-sectional view C-C of PWR shipping container (dimensions in inches).

ORNL 98-1531 EFG

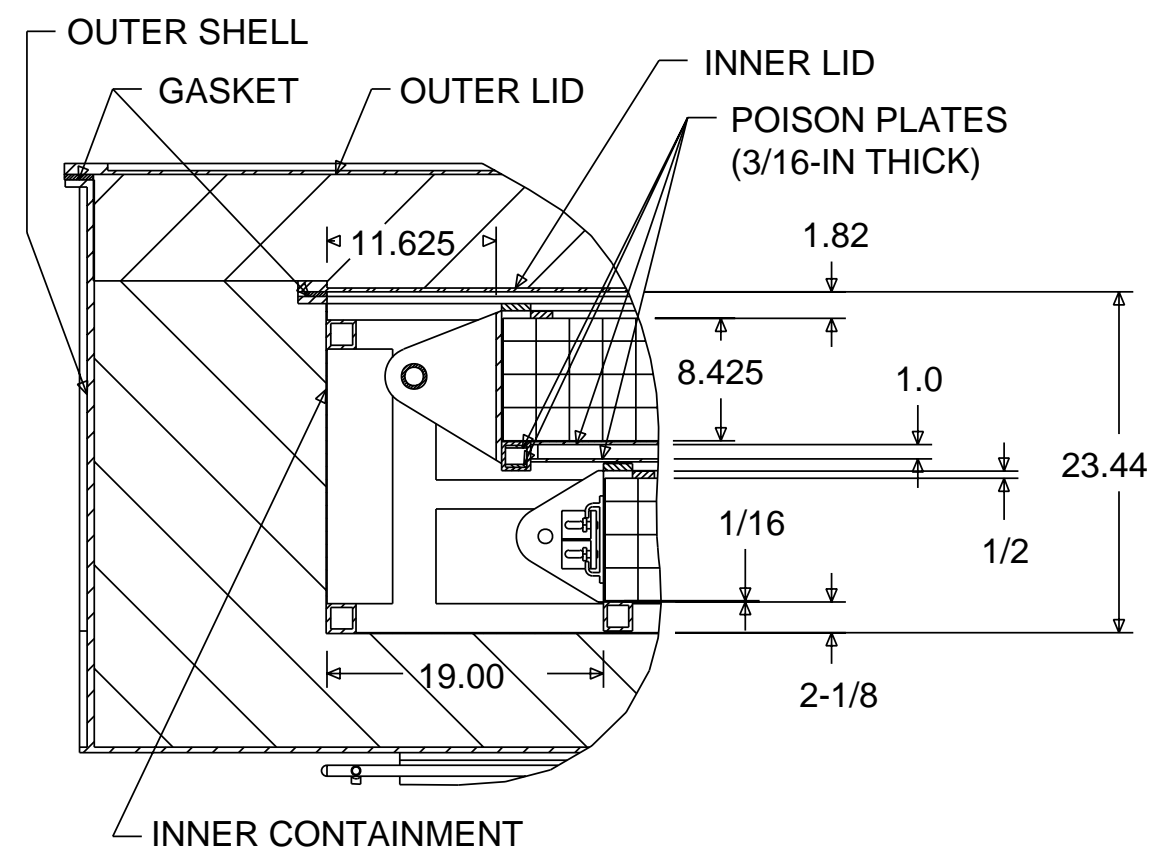

Fig. C.4. Detail view D1 of PWR shipping container (dimensions in inches). 


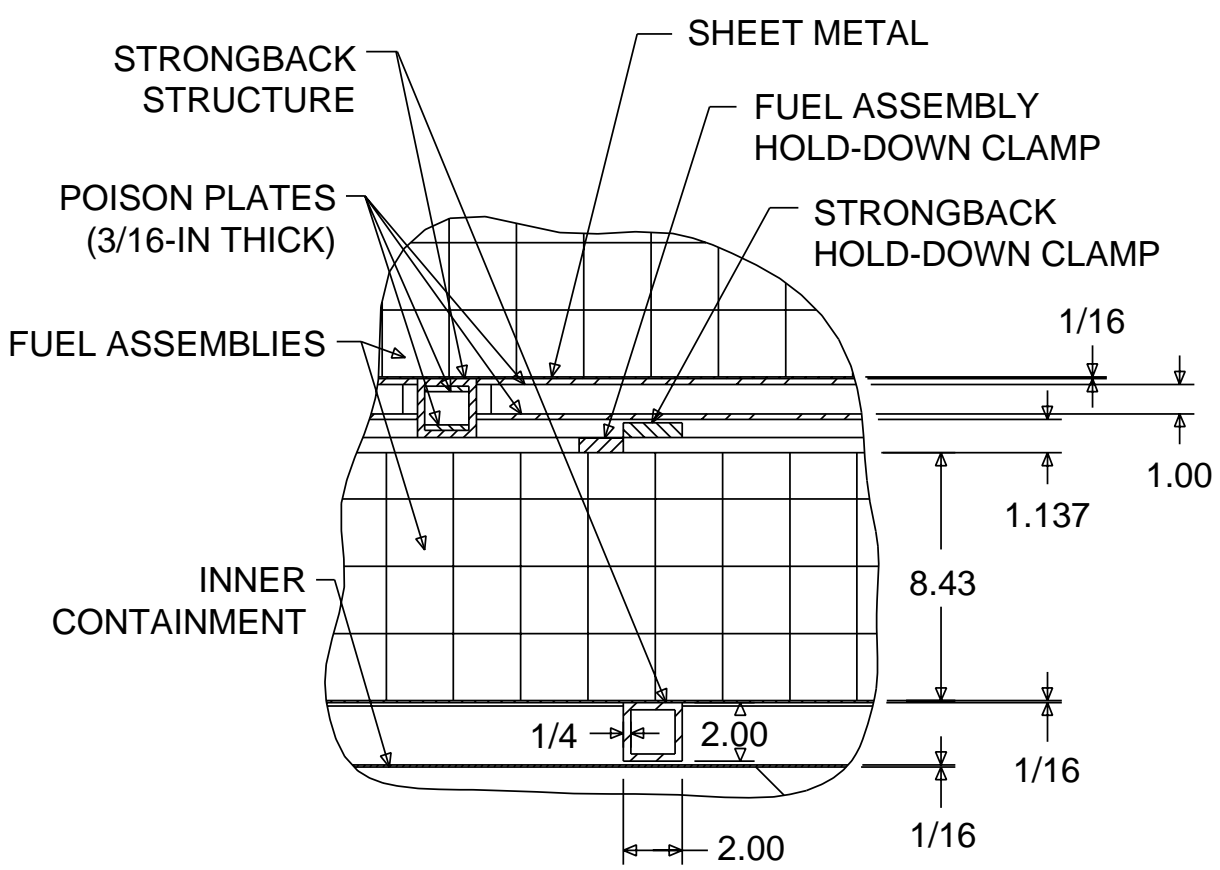

Fig. C.5. Detail view D2 of PWR shipping container (dimensions in inches).

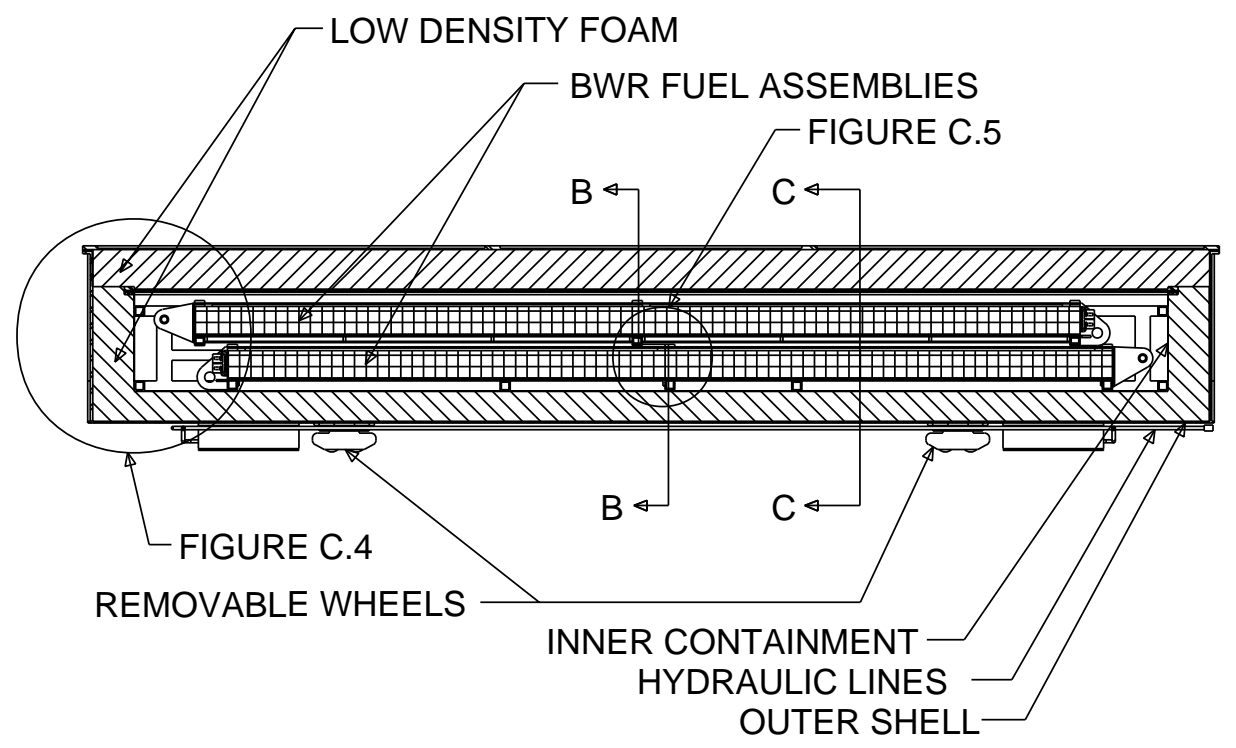

Fig. C.6. Cross-sectional view A-A of BWR shipping container (dimensions in inches). 
ORNL 98-1534 EFG

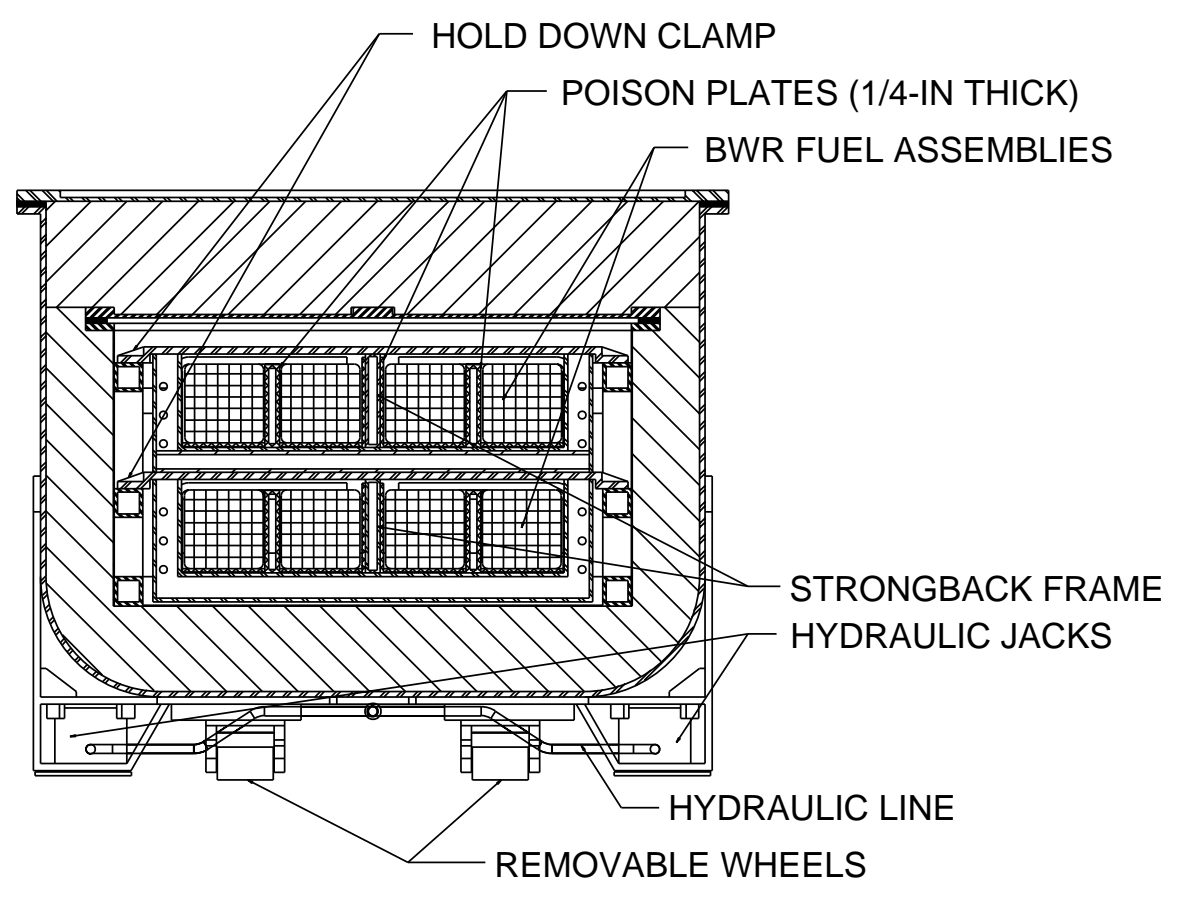

Fig. C.7. Cross-sectional view B-B of BWR shipping container (dimensions in inches).

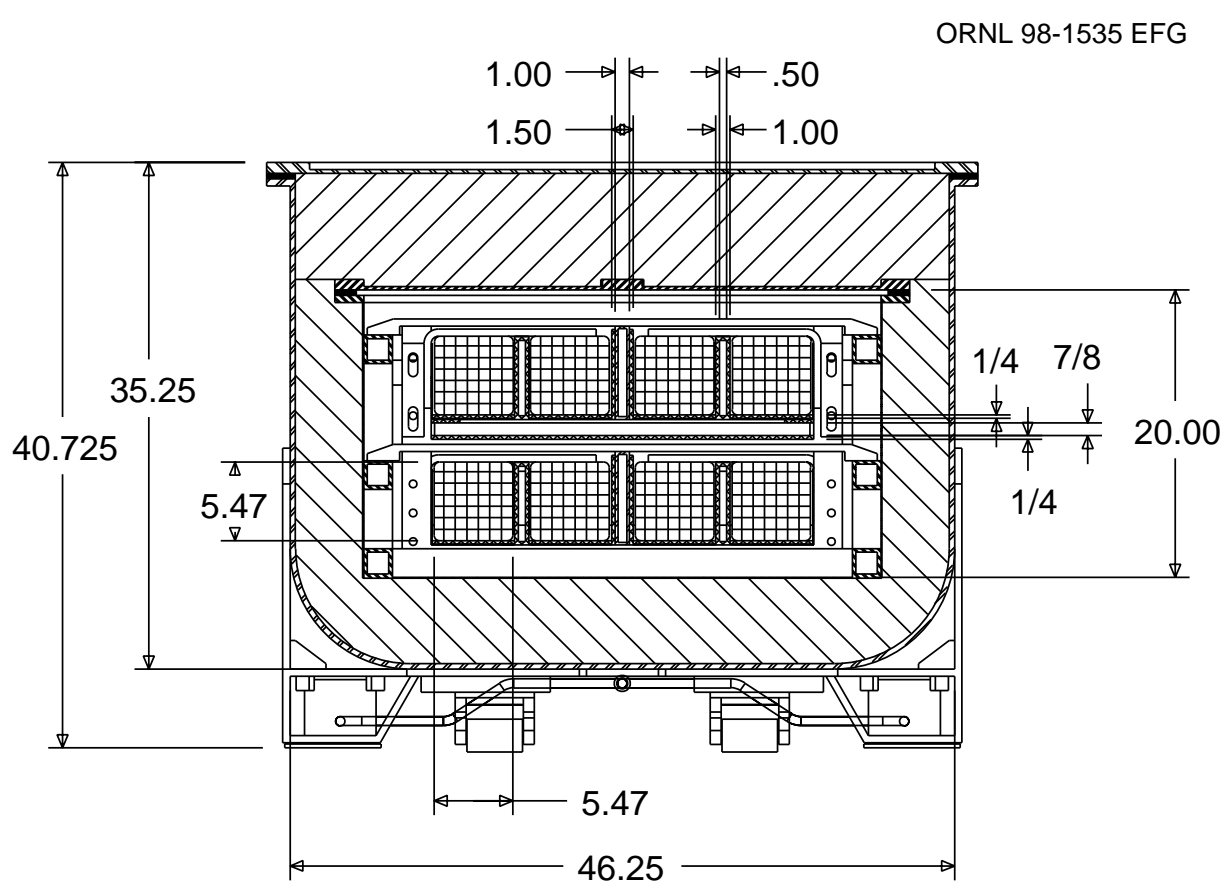

Fig. C.8. Cross-sectional view C-C of BWR shipping container (dimensions in inches). 
ORNL 98-1536 EFG

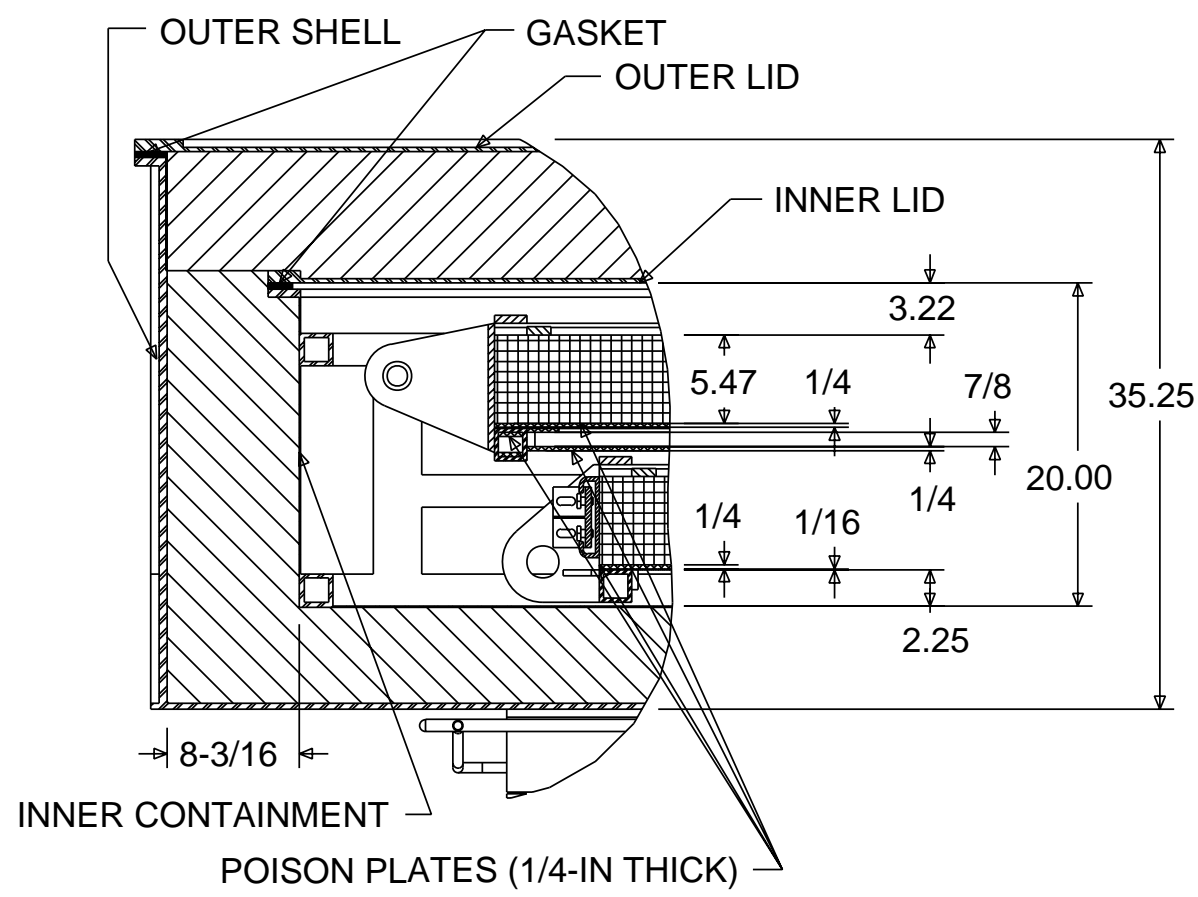

Fig. C.9. Detail view D1 of BWR shipping container (dimensions in inches). 
Page Intentionally Blank 


\section{Appendix D \\ NUCLEAR SAFETY DETAILS}

This appendix provides information and data that are relevant to the nuclear safety analysis but are not included in Chap. 4. The materials presented in this appendix are fuel assembly data, drawings of calculational models, and other calculated results.

\section{D.1 FUEL ASSEMBLY DATA}

Generic models were used for the mixed-oxide (MOX) pressurized-water reactor (PWR) and boilingwater reactor (BWR) assemblies in the conceptual package design calculations. Dimensions for the assemblies are given in Table D.1.

\section{D.2 DRAWINGS OF CALCULATIONAL MODELS}

Drawings of the KENO V.a calculational models are presented in Figs. D.1-D.6. The SAS4 calculational models are shown in Figs. D.7-D.10. All the drawings are cuts through the packages showing the assembly and fuel pin placements. The same material numbers are used for all drawings and are given in Table D.2. Any void is labeled explicitly. Note that the KENO drawings are for wet conditions, and the SAS4 drawings are for dry conditions.

\section{D.3 OTHER CALCULATED RESULTS}

This section contains tables of calculated results for preliminary design concepts. Table D. 3 shows $\mathrm{k}_{\text {eff }}$ values for a preliminary end-loading concept design that used borated inner steel cans. This design was not adopted because it is not desirable to use a structural member (the inner steel can) for criticality control.

Table D.4 gives dose rates for the preliminary end-loading concept with high-density (HD) foam. These cases did not include a gamma-ray source from $25 \mathrm{ppb}^{236} \mathrm{Pu}$. This preliminary design was not used because of a concern about structural integrity of the HD foam. Table D.5 shows dose rates for a preliminary end-loading concept with a $1.2 \mathrm{wt} \%$ borated inner steel can under dry conditions. Table D.6 presents dose rates for a preliminary double-strongback concept without poison plates under dry conditions. These two tables give primary gamma dose rates with and without a gamma-ray source from $25 \mathrm{ppb}^{236} \mathrm{Pu}$. Clearly, the gamma rays from the ${ }^{236} \mathrm{Pu}$ do not significantly increase the total dose rates of the packages.

Table D.1. Dimensions of generic PWR and BWR assemblies

\begin{tabular}{|c|c|c|}
\hline Component & PWR & BWR \\
\hline \multicolumn{3}{|l|}{ Assembly } \\
\hline Width, cm & 21.4166 & 13.6398 \\
\hline Zircalloy-2 fuel channel thickness, $\mathrm{cm}$ & N/A & 0.3175 \\
\hline Fuel pin array size & $17 \times 17$ (25 empty) & $8 \times 8(1$ empty $)$ \\
\hline \multicolumn{3}{|l|}{ Fuel pin } \\
\hline Fuel radius, $\mathrm{cm}$ & 0.4178 & 0.5398 \\
\hline Clad radius, $\mathrm{cm}$ & 0.4750 & 0.6261 \\
\hline Pitch, cm & 1.2598 & 1.6256 \\
\hline Fuel length, cm & 375.92 & 375.92 \\
\hline
\end{tabular}




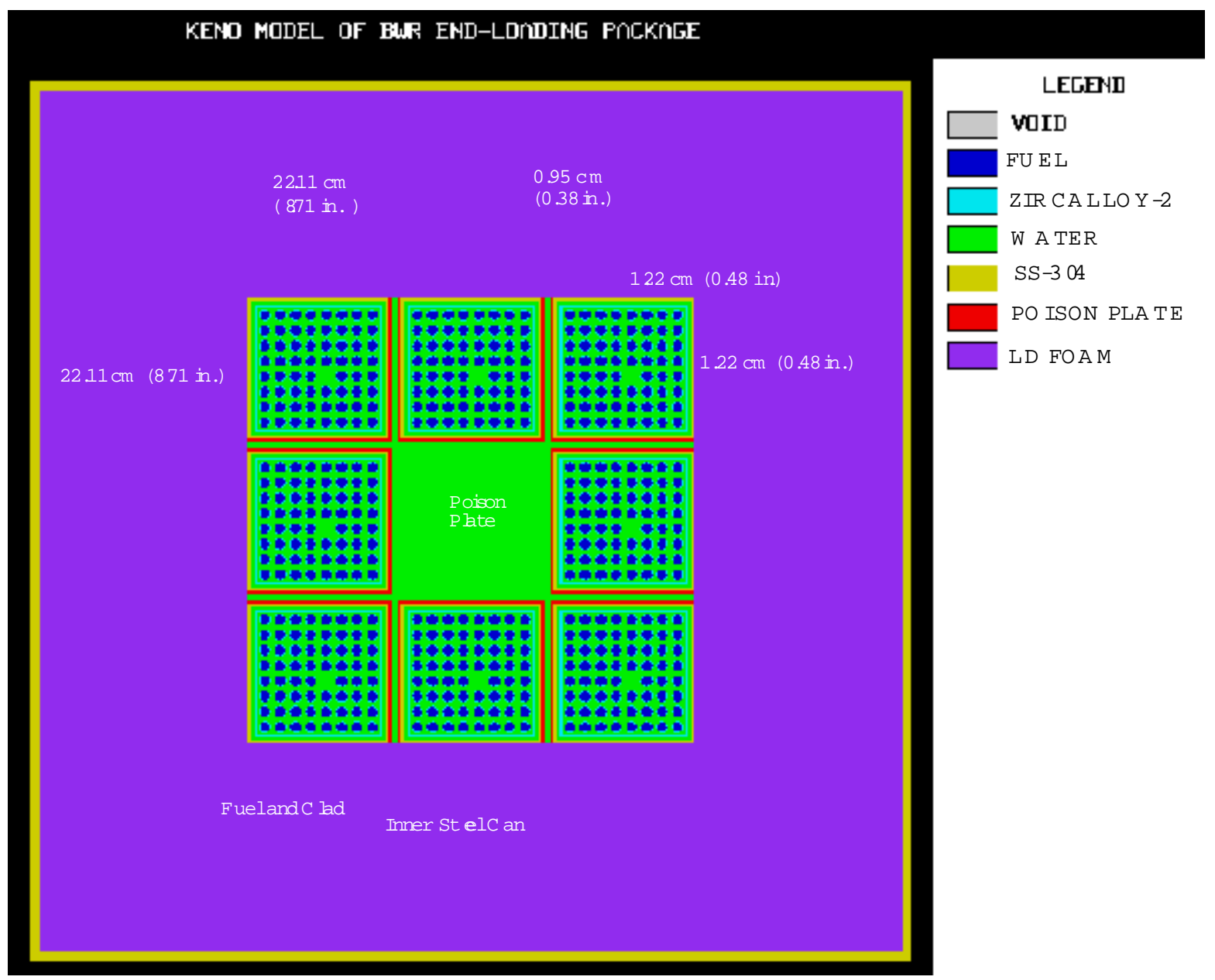

Fig. D.1. KENO model of BWR end-loading package. 


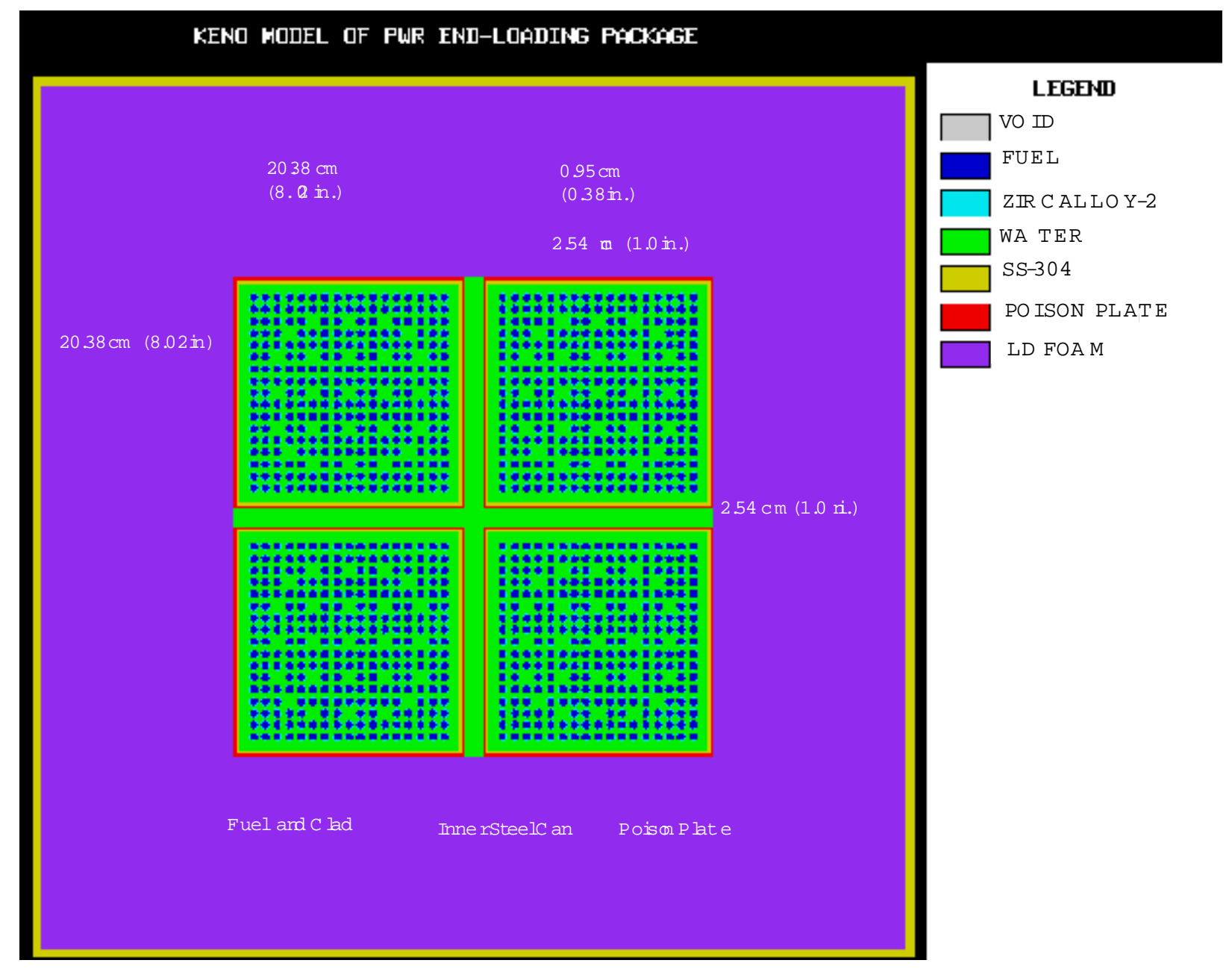

Fig. D.2. KENO model of PWR end-loading package. 


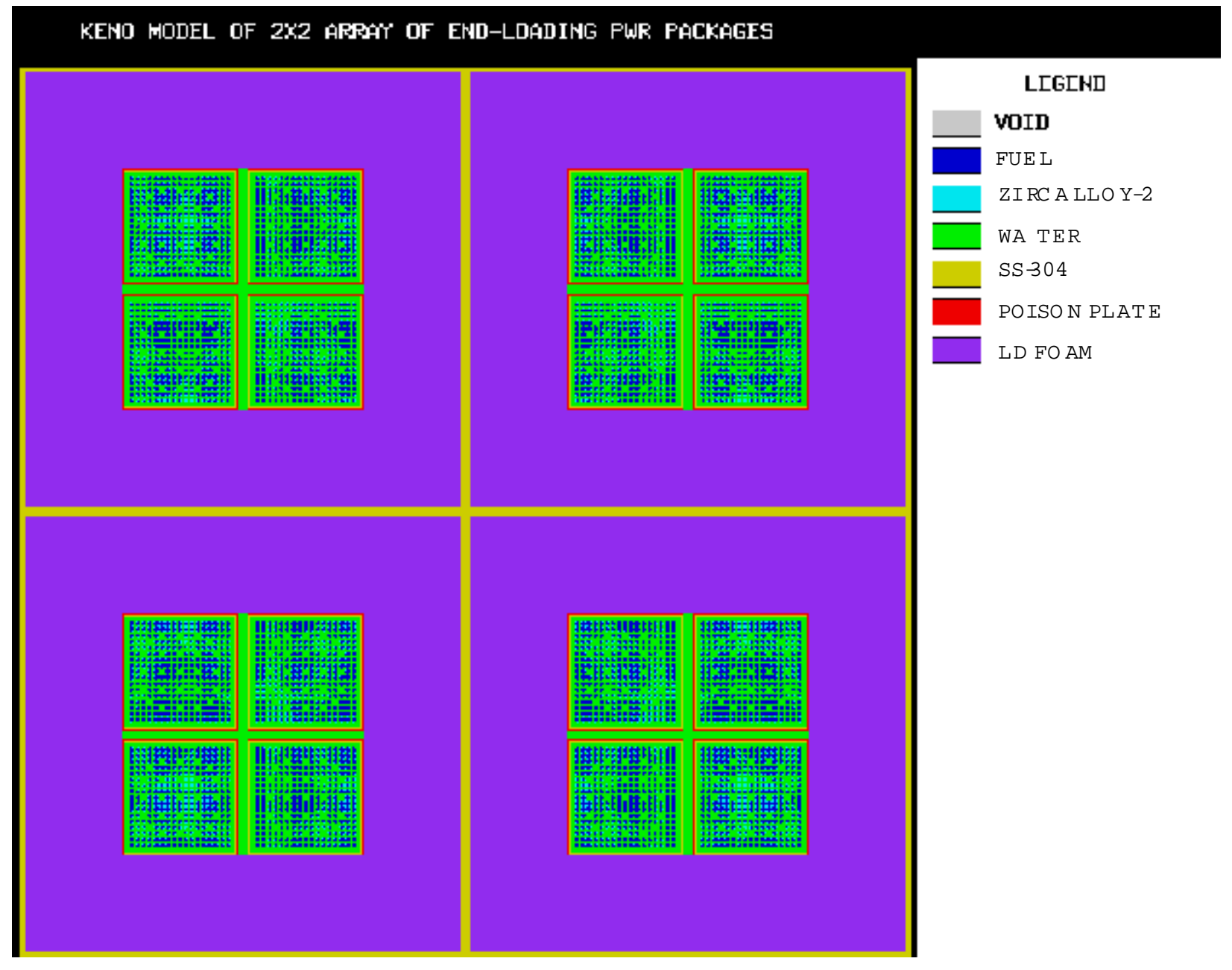

Fig. D.3. KENO model of $2 \times 2$ array of end-loading PWR packages. 


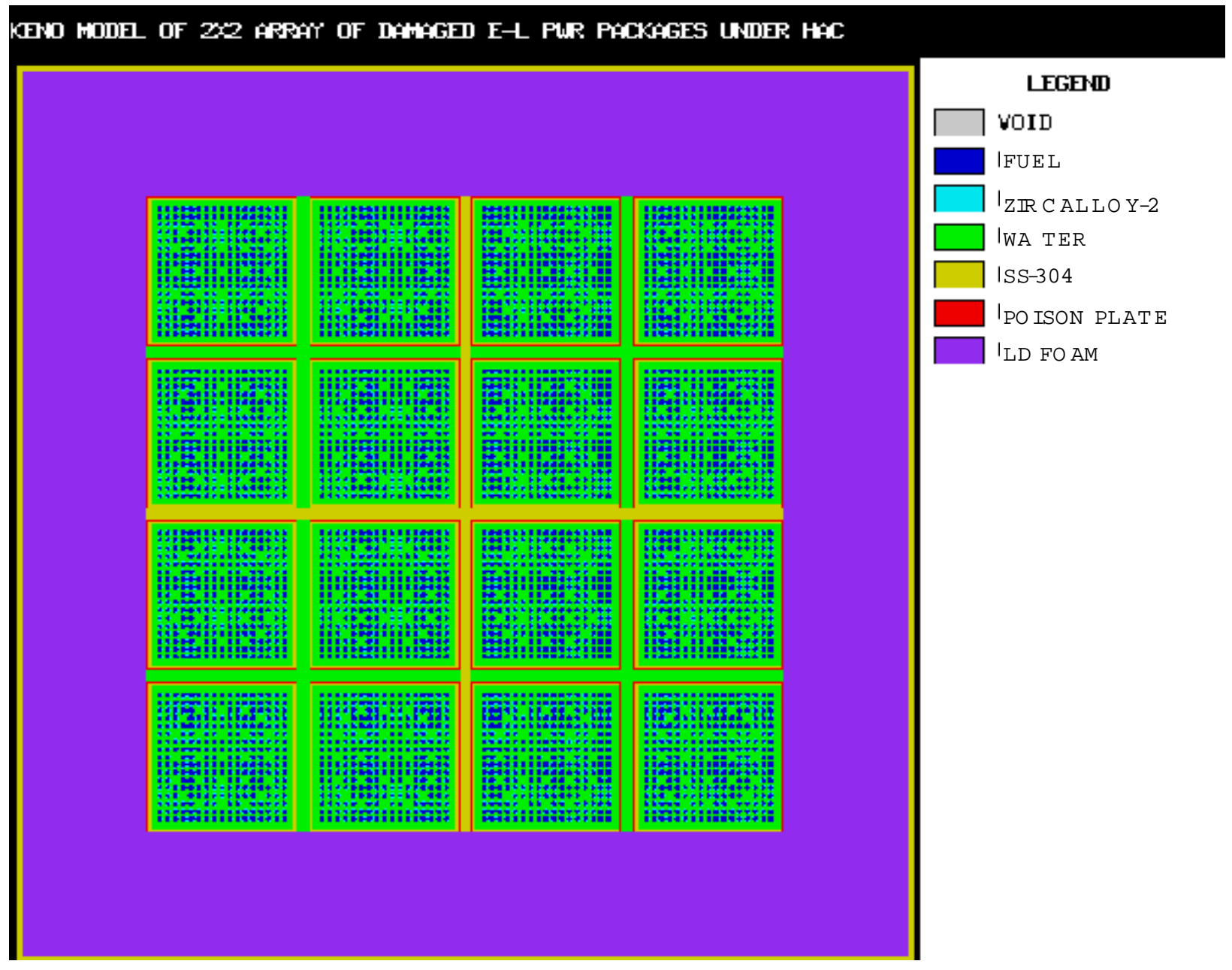

Fig. D.4. KENO model of $2 \times 2$ array of damaged end-loading PWR packages under hypothetical accident conditions. 


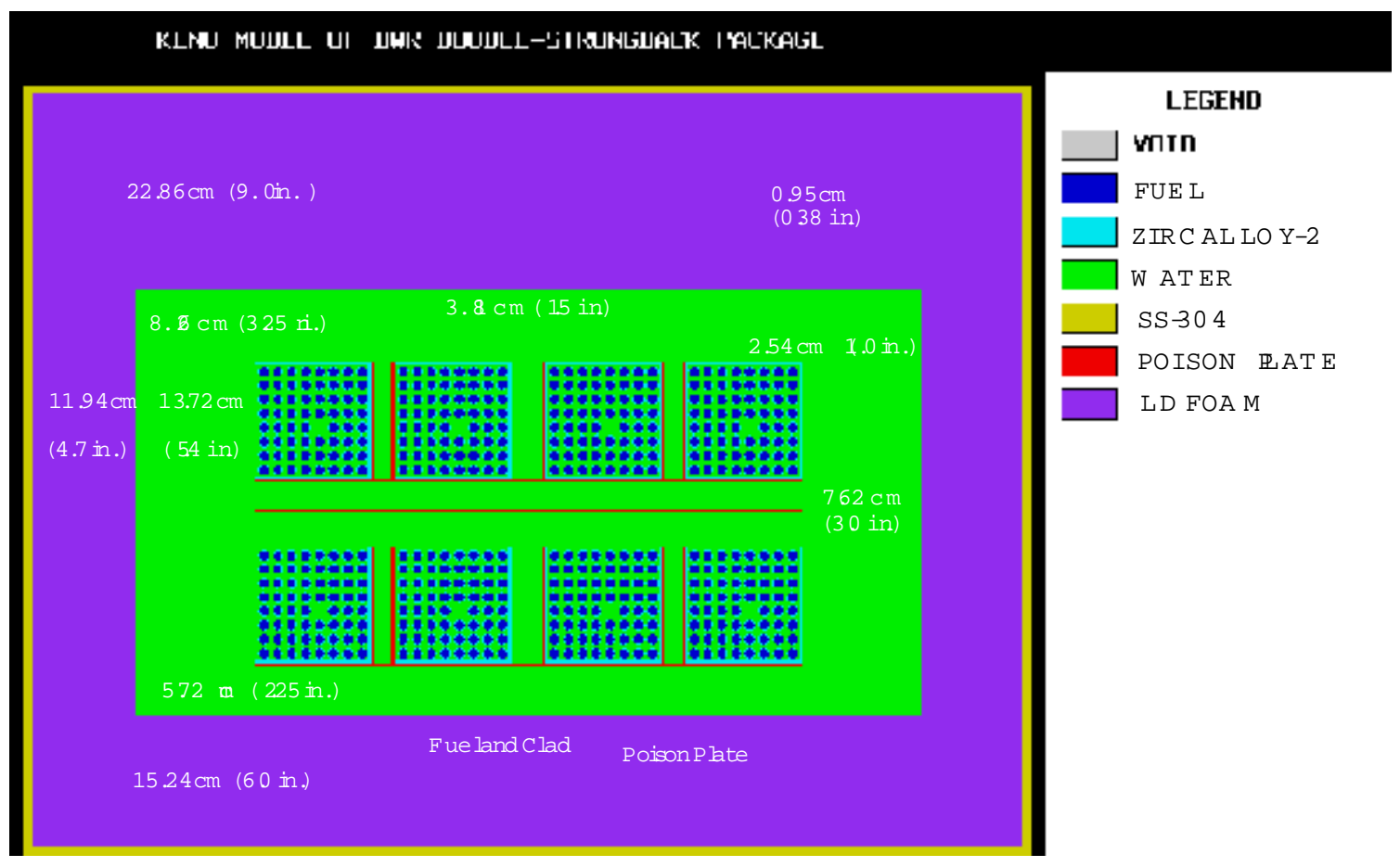

Fig. D.5. KENO model of BWR double-strongback package. 


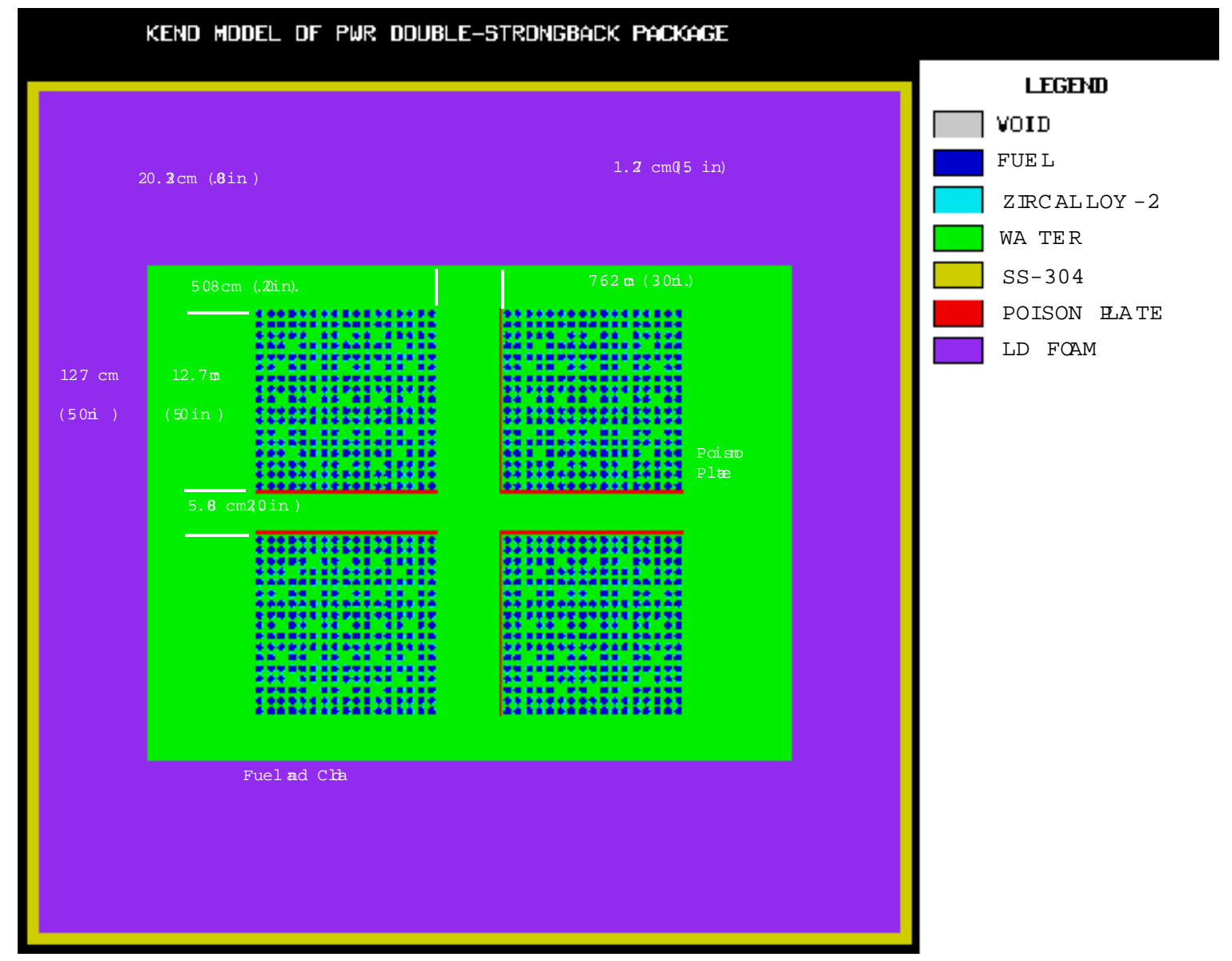

Fig. D.6. KENO model of PWR double-strongback package. 


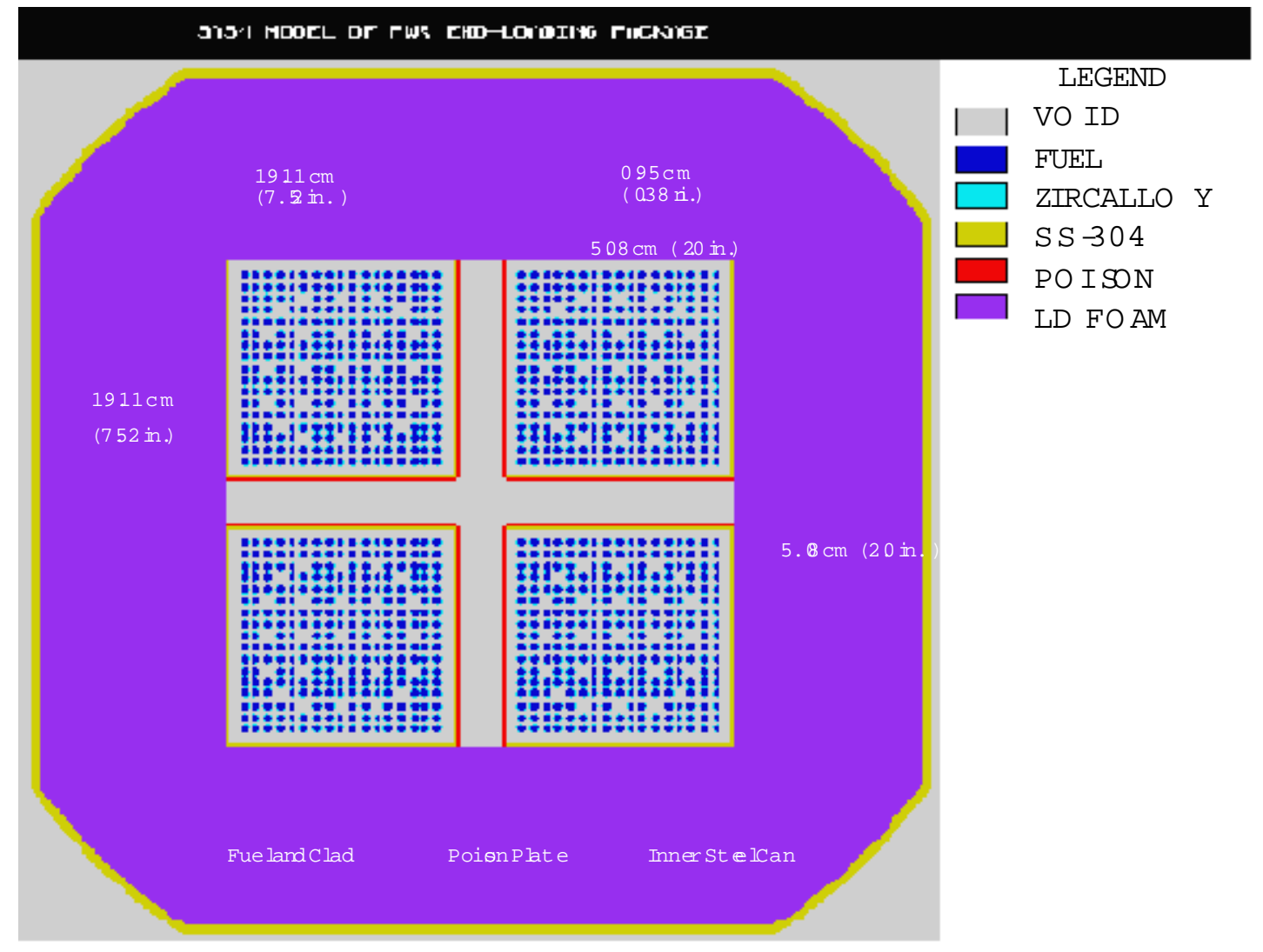

Fig. D.7. SAS4 model of BWR end-loading package. 


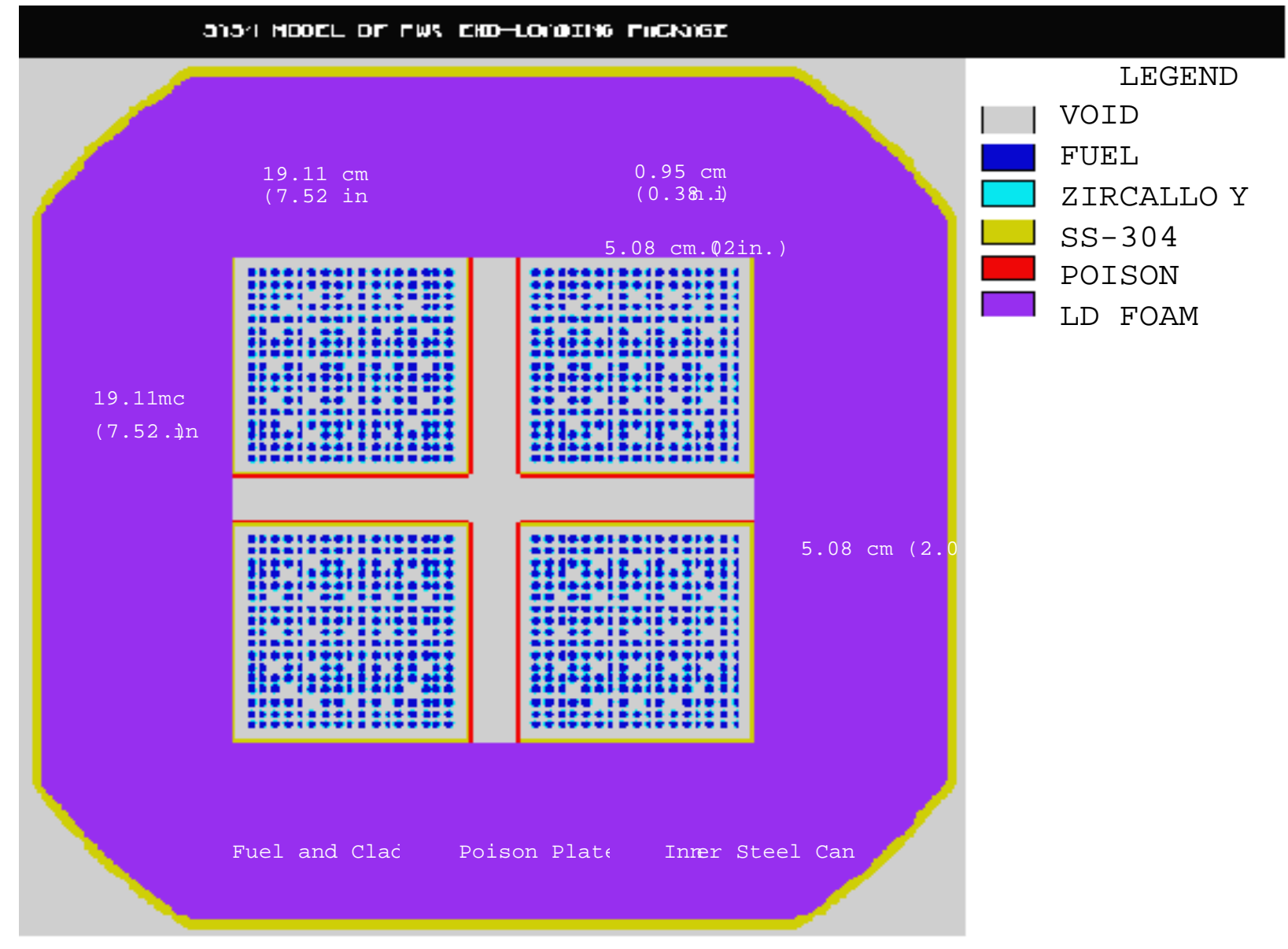

Fig. D.8. SAS1 model of PWR end-loading package. 


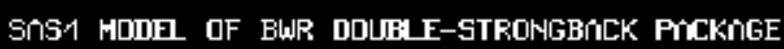

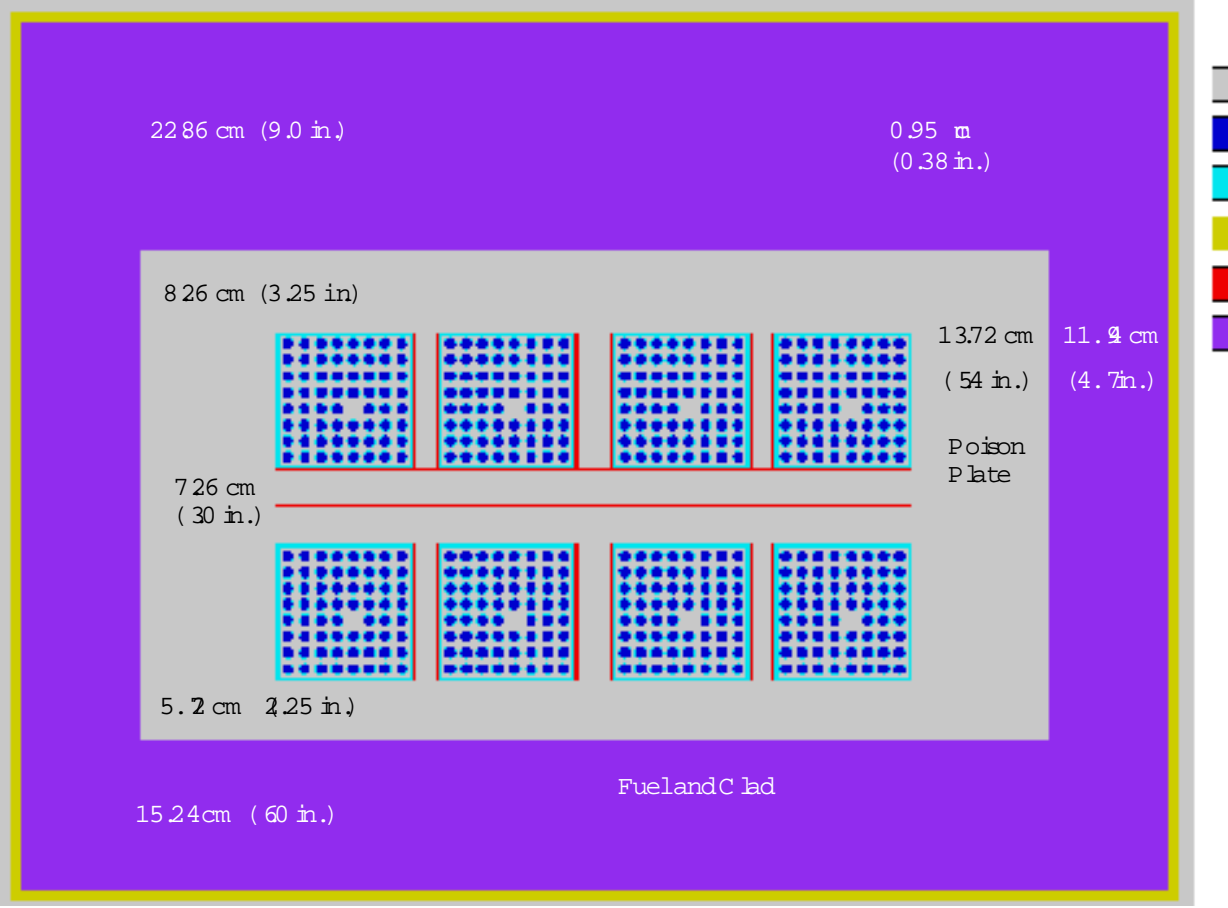

\section{LEGEMD}

VOID

FUE L

ZI RC A LLO Y-2

SS-304

POISON PLATE

LD FO RM

Fig. D.9. SAS1 model of BWR double-strongback package. 


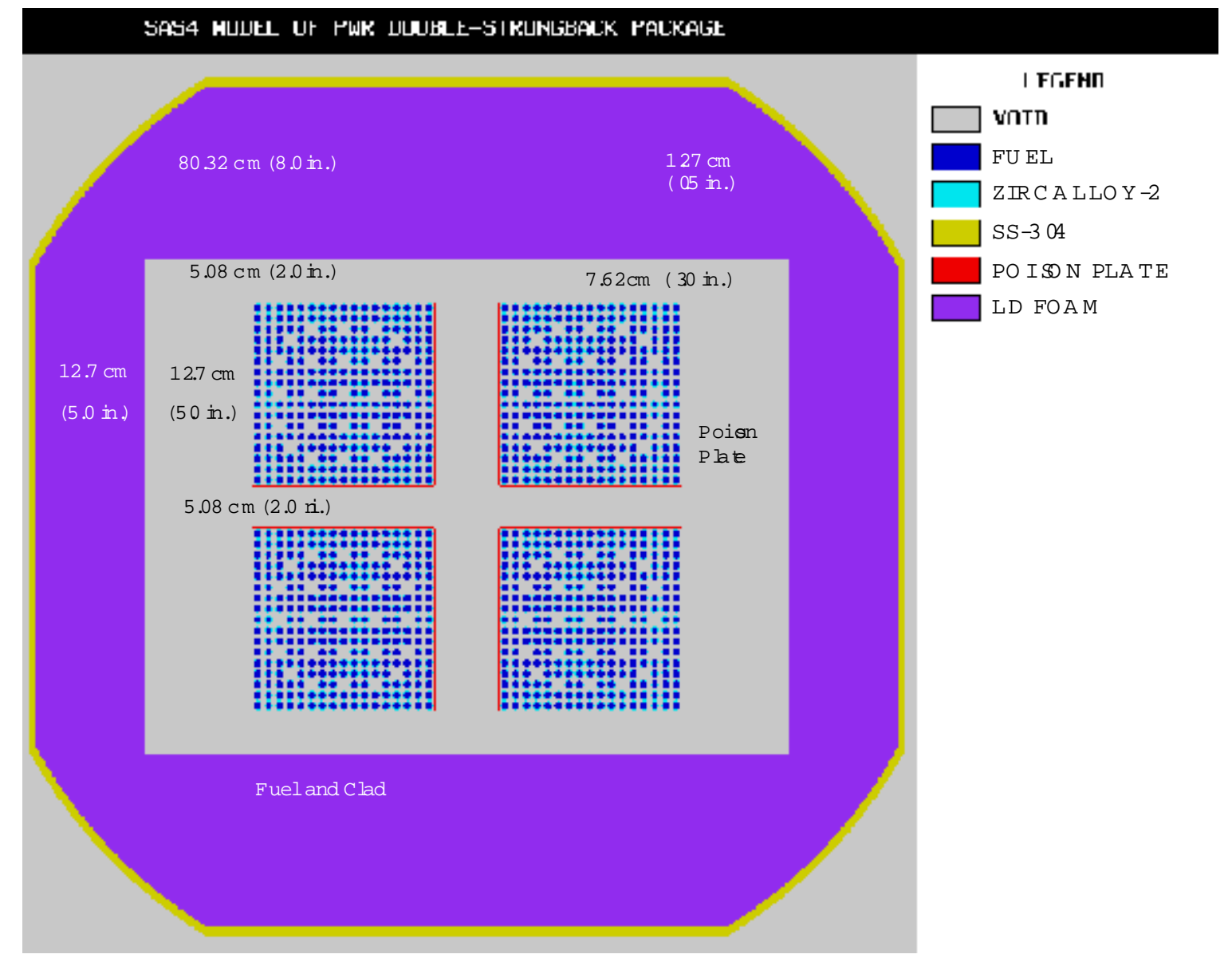

Fig. D.10. SAS4 model of PWR double-strongback package. 
Table D.2. Material number identification

\begin{tabular}{lc}
\hline \multicolumn{1}{c}{ Material } & $\begin{array}{c}\text { Identification } \\
\text { No. }\end{array}$ \\
\hline MOX fuel & \\
Zircalloy-2 & 2 \\
Water & 3 \\
Stainless steel & 4 \\
Steel-clad B $\mathrm{B}_{4}$ C poison plate & $a$ \\
Low-density foam $^{a}$ & 5 \\
\hline
\end{tabular}

${ }^{a}$ The steel clad and $\mathrm{B}_{4} \mathrm{C}$ components of the poison plate are modeled separately, but do not appear separately in a computer-generated drawing of the model.

Table D.3. The $k_{\text {eff }}$ values for MOX fuel end-loading concept with water and borated inner steel can

\begin{tabular}{|c|c|c|c|c|}
\hline \multirow{2}{*}{$\begin{array}{l}\text { Boron } \\
(\text { wt } \%)\end{array}$} & \multicolumn{2}{|c|}{$\begin{array}{c}\text { BWR } \\
\text { (1.22-cm spacing) }\end{array}$} & \multicolumn{2}{|c|}{$\begin{array}{c}\text { PWR } \\
\text { (5.08-cm spacing) }\end{array}$} \\
\hline & $\mathrm{k}_{\text {eff }}$ & $1 \sigma^{a}$ & $\mathrm{k}_{\mathrm{eff}}$ & $1 \sigma$ \\
\hline 2.0 & 0.65461 & 0.00192 & 0.86565 & 0.00177 \\
\hline 1.8 & 0.66226 & 0.00190 & 0.86693 & 0.00215 \\
\hline 1.6 & 0.66849 & 0.00171 & 0.87354 & 0.00206 \\
\hline 1.4 & 0.67957 & 0.00196 & 0.87417 & 0.00206 \\
\hline 1.2 & 0.68673 & (0.00206 & 0.87894 & 0.00202 \\
\hline $1.2^{b}$ & 0.67929 & 0.00181 & 0.87239 & 0.00201 \\
\hline
\end{tabular}

Table D.4. Dose rates for MOX fuel end-loading concept with HD foam

\begin{tabular}{|c|c|c|c|c|c|c|}
\hline \multirow{2}{*}{$\begin{array}{c}\text { Location at side } \\
\text { of package }\end{array}$} & \multicolumn{2}{|c|}{$\begin{array}{l}\text { Neutron dose } \\
\text { rate }\end{array}$} & \multicolumn{2}{|c|}{$\begin{array}{l}\text { Primary gamma } \\
\text { dose rate }\end{array}$} & \multicolumn{2}{|c|}{$\begin{array}{c}\text { Secondary gamma } \\
\text { dose rate }\end{array}$} \\
\hline & $\mathrm{mrem} / \mathrm{h}$ & $\mathrm{fsd}^{a}$ & $\mathrm{mrem} / \mathrm{h}$ & fsd & $\mathrm{mrem} / \mathrm{h}$ & fsd \\
\hline \multicolumn{7}{|c|}{$P W R(5.08-\mathrm{cm}$ foam $)$} \\
\hline Surface & 12.810 & 0.057 & 3.752 & 0.163 & 0.125 & 0.217 \\
\hline $1 \mathrm{~m}$ & 3.107 & 0.014 & 0.859 & 0.031 & 0.019 & 0.026 \\
\hline $2 \mathrm{~m}$ & 1.378 & 0.014 & 0.391 & 0.027 & 0.008 & 0.035 \\
\hline \multicolumn{7}{|c|}{$B W R(1.27-\mathrm{cm}$ foam $)$} \\
\hline Surface & 11.588 & 0.074 & 2.118 & 0.106 & 0.083 & 0.079 \\
\hline $1 \mathrm{~m}$ & 2.712 & 0.019 & 0.601 & 0.032 & 0.020 & 0.071 \\
\hline $2 \mathrm{~m}$ & 1.210 & 0.016 & .284 & 0.029 & 0.009 & 0.082 \\
\hline
\end{tabular}

${ }^{a}$ Fractional standard deviation: one standard deviation divided by the calculated mean. 
Table D.5. Dose rates for MOX fuel end-loading concept, dry, with $1.2 \mathrm{wt} \%$ borated inner steel can

\begin{tabular}{|c|c|c|c|c|c|c|c|c|}
\hline \multirow{2}{*}{$\begin{array}{l}\text { Location at side } \\
\text { of package }\end{array}$} & \multicolumn{2}{|c|}{$\begin{array}{l}\text { Neutron dose } \\
\text { rate }\end{array}$} & \multicolumn{2}{|c|}{$\begin{array}{l}\text { Primary gamma } \\
\text { dose rate }\end{array}$} & \multicolumn{2}{|c|}{$\begin{array}{c}\text { Primary gamma } \\
\text { dose rate }\end{array}$} & \multicolumn{2}{|c|}{$\begin{array}{c}\text { Secondary gamma } \\
\text { dose rate }\end{array}$} \\
\hline & $\mathrm{mrem} / \mathrm{h}$ & $\mathrm{fsd}^{c}$ & $\mathrm{mrem} / \mathrm{h}$ & fsd & $\mathrm{mrem} / \mathrm{h}$ & fsd & $\mathrm{mrem} / \mathrm{h}$ & fsd \\
\hline \multicolumn{9}{|c|}{ PWR (5.08 cm-spacing) } \\
\hline Surface & 14.640 & 0.064 & 4.450 & 0.122 & 8.761 & 0.165 & 0.075 & 0.117 \\
\hline $1 \mathrm{~m}$ & 3.410 & 0.016 & 0.908 & 0.033 & 1.882 & 0.024 & 0.017 & 0.032 \\
\hline $2 \mathrm{~m}$ & 1.578 & 0.011 & 0.424 & 0.038 & 0.874 & 0.022 & 0.007 & 0.033 \\
\hline \multicolumn{9}{|c|}{$B W R(1.27 \mathrm{~cm}$-spacing $)$} \\
\hline Surface & 11.864 & 0.070 & 4.991 & 0.397 & 4.826 & 0.059 & 0.050 & 0.053 \\
\hline $1 \mathrm{~m}$ & 2.735 & 0.012 & 0.626 & 0.028 & 1.436 & 0.024 & 0.015 & 0.068 \\
\hline $2 \mathrm{~m}$ & 1.230 & 0.010 & 0.289 & 0.025 & 0.670 & 0.022 & 0.007 & 0.044 \\
\hline
\end{tabular}

${ }^{a}$ Includes only gammas from $6000 \mathrm{ppm}^{241} \mathrm{Am}$.

$b_{\text {Includes gammas from } 6000 \mathrm{ppm}}{ }^{241} \mathrm{Am}$ and from $25 \mathrm{ppb}{ }^{236} \mathrm{Pu}$.

${ }^{c}$ fsd $=$ fractional standard deviation.

Table D.6. Dose rates for MOX fuel double-strongback concept, dry, without poison plates

\begin{tabular}{|c|c|c|c|c|c|c|c|c|}
\hline \multirow[t]{2}{*}{ Location } & \multicolumn{2}{|c|}{$\begin{array}{c}\text { Neutron dose } \\
\text { rate }\end{array}$} & \multicolumn{2}{|c|}{$\begin{array}{c}\text { Primary gamma }^{a} \\
\text { dose rate }\end{array}$} & \multicolumn{2}{|c|}{$\begin{array}{c}\text { Primary gamma } \\
\text { dose rate }\end{array}$} & \multicolumn{2}{|c|}{$\begin{array}{c}\text { Secondary gamma } \\
\text { dose rate }\end{array}$} \\
\hline & $\mathrm{mrem} / \mathrm{h}$ & $\mathrm{fsd}^{c}$ & $\mathrm{mrem} / \mathrm{h}$ & fsd & $\mathrm{mrem} / \mathrm{h}$ & fsd & $\mathrm{mrem} / \mathrm{h}$ & fsd \\
\hline \multicolumn{9}{|c|}{$P W R^{d}$} \\
\hline Surface & 14.15 & 0.0572 & 3.37 & 0.085 & 7.420 & 0.092 & 0.06 & 0.075 \\
\hline $1 \mathrm{~m}$ & 3.69 & 0.0103 & 1.03 & 0.034 & 2.148 & 0.044 & 0.02 & 0.044 \\
\hline $2 \mathrm{~m}$ & 1.65 & 0.009 & 0.46 & 0.028 & 0.957 & 0.032 & 0.007 & 0.041 \\
\hline \multicolumn{9}{|c|}{$B W R^{e}$} \\
\hline Surface & 15.415 & 0.069 & 3.855 & 0.113 & 7.856 & 0.044 & 0.067 & 0.088 \\
\hline $1 \mathrm{~m}$ & 4.062 & 0.028 & 1.103 & 0.021 & 2.383 & 0.017 & 0.021 & 0.069 \\
\hline $2 \mathrm{~m}$ & 1.761 & 0.009 & 0.490 & 0.019 & 1.047 & 0.014 & 0.009 & 0.056 \\
\hline
\end{tabular}

${ }^{a}$ Includes only gammas from $6000 \mathrm{ppm}{ }^{241} \mathrm{Am}$.

$b_{\text {Includes gammas from } 6000 \mathrm{ppm}}{ }^{241} \mathrm{Am}$ and from $25 \mathrm{ppb}{ }^{236} \mathrm{Pu}$.

$c_{\text {fsd }}=$ fractional standard deviation.

${ }^{d}$ Dose rates for PWR are at side of cask.

${ }^{e}$ Dose rates for BWR are at bottom of cask. 
Page Intentionally Blank 


\section{Appendix E MATERIAL DESCRIPTIONS}

This appendix contains information about the characteristics of various materials used in the design of the fresh MOX fuel transport package. Section E.1 contains compositional data on the various materials that affect the nuclear characteristics of the package design. Section E.2 contains engineering characteristics of the rigid, closed-cell, flame-retardant polyurethane foam that is used in the package design.

\section{E.1 NUCLEAR CHARACTERISTICS OF MATERIALS}

This section presents the compositions of the materials used in the nuclear analyses. A separate table is used for each material (Tables E.1-E.5). No table is given for standard water. The $\mathrm{B}_{4} \mathrm{C}$ has a density of $2.54 \mathrm{~g} / \mathrm{cm}^{3}$, and the boron is $18.431 \mathrm{wt} \%{ }^{10} \mathrm{~B}$ and $81.569 \mathrm{wt} \%{ }^{11} \mathrm{~B}$.

Table E.1. Composition of MOX fuel

\begin{tabular}{lr}
\hline \multicolumn{1}{c}{ Component } & $\begin{array}{c}\text { Composition } \\
(\mathrm{wt} \%)\end{array}$ \\
\hline $\mathrm{UO}_{2}\left(\right.$ density $\left.=9.8130 \mathrm{~g} / \mathrm{cm}^{3}\right)$ & \\
$234 \mathrm{U}$ & 0.0014 \\
$235 \mathrm{U}$ & 0.2718 \\
$236 \mathrm{U}$ & 0.0011 \\
$238 \mathrm{U}$ & 99.7257 \\
$\mathrm{PuO}_{2}\left(\right.$ density $\left.=0.6262 \mathrm{~g} / \mathrm{cm}^{3}\right)$ & \\
$238 \mathrm{Pu}$ & 0.0111 \\
$239 \mathrm{Pu}$ & 93.8044 \\
$240 \mathrm{Pu}$ & 6.0329 \\
$241 \mathrm{Pu}$ & 0.1278 \\
$242 \mathrm{Pu}$ & 0.0238 \\
\hline
\end{tabular}

Table E.2. Composition

of Zircalloy-2

$\left(\right.$ density $\left.=6.56 \mathrm{~g} / \mathrm{cm}^{3}\right)$

\begin{tabular}{cr}
\hline Element & $\begin{array}{c}\text { Composition } \\
\text { (wt \%) }\end{array}$ \\
\hline $\mathrm{Zr}$ & 98.250 \\
$\mathrm{Sn}$ & 1.450 \\
$\mathrm{Fe}$ & 0.135 \\
$\mathrm{Cr}$ & 0.100 \\
$\mathrm{Ni}$ & 0.055 \\
$\mathrm{Hf}$ & 0.010 \\
\hline
\end{tabular}


Table E.3. Composition

of stainless steel 304

$\left(\right.$ density $\left.=7.94 \mathrm{~g} / \mathrm{cm}^{3}\right)$

\begin{tabular}{lr}
\hline Component & $\begin{array}{c}\text { Composition } \\
\text { (wt \%) }\end{array}$ \\
\hline${ }^{12} \mathrm{C}$ & 0.080 \\
$\mathrm{Si}$ & 1.000 \\
${ }^{31} \mathrm{P}$ & 0.045 \\
$\mathrm{Cr}$ & 19.000 \\
${ }^{55} \mathrm{Mn}$ & 2.000 \\
$\mathrm{Fe}$ & 68.375 \\
$\mathrm{Ni}$ & 9.500 \\
\hline
\end{tabular}

Table E.4. Composition

of low-density foam

$\left(\right.$ density $\left.=0.112 \mathrm{~g} / \mathrm{cm}^{3}\right)$

\begin{tabular}{cc}
\hline Nuclide & $\begin{array}{c}\text { Composition } \\
\text { (wt \%) }\end{array}$ \\
\hline${ }^{12} \mathrm{C}$ & 60.000 \\
${ }^{16} \mathrm{O}$ & 24.000 \\
${ }^{14} \mathrm{~N}$ & 8.000 \\
${ }^{1} \mathrm{H}$ & 7.000 \\
${ }^{31} \mathrm{P}$ & 1.000 \\
\hline
\end{tabular}

Table E.5. Composition of borated high-density foam $\left(\right.$ density $\left.=0.48 \mathrm{~g} / \mathrm{cm}^{3}\right)$

\begin{tabular}{cr}
\hline Nuclide & $\begin{array}{c}\text { Composition } \\
\text { (wt \%) }\end{array}$ \\
\hline${ }^{10} \mathrm{~B}$ & 1.457 \\
${ }^{11} \mathrm{~B}$ & 6.448 \\
${ }^{12} \mathrm{C}$ & 58.762 \\
${ }^{16} \mathrm{O}$ & 20.000 \\
${ }^{14} \mathrm{~N}$ & 6.667 \\
${ }^{1} \mathrm{H}$ & 5.833 \\
${ }^{31} \mathrm{P}$ & 0.833 \\
\hline
\end{tabular}

\section{E.2 ENGINEERING CHARACTERISTICS OF FOAM}

Two structural materials would be used for construction of the MOX fresh fuel shipping containers. The outer shell and the inner containment are designed to be fabricated using austenitic stainless steel such as 304L. The space between the outer shell and the inner containment will be filled with rigid crushable foam, specifically LAST-A-FOAM ${ }^{\circledR}$ FR-3700 by General Plastics Manufacturing Company (Phone: 206473-5000). 
The rigid foam is used in the MOX fuel shipping container design for its crush strength and fire resistance. The rigid foam is designed to absorb high-impact energies by crushing the foam. It is a closed cell, chlorofluorocarbon-free polyurethane foam with densities from 3 to $40 \mathrm{lb} / \mathrm{ft}^{3}$. The foam can be formed in place or machined to shape. The rigid foam is also engineered as a fire-retardant polyurethane. Unlike other urethane foams that char and shrink, the FR-3700 foam will produce intumescent char when thermally degraded which seals the voids and punctures that could occur in an accident. In addition, there is no danger of the foam melting and running out of the damaged package because urethanes are thermoset plastics that do not melt and will remain solid until decomposition occurs. Detailed information has been obtained from the manufacturer and is included in Attachments 1-3. The attachments are available only in the hard-copy version of this report. 
Page Intentionally Blank 


\section{Appendix F EXAMPLE OF DYNAMIC STRESS ANALYSIS}

An example of a shipping container modeled with LS-Dyna and Ingrid is the slapdown impact of the horizontal shipping container (HSC). A slapdown impact is an impact configuration where the model axis is initially not parallel to the impacted rigid surface. The lower corner of the container strikes the rigid surface causing a rotation of the package. The opposite end of the package then strikes the rigid surface with local velocities greater than the initial translational velocity. The initial configuration of the HSC model is shown in Fig. F.1. HSC is an outer stainless steel-lined container with a bolted flange. The individual bolts are modeled, and the flange joint surfaces are able to flex, slide, and bear as in the real joint. Bolting preload is not included in the model. Figure F.1 shows the container initially raised at one end and striking the rigid surface on its side (directly on the bolted flange). The bottom support apparatus/stiffeners are visible in the figure.

The final deformed shape of the HSC shipping container is shown in Fig. F.2 with the visual rigid surface removed for clarity. Figure F.2 illustrates that four of the flange bolts have broken and have become free bodies. The flanges in the area of the broken bolts have separated slightly. The LS-Dyna piecewise

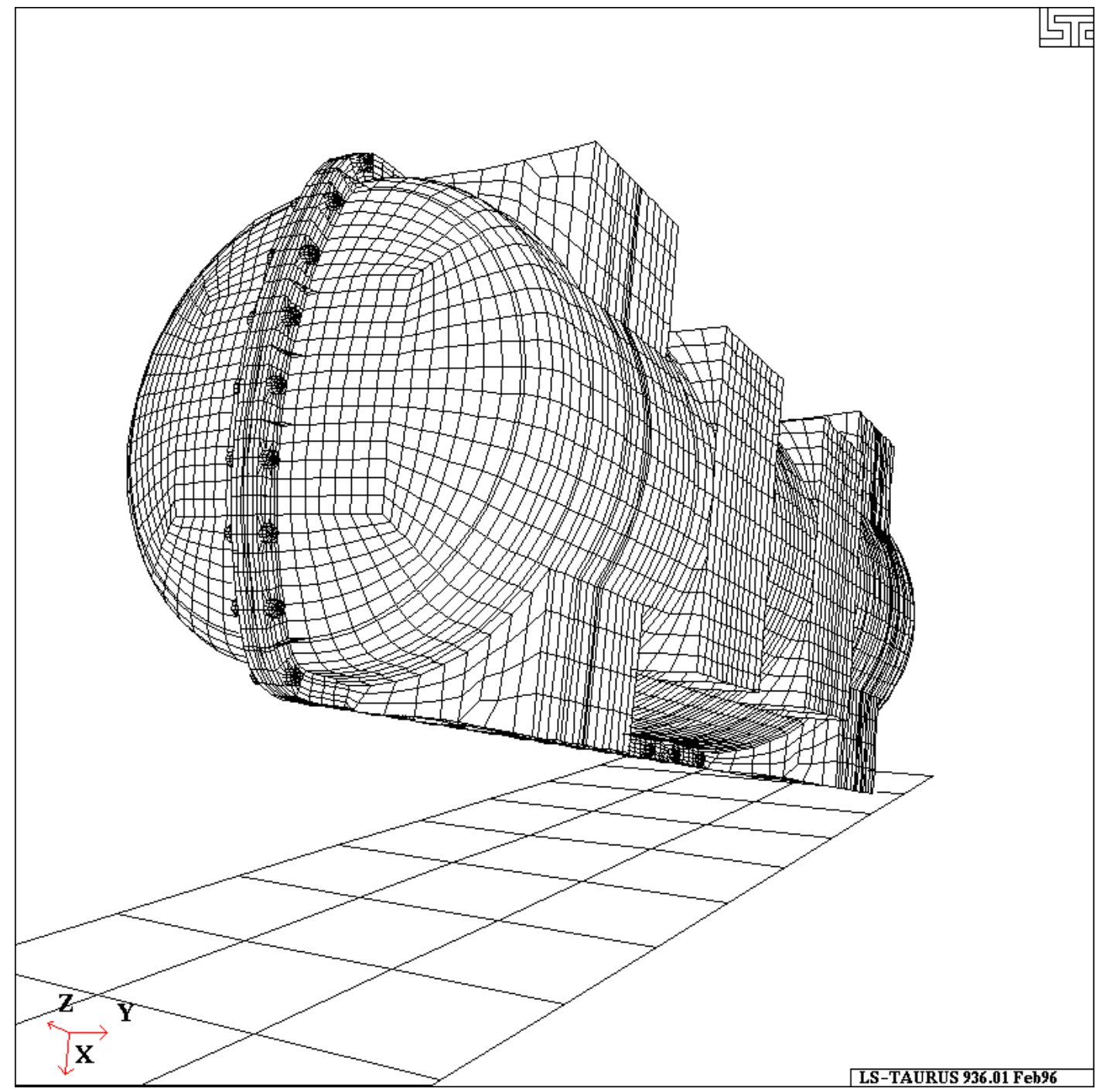

Fig. F.1. Initial configuration of HSC. 


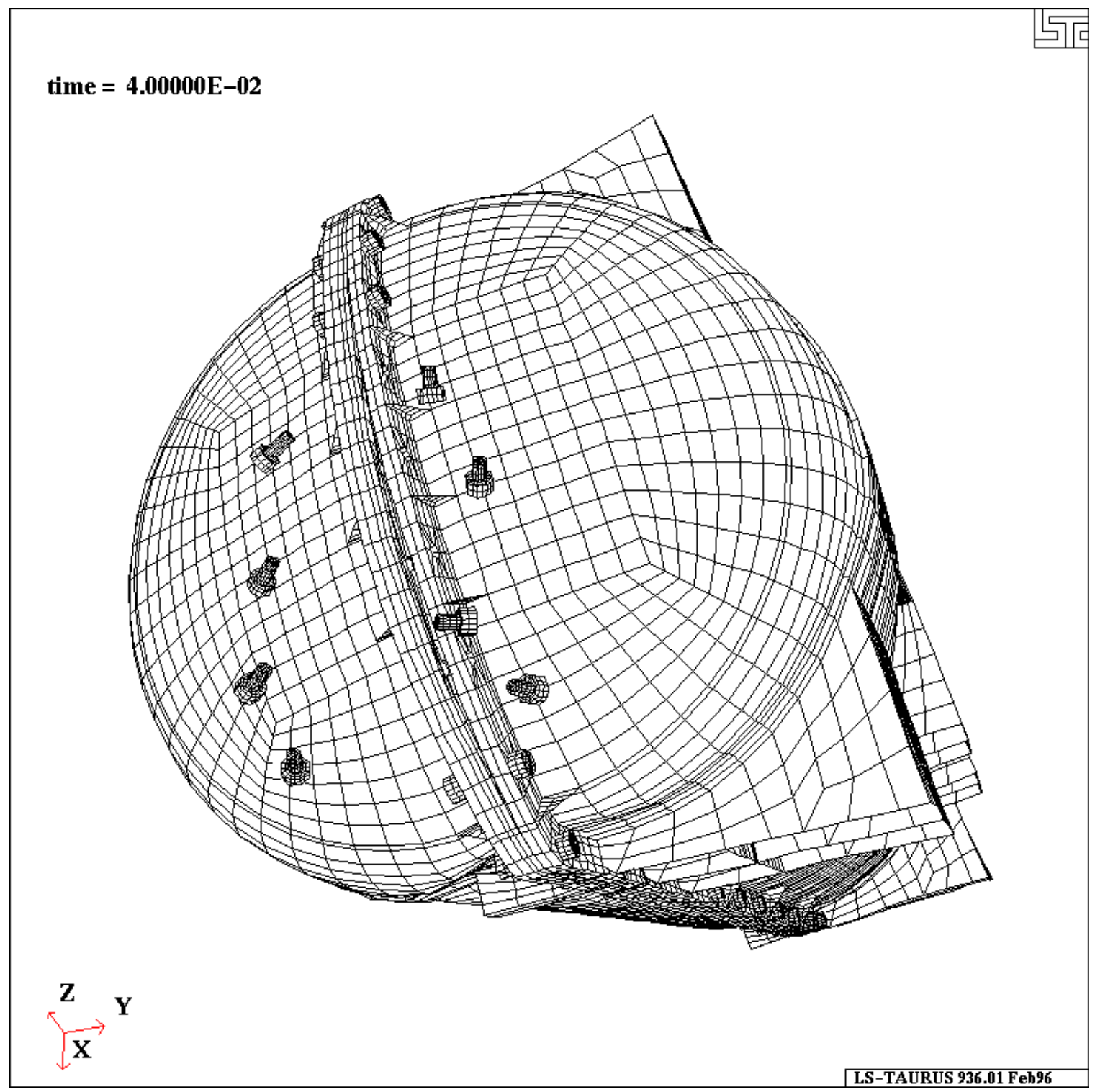

Fig. F.2. Final configuration of HSC.

linear material model with failure was used for the bolting. The loading caused the strain level in some of the bolt elements to exceed the specified failure strain at which point the elements were deleted by LS-Dyna. When an entire cross section of bolt elements is deleted, then the remaining bolt elements become a free body as shown in Fig. F.2.

Each material can be investigated for the stress and/or strain levels. From the HSC container example, the effective plastic surface strain in the stainless steel lid is shown in Fig. F.3. These levels can be compared to known material properties to determine how much damage is done to the material. 


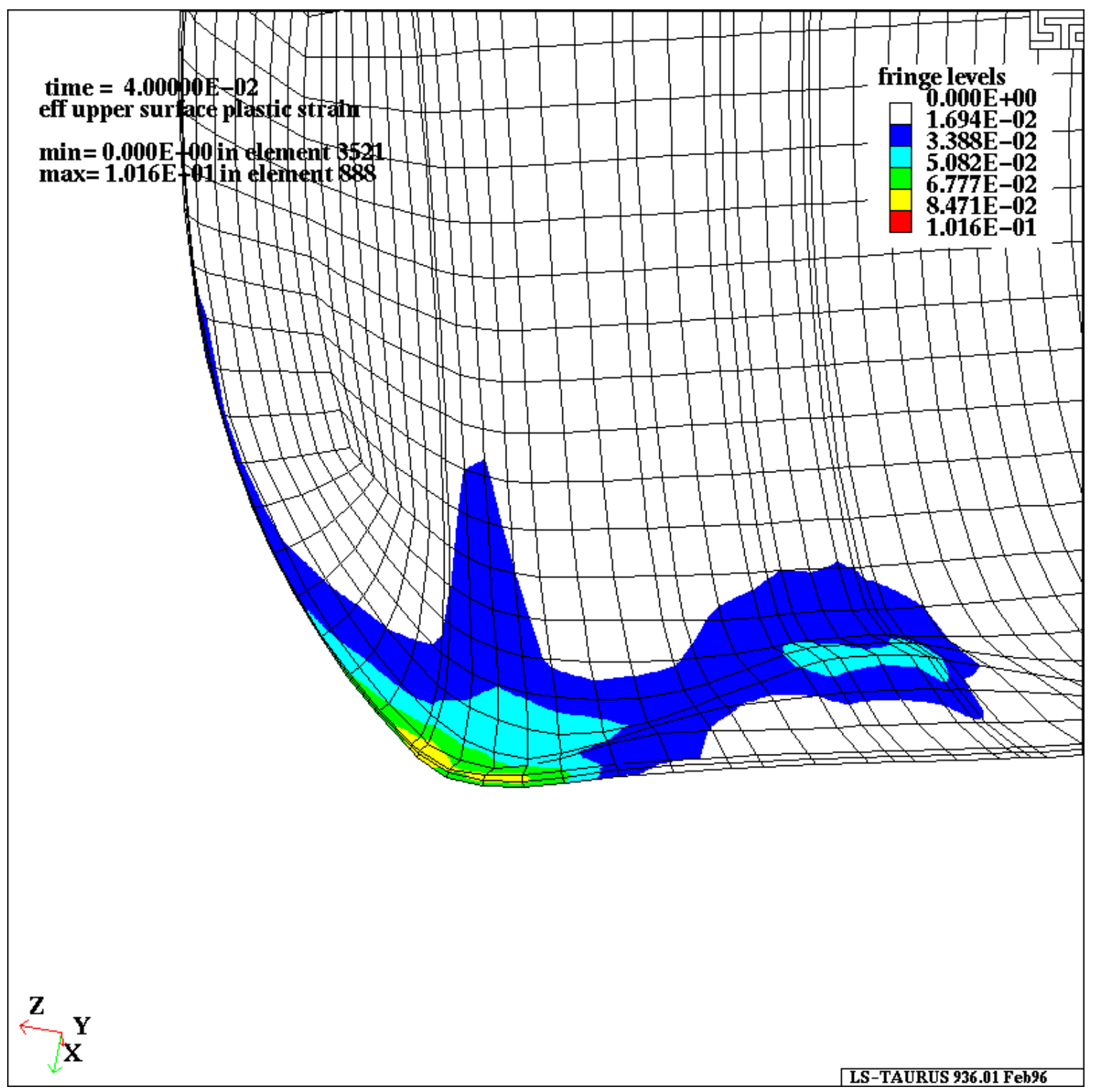

Fig. F.3. Surface effective plastic strain in the HSC stainless steel lid. 
Page Intentionally Blank 
ORNL/TM-13574

Dist. Category UC-523

\section{INTERNAL DISTRIBUTION}

$\begin{aligned} \text { 1. } & \text { J. M. Begovich } \\ 2 . & \text { B. B. Bevard } \\ 3 . & \text { B. L. Broadhead } \\ 4 . & \text { S. L. Byerly } \\ 5 . & \text { S. M. Chae } \\ 6 . & \text { B. S. Cowell } \\ 7 . & \text { A. G. Croff } \\ \text { 8. } & \text { M. M. Dawson } \\ 9 . & \text { L. S. Dickerson } \\ \text { 10. } & \text { E. E. Duncan } \\ \text { 11. } & \text { C. W. Forsberg } \\ \text { 12. } & \text { E. C. Fox } \\ \text { 13. } & \text { S. R. Greene } \\ \text { 14. } & \text { S. A. Hodge } \\ \text { 15. } & \text { R. F. Holdaway } \\ 16 . & \text { A. M. Krichinsky } \\ \text { 7-21. } & \text { S. B. Ludwig } \\ 22 . & \text { G. T. Mays }\end{aligned}$

\author{
23. L. E. McNeese \\ 24. G. E. Michaels \\ 25. R. D. Michelhaugh \\ 26. D. G. O'Connor \\ 27. C. V. Parks \\ 28. R. B. Pope \\ 29. R. T. Primm III \\ 30. W. J. Reich \\ 31. L. B. Shappert \\ 32. B. H. Singletary \\ 33. P. T. Singley \\ 34. C. C. Southmayd \\ 35-39. D. J. Spellman \\ 40. K. A. Williams \\ 41. D. L. Williams \\ 42. Central Research Library \\ 43-44. ORNL Laboratory Records (OSTI) \\ 45. ORNL Laboratory Records-RC
}

\section{EXTERNAL DISTRIBUTION}

46-47. P. T. Rhoads, U.S. Department of Energy, MD-3, Forrestal Building, Room 6G-050, 1000 Independence Avenue SW, Washington, DC 20585.

48-50. J. H. Thompson, U.S. Department of Energy, MD-3, Forrestal Building, Room 6G-050, 1000 Independence Avenue SW, Washington, DC 20585.

51. T. Barr, U.S. Department of Energy, EPG, Argonne National Laboratory, 9800 South Cass Avenue, Argonne, IL 60439.

52 Selby, U.S. Department of Energy, EPG, Argonne National Laboratory, 9800 South Cass Avenue, Argonne, IL 60439.

53. D. Alberstein, Los Alamos National Laboratory, P.O. Box 1663, MS-K551, Los Alamos, NM 87545.

54. J. J. Buksa, Los Alamos National Laboratory, P.O. Box 1663, MS-K551, Los Alamos, NM 87545.

55. S. L. Eaton, Los Alamos National Laboratory, P.O. Box 1663, MS-K551, Los Alamos, NM 87545.

56. L. L. Luna, Sandia National Laboratories, MS-0790, P.O. Box 5800, Albuquerque, NM 87185-0790.

57. C. G. Cowart, Science Applications International Corp., P.O. Box 2501, 800 Oak Ridge Turnpike, Oak Ridge, TN 37831-2501.

58. S. P. Schmid, Science Applications International Corp., P.O. Box 2501, 800 Oak Ridge Turnpike, Oak Ridge, TN 37831-2501.

\section{WWW DISTRIBUTION}

The FMDP Web site, with a list of relevant topical reports, is located at the following URL:

http://www.ornl.gov/etd/FMDP/ORNLFMDP.htm 